PHOSPHATE ANALOGUES AS PROBES OF THE CATALYTIC MECHANISMS OF MURA AND AROA, TWO CARBOXYLVINYL TRANSFERASES 


\title{
PHOSPHATE ANALOGUES AS PROBES OF THE CATALYTIC MECHANISMS OF MURA AND AROA, TWO CARBOXYLVINYL TRANSFERASES
}

By

FUZHONG ZHANG B.Sc.

A thesis submitted to the faculty of graduate studies in the partial fulfillment of the requirements for the degree of Master of Sciences

\author{
McMaster University
}

(C) Copyright by Fuzhong Zhang, August 2005 
Title: Phosphate Analogues as Probes of the Catalytic Mechanisms of MurA and AroA, Two Carboxyvinyl Transferases

Author: Fuzhong Zhang B.Sc. (Peking University, Beijing, P.R.China)

Supervisor: Dr. Paul J. Berti

Number of Pages: 95 


\section{Abstract}

The two carboxyvinyl transferases MurA and AroA are essential for bacterial survival, and are proven or potential antibiotic targets. The reactions they catalyze are chemically challenging, involving protonation of an ethylene group in the first step, and deprotonation of a methyl in the second step. In order to probe how the enzymes promote these reactions, the reverse reactions from enolpyruvyl compounds (EP-OR) plus phosphate to phosphoenolpyruvate (PEP) plus R-OH were investigated, and compared with EP-OR hydrolysis reactions catalyzed by phosphate analogues.

Thirteen phosphate analogues were used to study EP-OR hydrolysis. Among these phosphate analogues, many could bind to the free enzymes, but only three could promote hydrolysis. The products were pyruvate and the corresponding alcohol (S3P in AroA/EPSP reaction and UDP-GIcNAc in MurA/EP-UDP-GlcNAc reaction). The most effective analogue was arsenate. The mechanism of the arsenate-promoted reaction was examined in detail. The hydrolysis reaction proceeded though an arseno-tetrahedral intermediate with AroA, a similar reaction pathway to the natural reaction. This arseno-tetrahedral intermediate was converted to arsenoenolpyruvate and hydrolyzed spontaneously. MurA also likely catalyzed arseno-tetrahedral intermediate formation, and 
appeared to catalyze arsenoenolpyruvate breakdown, though it is possible that it was a bystander in the reaction, with the tetrahedral intermediate being formed by water attack on C2 of EP-UDP-GICNAC. There was a fast solvent exchange step before EP OR was converted to arseno-THI by AroA or MurA. This strongly indicated an oxacarbenium ion like intermediate before the arseno-tetrahedral intermediate.

The catalytic machinery for stabilizing such an unstable oxacarbenium ion like intermediate was investigated by studying ligand binding. Based on information from all the phosphate analogues, there were evidence that the enzyme undergoes an conformational change upon binding with phosphate, by which EPSP was distorted into an oxacarbenium ion like intermediate. 


\section{Acknowledgement}

First, I would like to thank Dr. Paul Berti for giving me the opportunity to come to McMaster University and introducing me to the amazing scientific world. This work, plus the continuing work on KIE measurement in EP-UDP-GIcNAc hydrolysis reactions were under assistance from McMaster University mass spectrometry facility. As well, I thank Dr. Paul Loncke for his great help in the computational section, Joe McCann for his constant ideas and support. I thank Meghann Clark and other lab members in creating such a fantastic environment. Thank you to all my family members for their encouragement and support. Finally, I would like to thank my beloved girl friend, Jinyu $\mathrm{Du}$, for all the hard time she got through together with me, even far away from China. I could not have done this without her unending encouragement. 


\section{Table of Contents}

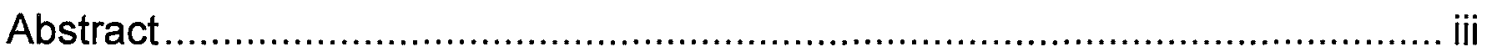

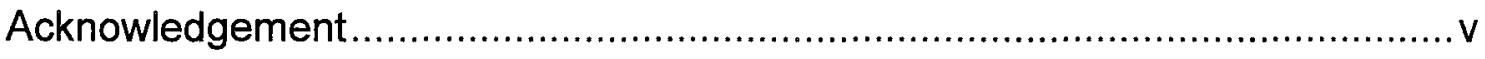

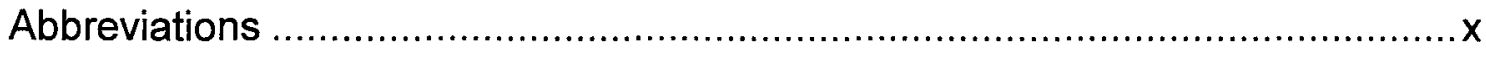

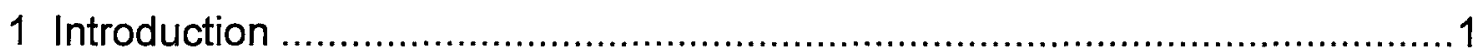

1.1 MurA and AroA, two carboxyvinyl transferases ..................................1

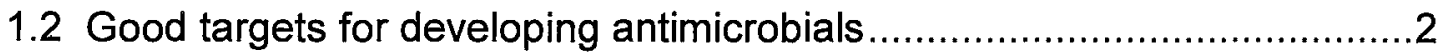

1.3 General acid base catalysis and tetrahedral intermediate ......................3

1.4 Evidence of oxacarbenium ion in addition steps ...................................4

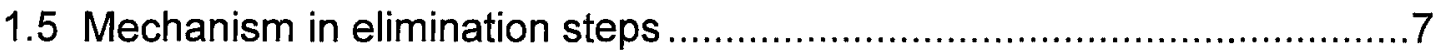

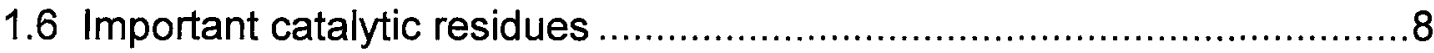

1.7 Mechanism based inhibitor and transition state analogue ...................12

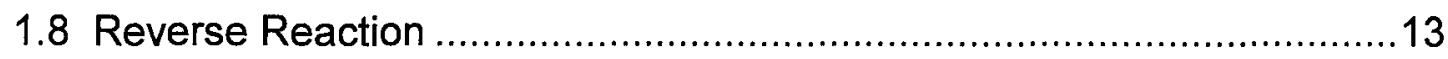

1.9 Reaction coordinate in MurA-catalyzed reaction.................................18

1.10 Non-enzymatic THI breakdown ......................................................18

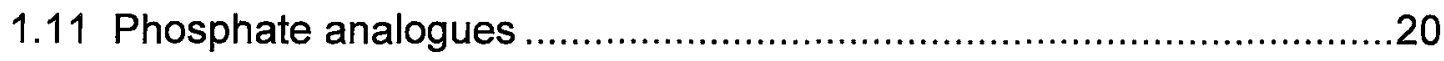

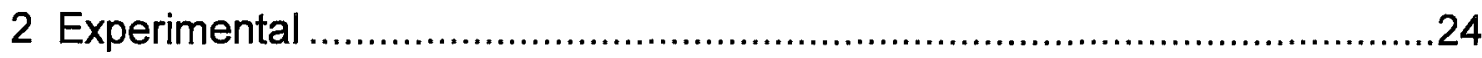

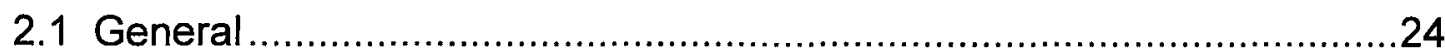

2.2 Enzyme purification and compounds synthesis ..............................25

2.2.1 E. coli MurA expression and purification...................................25

2.2.2 E. coli AroA $\mathrm{A}_{\mathrm{H} 6}$ expression and purification ................................27 
2.2.3 E. coli PPDK expression and purification ...................................27

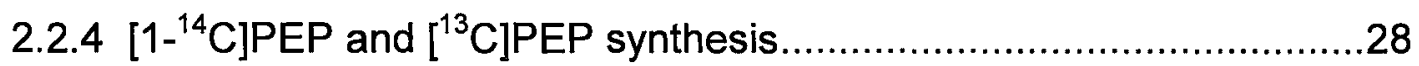

2.2.5 EP-UDP-GIcNAc and EPSP synthesis ....................................29

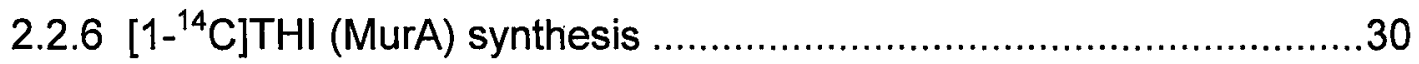

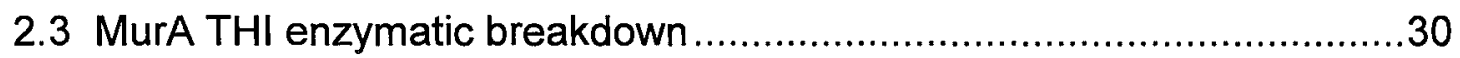

2.4 Phosphate analogue/enzyme-catalyzed EP-OR hydrolysis products .....32

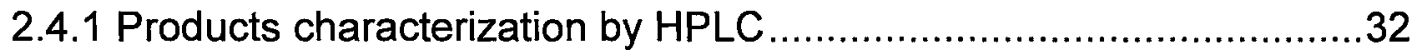

2.4.2 Products characterization by Radioactivity assay ...........................32

2.4.3 Lactate Dehydrogenase reaction assay ....................................33

2.4.4 Products characterization by Mass spectrometry ...........................33

2.5 Kinetics of phosphate analogues/enzyme-catalyzed EP-OR

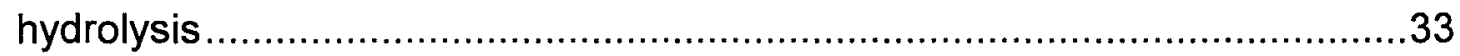

2.6 Mechanism of arsenate/enzyme-catalyzed EP-OR hydrolysis................34

2.6.1 Phosphate analogue/enzyme-catalyzed EP-OR C3 proton

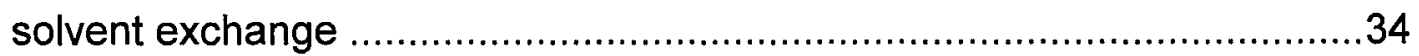

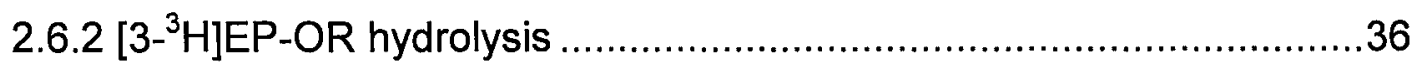

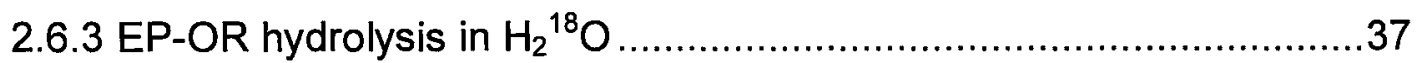

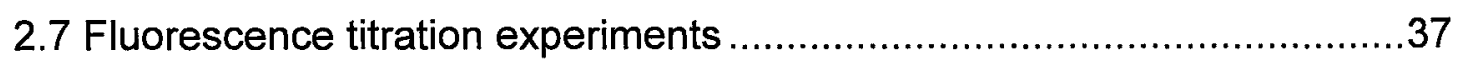

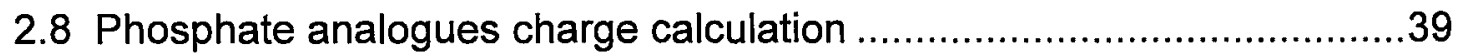

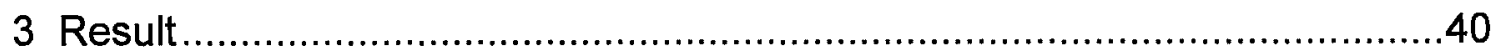

3.1 Enzyme purity, concentration and specific activity measurement ...........40

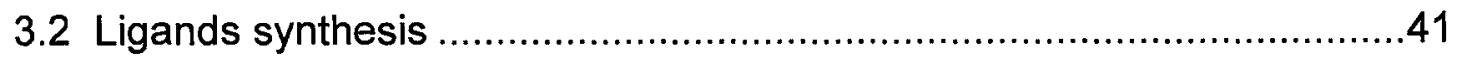


3.3 MurA THI enzymatic breakdown ..............................................44

3.4 Phosphate analogue/enzyme-catalyzed EP-OR hydrolysis products .....45

3.4.1 Products characterization by HPLC .........................................45

3.4.2 Products characterization by radioactivity assay ..........................48

3.4.3 Lactate Dehydrogenase reaction assay ...................................50

3.4.4 Products characterization by mass spectrometry .........................51

3.5 Kinetics of phosphate analogue/enzyme-catalyzed EP-OR

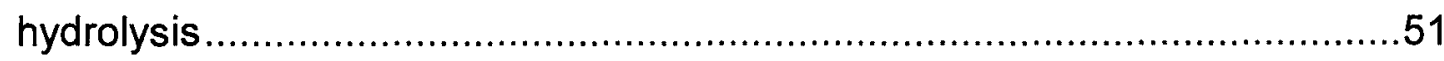

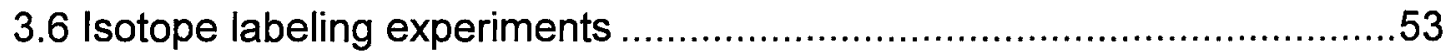

3.6.1 Phosphate analogue/enzyme-catalyzed EP-OR C3 proton

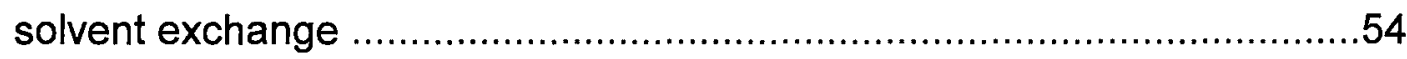

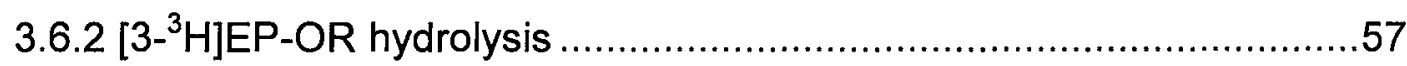

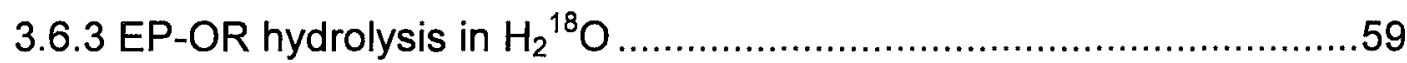

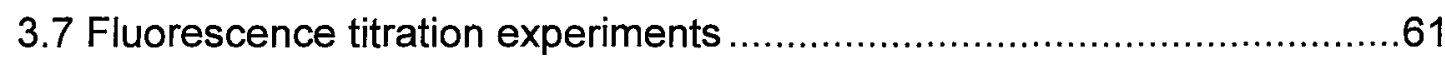

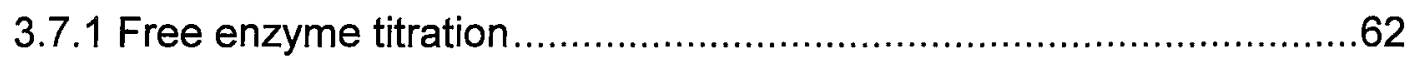

3.7.2 EPSP titration to enzyme analogue complex..............................65

3.7.3 Second step titration with D313A ..............................................68

3.8 Phosphate analogue charge calculation ........................................69

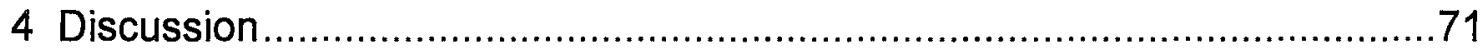

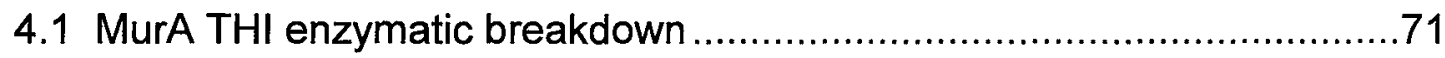

4.2 Mechanism of arsenate-promoted EP-OR breakdown.......................72

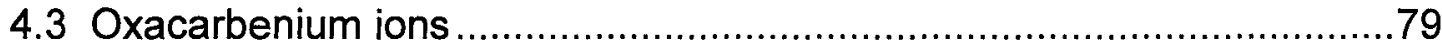




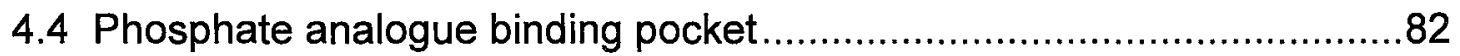

4.5 Two conformational changes upon substrate binding .........................83

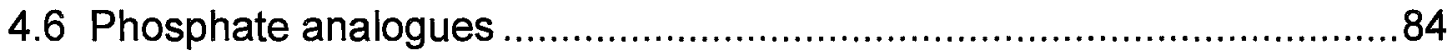

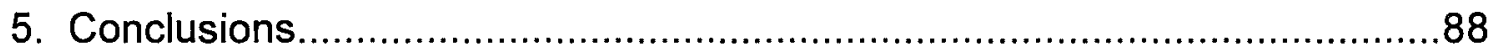

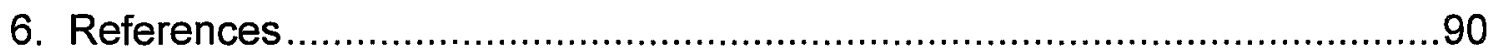




\section{Abbreviations}

AroA 5-eno/pyruvyl shikimate 3-phosphate synthase

AroA $_{H 6} \quad$ AroA containing a C-terminal His sequence $_{6}$

DTT dithiothreitol

EP-OR either EPSP or EP-UDP-GICNAC

EPSP 5-enolpyruvyl shikimate 3-phosphate

EP-UDP-GlcNAc eno/pyruvyl uridine diphosphate $\mathrm{N}$-acetyl-glucosamine

$K_{\mathrm{d}, \mathrm{L}} \quad$ equilibrium dissociation constant of enzyme with ligand

L

$\mathrm{LDH} \quad$ lactate dehydrogenase.

MurA UDP-GIcNAc enolpyruvyl transferase

$\mathrm{NADH}$ nicotinamide adenine dinucleotide;

NPA Natural Population Analysis

PEP phosphoeno/pyruvate

S3P shikimate 3-phosphate

THI tetrahedral intermediate

TS transition state

UDP-GlcNAc uridine diphosphate $\mathrm{N}$-acetylglucosamine 


\section{Introduction}

\subsection{MurA and AroA, two carboxyvinyl transferases}

MurA (UDP-GlcNAc enolpyruvyl transferase) and AroA (EPSP

synthase) are the only two enzymes found to date to catalyze carboxyvinyl transfer. MurA catalyses the first committed step in peptidoglycan biosynthesis (1), which is the main component of the bacterial cell wall. It transfers the carboxyvinyl group of phosphoenolpyruvate (PEP) to the 3'hydroxyl of UDP-GICNAc, yielding EP-UDP-GIcNAc (Fig. 1) (2, 3). AroA is in the shikimate pathway leading to aromatic compounds in microorganisms and plants (4). It transfers the same carboxyvinyl group of PEP to shikimate-3-phosphate, yielding $\operatorname{EPSP}(5,6)$. Both reactions are reversible.

MurA and AroA are homologous, sharing the same overall three-dimensional architecture: two globular inside-out $\alpha / \beta$-barrel domains connected by a two-stranded hinge (7). Both undergo substrate-induced conformational changes that form the active center for catalysis, and which can be monitored by fluorescence changes $(5,8)$. 

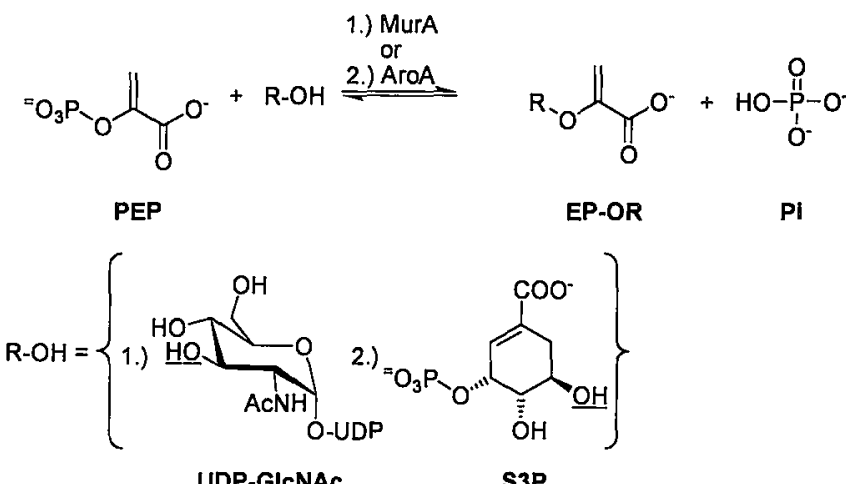

Figure 1. Reactions catalyzed by MurA and AroA.

\subsection{Good targets for developing antimicrobials}

The reaction catalyzed by MurA is in the pathway leading to peptidoglycan in bacteria. Peptidoglycan is a crosslinked carbohydrate polymer that comprises bacterial cell walls, enabling the cells to withstand extreme osmotic pressure fluctuations. Damage to the peptidoglycan layers results in bacterial cell death (9). Because peptidoglycan biosynthesis is highly conserved in eubacteria (9), it is a prime target for broad spectrum antibiotics. EP-UDP-GIcNAc is a precursor in the peptidoglycan biosynthesis pathway. MurA catalyzes the formation of EPUDP-GIcNAc from UDP-GIcNAc. Inhibition of this enzyme provides an efficient way to kill bacteria.

The aromatic amino acids tyrosine, phenylalanine and tryptophan are synthesized by bacteria (including pathogenic bacteria), parasites, and plants. But these biosynthetic pathways are missing in vertebrates. The 
aromatic amino acids can be only obtained from degradation of dietary proteins. The lack of aromatic biosynthetic pathways provides good targets for developing antimicrobials. AroA, one enzyme in the pathway, catalyzes the formation of EPSP.

There are inhibitors for both carboxyvinyl transferases. Fosfomycin, a broad-spectrum antibiotic, inhibits of MurA with $I_{50}$ approximately $1 \mu \mathrm{M}$ (10). It alkylates Cys115, a general acid residue in E. coli MurA. However Cys 115 is not conserved in all bacteria, being Asp in MurA from tuberculosis and other pathogenic organisms, which are fosfomycin resistant (11). AroA is inhibited by glyphosate, a herbicide which inhibits both AroA and its orthologue in plants $(12,13)$, but it is not an antibiotic.

Bacterial survival strongly depends on the functionality of a unique class of enzymes, carboxyvinyl transferases. They are good targets for developing antimicrobials.

\subsection{General acid base catalysis and tetrahedral intermediate}

The reaction mechanisms of both MurA and AroA have been studied intensively with pre-steady state experiments $(11,14,15)$, sitedirected mutagenesis (11), substrate analogues (16-18), x-ray crystallography $(7,19,20)$, fluorescence titration (21) and NMR experiments $(6,22)$. Their mechanisms are similar in several aspects. 
Both are believed to use general acid-base catalysis (23). The reactions are easily reversible, proceeding via an addition-elimination pathway through a non-covalently bound tetrahedral intermediate $(\mathrm{THI})(14,15)$ (Fig. 2).

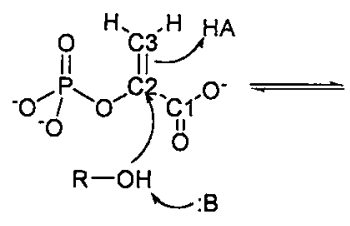

PEP + R-OH

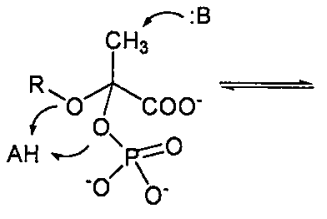

THI

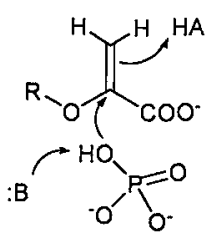

$E P-O R+P I$

Figure 2. MurA AroA reaction pathways, proceeding through a tetrahedral intermediate (THI).

In the addition step, the ethylene group of PEP is protonated at $\mathrm{C} 3$ by the general acid and $\mathrm{C} 2$ was attacked by the hydroxyl oxygen from the corresponding alcohol (UDP-GIcNAc in the MurA reaction and S3P in the AroA reaction) with the help of general base. A tetrahedral intermediate can be isolated by denaturing the enzyme under basic conditions. In the elimination step, the C 3 methyl is deprotonated by a general base catalyst and inorganic phosphate is eliminated.

\subsection{Evidence of oxacarbenium ion in addition steps}

Even though the mechanism has been widely studied for several decades, there are still several mechanistic controversies. The mechanism for the addition step from PEP, and alcohol to $\mathrm{THI}$ is relatively clear. There 
were several pieces of evidence suggesting an oxacarbenium ion transition state.

In MurA, Brown et al. first characterized a phospholactoyl-enzyme adduct (24), where PEP was covalently linked to the enzyme at Cys115. This was later studied in more detail with fluoro-labeled PEP (16). It was found that the formation of phospholactoyl-enzyme adduct was slower than fluoro-THI, and it only occurred when UDP-GICNAc was in present (Fig. 3). They concluded that PEP inside the catalytic center was protonated and the enzyme stabilized an oxacarbenium ion upon binding with UDP-GIcNAc. The substrate-induced conformational change was later demonstrated in both crystal structure $(7,25,26)$ and fluorescence experiments (21).

The oxacarbenium ion was also supported by site-directed mutagenesis experiments (11). When Cys 115 was mutated to Asp, the enzyme lost the ability to be inhibited by fosfomycin. The inhibitor of MurA, fosfomycin, can be irreversibly attached to Cys115 and form a covalently fosfomycin adduct, thus alkylating the proposed catalytic base and taking the position of PEP in the active centre of MurA. The loss of inhibition by fosfomycin in C115D is consistent with this mechanism. However, C115D is still active. Its $k_{\text {cat }}$ is even higher than wild-type MurA at pH from 5.5 to 7 . This suggested that the phospholactoyl-enzyme adduct is not necessary 
for catalysis. It is also consistent with Asp, a better oxacarbenium ion stabilizer, lowering the energy of TS further.

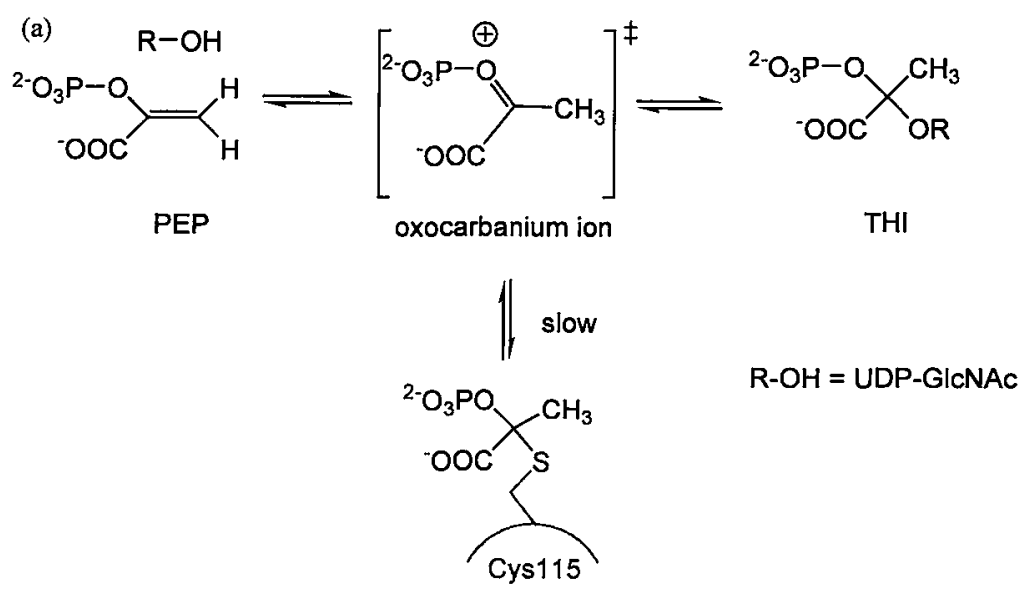

phospholactoyl-enzyme adduct

(b)

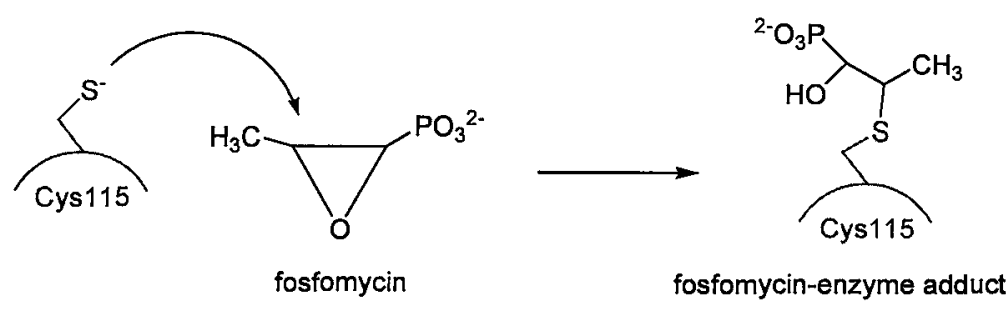

Figure 3. Oxacarbenium ion-like TS during the addition step of MurA reaction. (a) The phospholactoyl-enzyme adduct was believed a side product of the reaction. (b) Fosfomycin inhibition mechanism.

Evidence for an oxacarbenium ion during the addition step in the AroA reaction is more straightforward. Upon incubating AroA with dideoxyS3P (ddS3P), where the nucleophilic hydroxyl was missing, Anton et al. observed tritium was incorporated from water into the C3 of PEP without formation of any EPSP or THI (27). This strongly suggested that C3 was protonated inside the active site and formed the 
oxacarbenium ion form of PEP. This oxacarbenium ion exists long enough for the $\mathrm{C} 3$ to rotate, and one of the methyl protons to be removed during deprotonation, allowing tritium to remain in PEP. The formation of the oxacarbenium ion also requires a conformational change in AroA, which was monitored by fluorescence titrations (21).
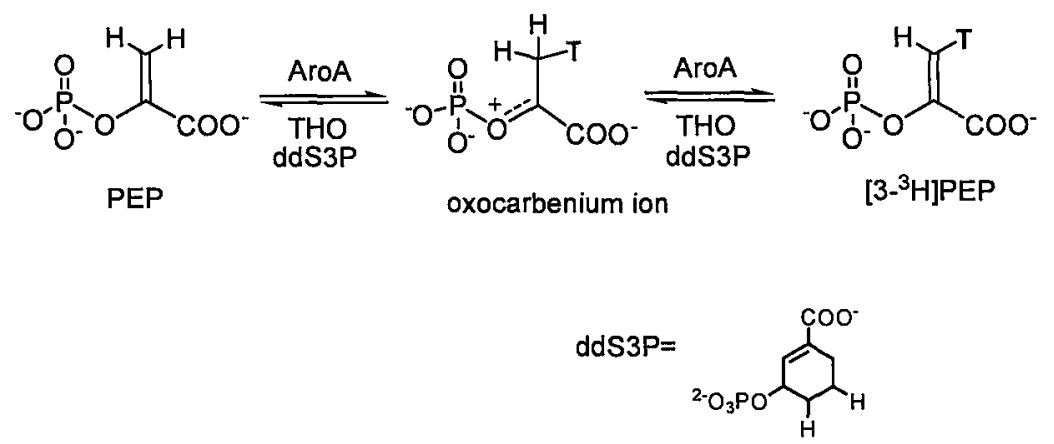

Figure 4. Oxacarbenium ion form in the addition step of AroA-catalyzed reaction, showing that tritium can be incorporated into $\mathrm{C} 3$ of PEP.

\subsection{Mechanism in elimination steps}

The detailed mechanism of the elimination step is not clear. Based on the lack of formation of a fluoro-EP-UDP-GIcNAc like product from fluorine substituted THI, Walsh and coworkers believed it went through an oxacarbenium ion intermediate (11). They assumed an E2-type mechanism for the elimination step would not be affected by the substitution of fluorine at C3. In contrast, An et al. assigned the stereochemical course of AroA reaction and found the second step in AroA reaction went through a syn elimination (28). They referred to the 
position of previous proposed catalytic base Glu341, which was orientated $90^{\circ}$ to the other leaving group, phosphate, based on crystal structures (Fig. 6). For a syn elimination, this angle would be expected to be $180^{\circ}$. They pointed out the inconsistency and proposed a phosphate-assisted concerted mechanism, where phosphate acts as a base (Fig. 5).
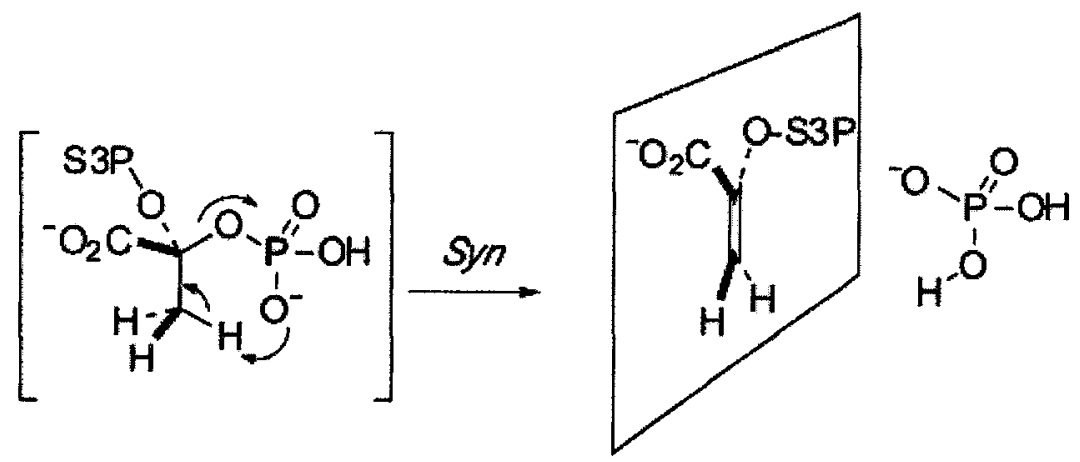

Figure 5. Proposed AroA-catalyzed elimination step. The syn elimination is consistent with phosphate assisted deprotonation.

\subsection{Important catalytic residues}

Even though people agree the overall reaction is general acid-base catalyzed. The catalytic residues are still disputed.

In MurA, Cys 115 is the most interesting residue. It can be alkalyted by fosfomycin, inhibiting the enzyme. PEP also interacts with it to form a covalently linked phospholactoyl-enzyme adduct. Cys 115 is located in a loop which undergoes a large conformational change as the enzyme binds to the substrates (26). Site-directed mutagenesis experiments suggest it 
acts as a general acid in protonating the $\mathrm{C} 3$ position in the addition step, and a general base for decomposition of $\mathrm{THI}$ in both forward and backward directions (11). Its $p K_{a}$ inside the enzyme was determined to be 8.3, suggesting that Cys 115 is appreciably protonated at physiological $\mathrm{pH}$ (29). This supported Cys 115 as a general acid.

In AroA, Glu341, the equivalent residue to Cys115 in MurA, was proposed to act dual role in both protonation of C3 of PEP and deprotonation of $\mathrm{THI}(30)$.

However, results from combination of stereochemistry and crystal structure indicated Cys 115 and Glu341 are not well aligned with phosphate for a syn elimination in the second step (Fig. 6). Both Duncan (19) and Bartlett (28) pointed out that phosphate could act as an intramolecular proton acceptor.

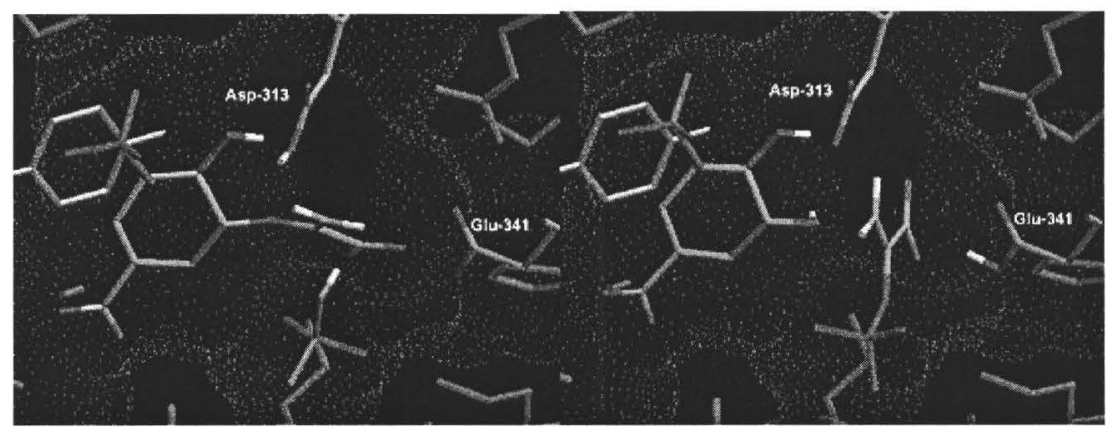

Figure 6. Residues in AroA catalytic centre from X-ray crystallography. Glu341 was orientated $90^{\circ}$ to the phosphate moiety based on this crystal structure, which is not consistent with the expected $180^{\circ}$ for syn elimination. 
another unresolved problem. Asp305 was demonstrated to be important for the catalysis in MurA. Samland et al. showed D305A, D305C, D305H mutant proteins did not have detectable enzymatic activity $(25,31)$. They argued that Asp305 serves as both a general base and an essential binding partner to UDP-GICNAc in the addition step. Its equivalent residue Asp313 in AroA was proposed to have the same role by Schonbrunn and co-workers from crystal structure (25). However, this was not consistent with former proposed base Lys22 in AroA, which also located close to S3P C5 oxygen (32). The $\mathrm{pK}_{\mathrm{a}}$ of this residue was measure to be 7.6 , lower than a normal Lys side chain (approximately 10.8), ensuring enough deprotonated form at physiological condition.

More recently, Mizyed et al. from this lab studied the effects of active site mutations on the partitioning of $\mathrm{THI}(30)$. While many mutations reduced the catalytic activity significantly, none produced a large change in the partition ratio. This indicated "ensemble catalysis" with a large number of residues being important for catalysis. Among them, Glu341 and Lys22 act as the dual-role acid/base catalysts; that is Glu341 would be the proton donor in formation of the THI from S3P and PEP and the proton acceptor in elimination of the THI to EPSP and phosphate. Lys22 would serve as the proton acceptor from S3P in the addition step and proton donor for phosphate elimination. 
Making it more complicated, a new view of the two carboxyvinyl transferases from $\mathrm{x}$-ray structures of their THI states was published by Schonbrunn and co-workers (33). They made D305A mutation for MurA and D313A for AroA. Their experiments showed the reaction stopped after formation of THI. They measured distance between Cys 115 (MurA)/Glu341 (AroA) and C3 carbon of THI from the crystal structures of the two mutations. They were $7.0 \AA$ and $3.4 \AA$ respectively. They concluded that these residues were too far away to deprotonate C3 methyl. However, they noticed the carboxylate groups of the modeled Asp side chains are in good hydrogen-bonding distance to the 4'-OH of the UDP-GIcNAc (2.7 $\AA$ ) in MurA, and to the 4-OH of the S3P in AroA. These hydroxyls are close to the hydroxyls where the bonds are forming during the reaction, $3.4 \AA$ and $3.1 \AA$ in MurA and AroA respectively. They proposed that the deprotonation of $\mathrm{C} 3 \mathrm{THI}$ methyl group might proceed intramolecularly, where Asp residues abstracts the proton from 4-OH (or 4'-OH in MurA), the resulting oxyanion then would abstract a proton from C3 methyl (Fig. 7). 


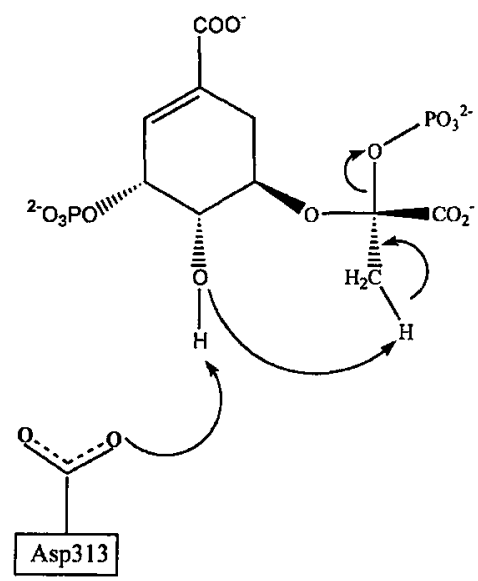

Figure 7. Proposed mechanism in AroA-catalyzed reaction, where D313 serves as catalytic base.

Overall, there are many disputed aspects on the mechanism of the two carboxyvinyl transfer reactions. Studying the mechanism of the two enzymes is still necessary.

\subsection{Mechanism based inhibitor and transition state analogue}

Enzymes catalyze reactions by lowering the energy of the transition state(s) (TS). In any reaction, the transition state (TS) is the highest energy point in the energy profile. Enzymes exert their catalytic activity by binding tightly with TS rather than substrates or products (34), stabilizing the TS, and lowering the activation energy of the reaction (Fig. 8). As compared with equilibrium dissociation constants with substrates or products, which are generally in the $10^{-3}$ to $10^{-6} \mathrm{M}$ range, equilibrium dissociation constant can be as low as $10^{-13} \mathrm{M}$ for the enzyme $\cdot$ TS complex. An effective way to inhibit an enzyme is to mimic the TS. Such 
an inhibitor is called a transition state inhibitor, which would be extremely difficult for the enzyme to evolve other catalytic machinery to avoid.

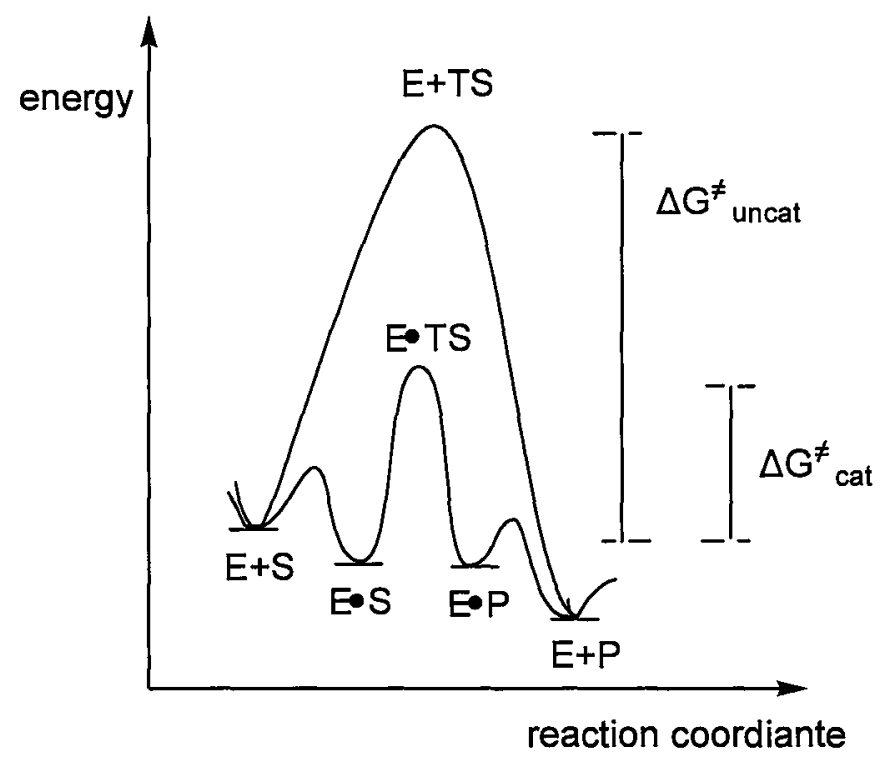

Figure 8. Enzymatic transition state stabilization. Black line, reaction pathway without enzyme. Red line, pathway of enzyme-catalyzed reaction. Enzymes catalyze reactions by binding with transition state, lowering the activation energy.

Determination of TS structures can help us to understand enzyme mechanisms, and, what is more important from the application point of view, design of TS analogues. TS analogues are stable molecules having almost the same structure as TS, which can bind with enzymes almost as tightly as TSs. TS analogues would be potential lead compounds for novel effective inhibitors. All of these will provide us a clear clue for drug design. So there is significant need to study the structure of TSs.

\subsection{Reverse Reaction}


In the reverse reaction of the two carboxyvinyl transferases, phosphate reacts with EP-OR, yielding THI in the first step. THI is then converted into PEP and the corresponding alcohol. In the first step, phosphate is covalently linked to $\mathrm{C} 2$ carbon to form a $\mathrm{C}-\mathrm{O}$ bond. The challenge is to understand how the enzyme takes phosphate, a small, poor nucleophile, to undertake a nucleophilic attack at C2 carbon, a nonreactive site. The exact mechanism of this step was not known; it could be either a stepwise mechanism, with protonation of $\mathrm{C} 3$ occurring to form a cationic intermediate before nucleophilic attack at $\mathrm{C} 2$, or an asynchronous concerted addition step with significant cationic character at C2.

Phosphate is a biologically important molecule. It is involved in countless processes such as biosynthetic pathways, protein posttranslational modifications and regulation of signal transduction. At an oxidation state of +5 , the phosphorus atom (including those in phosphate esters) does not react readily as a nucleophile, but as electrophile, undergoing attack by a variety of other nucleophiles. For example, phosphatases and phosphodiesterases take water as a nucleophile to attack phosphorus; kinases use other nucleophiles to transfer a phosphoryl group $\mathrm{PO}_{3}$, where phosphorus is still an electrophile.

However, there are rare cases that phosphate is used as a nucleophile. In phosphorylases, inorganic phosphate, specifically one of 
the anionic oxygen atoms, serves as a nucleophile. Saccharide phosphorylases transfer the glucosyl group to phosphate and form sugar1-phosphate in most of cases. The reaction has either $S_{N} 1$ or $S_{N} 2$ mechanisms. In the cellobiose phosphorylase (35) and maltose phosphorylase (36), the disaccharide was cleaved at the oxygen-bridge bond, yielding glucose-1-phosphate and another free glucose. The configuration of $\mathrm{C} 1$ is inverted from substrate to product in both of the two enzymatic reactions. This implied a direct $S_{N} 2$ displacement by the inorganic phosphate at $\mathrm{C} 1$ of the disaccharide moiety. (Fig. 9)
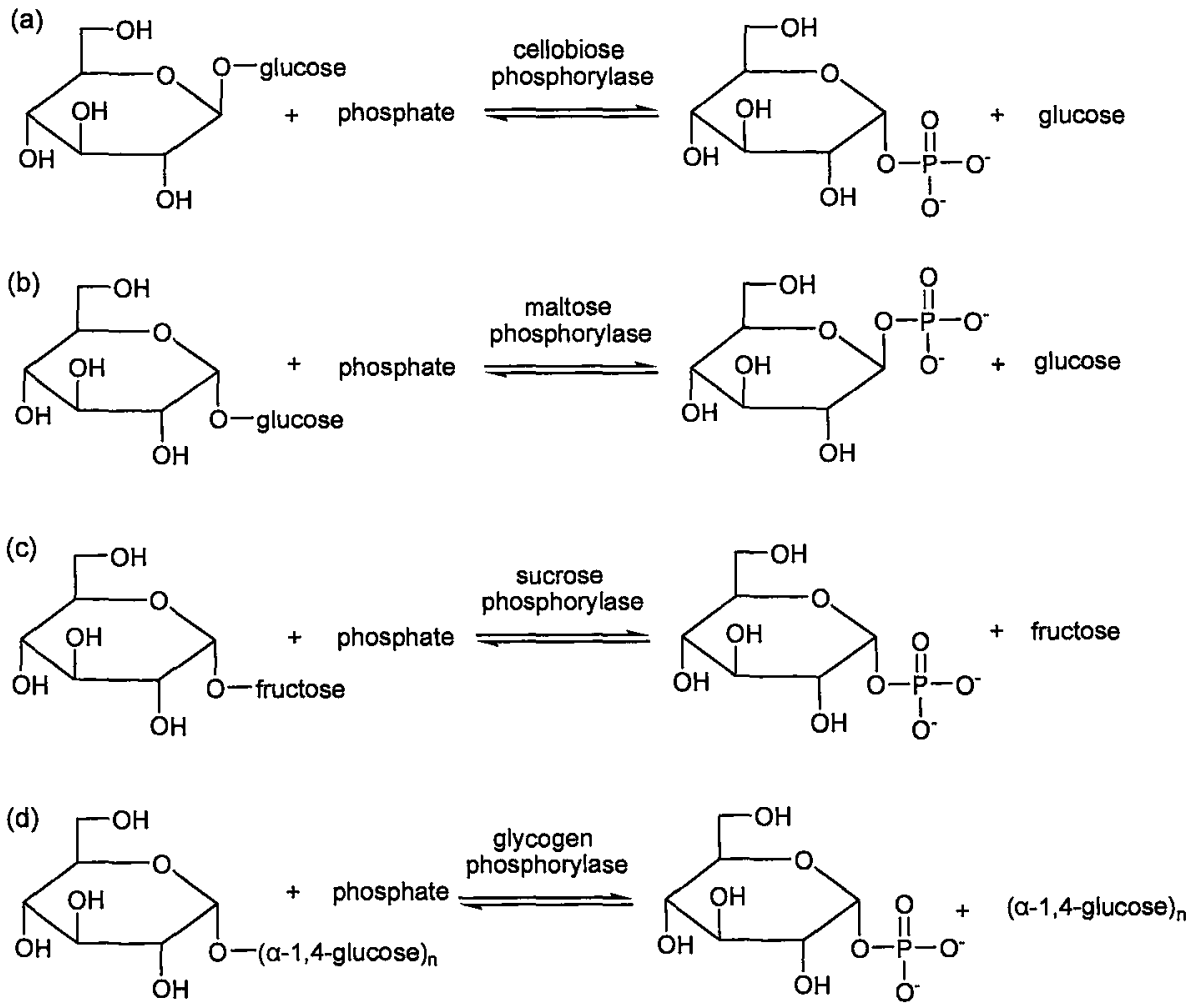

Figure 9. Reactions catalyzed by phosphorylases where phosphate is used as a nucleophile. Reaction catalyzed by (a) cellobiose phosphorylase and (b) maltose phosphorylase have conformation inversion at $\mathrm{C}_{1}$, indicating $\mathrm{S}_{\mathrm{N}} 2$ mechanism. Reaction 
catalyzed by (c) sucrose phosphorylase and (d) glycogen phosphorylase proceed with retention of conformation.

If the configuration at $\mathrm{C} 1$ is retained, the mechanism could be either two $S_{N} 2$ displacements (double inversion) or $S_{N} 1$ with exclusive front side attack due to the shielding by the enzyme. In sucrose phosphorylase (3739), ${ }^{14} \mathrm{C}$ in fructose (the free sugar product) is incorporated into the sucrose in the absence of inorganic phosphate. This suggests an enzyme covalently linked adduct is involved in the reaction (Fig. 9c, Fig. 10a), where the enzyme attacks $\mathrm{C} 1$ and releases fructose. The ${ }^{14} \mathrm{C}$ labeled fructose was incorporated into sucrose by the reverse reaction of this step. In another experiment, arsenolysis of glucose-1-phosphate by this enzyme indicated that glucose-1-phosphate undergoes a normal reverse reaction to glucosyl enzyme, which is then attacked by arsenate (phosphate analogue) to form unstable glucose-1-arsenate, which is quickly hydrolyzed to glucose and arsenate (Fig. 10b). The enzyme adduct was later isolated and identified. The kinetic mechanism was shown to be a ping-pong $\mathrm{BiBi}$ substrate binding. All these supported a double $\mathrm{S}_{\mathrm{N}} 2$ displacements mechanism. In glycogen phosphorylase $(40,41)$, which phosphorylates polysaccharides, evidence favours a $S_{N} 1$ mechanism (Fig. 10c). (1) Initial-velocity measurements reveal a random kinetic mechanism; (2) The $\mathrm{C} 1$ configuration of the glucose is retained in glucose1-phosphate. (3) There was no incorporation of ${ }^{32} \mathrm{P}$ into glucose-1- 
phosphate when glucose-1-phosphate was incubated together with [ $\left.{ }^{32} \mathrm{P}\right]-$ phosphate. These observations are consistent with a shielded $\mathrm{C}_{1}$ oxacarbenium ion mechanism.

(a)

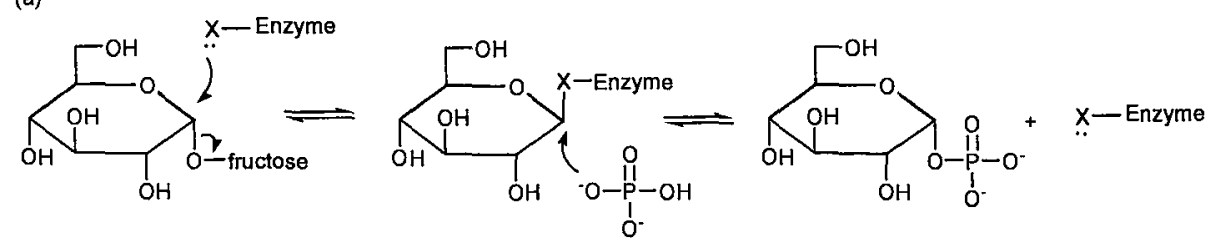
covalent glucosyi enzyme

(b)

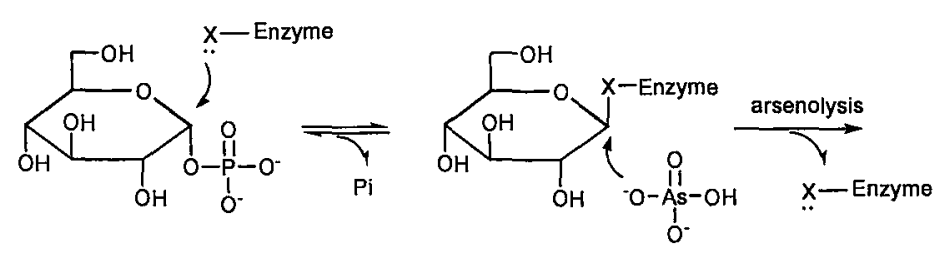<smiles>O=C[C@]1(OS(=O)(=O)[O-])OC(CO)C(O)C(O)C1O</smiles>

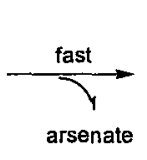<smiles>OCC1OC(O)C(O)C(O)C1O</smiles>

(c)<smiles></smiles><smiles>C=C(O)C1CC1</smiles>

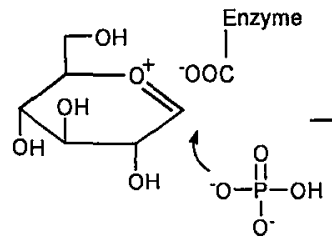<smiles>O=P([O-])([O-])OC(O)C1OC2COC1C(O)C2O</smiles>
$R=(a-1,4-g l u \cos e)_{n}$

Figure 10. Phosphorylase Mechanisms. (a) sucrose phosphorylase. (b) arsenolysis catalyzed by sucrose phosphorylase. (c) glycogen phosphorylase.

In each enzyme, inorganic phosphate attacks a sp ${ }^{3}$ hybridized carbon. There are rare cases that phosphate is taken as a nucleophile to 
attack a $\mathrm{sp}^{2}$ hybridized ethylene carbon as in AroA and MurA. So the question was if phosphate attack was concerted with C3 protonation, or a stepwise mechanism where C 3 was protonated first. And how does the enzyme lower the energy barrier to make phosphate undergo a nucleophilic attack?

\subsection{Reaction coordinate in MurA-catalyzed reaction}

In the MurA-catalyzed reaction, a non-covalently linked THI is formed. This makes the reaction coordinate complicated, with at least two transition states and one intermediate, possibly more. The overall reaction is reversible, meaning that the THI can partition both forward and backward. Partitioning of the MurA THI was measured in this study for two reasons. One was that it was useful for interpreting the phosphate analogue results. As well, our ultimate goal is to perform transition state analysis on MurA. Kinetic isotope effects will reflect a mixture of steps, including partitioning of the THI, unless it partitions predominantly in one direction or the other. However, unlike AroA, which bound its $\mathrm{THI}$ and degraded it rapidly, MurA-catalyzed THI breakdown was very slow, and a new approach to measuring partitioning had to be developed.

\subsection{Non-enzymatic THI breakdown}

MurA THI is relatively stable as compared with most of other 
enzyme THIs. It is acid-labile, with half-lives of about $1 \mathrm{~s}$ at $\mathrm{pH} 1,1 \mathrm{~h}$ at $\mathrm{pH}$ 7.5 , and 89 days at $\mathrm{pH} 12$ at $25^{\circ} \mathrm{C}$ (Fig. 11) (42). This allowed us to separate $\mathrm{THI}$ from the MurA reaction under basic conditions. The mechanism of non-enzymatic MurA THI breakdown was studied in detail by Bart Byczynski from this lab (42). The study showed that the rate and the product distribution are controlled by protonation of different functional groups. The products are predominately UDP-GIcNAc, pyruvate and inorganic phosphate under a large $\mathrm{pH}$ range, from $100 \%$ at $\mathrm{pH}<1.6$ to $90 \%$ at $\mathrm{pH}>6.4$ (Fig. 12). Protonation of the bridging oxygen of the phosphate moiety leads to $\mathrm{THI}$ breakdown through $\mathrm{C}-\mathrm{O}$ bond cleavage with the formation of an oxacarbenium ion intermediate (or TS). Nevertheless, little is known about MurA-catalyzed THI breakdown.

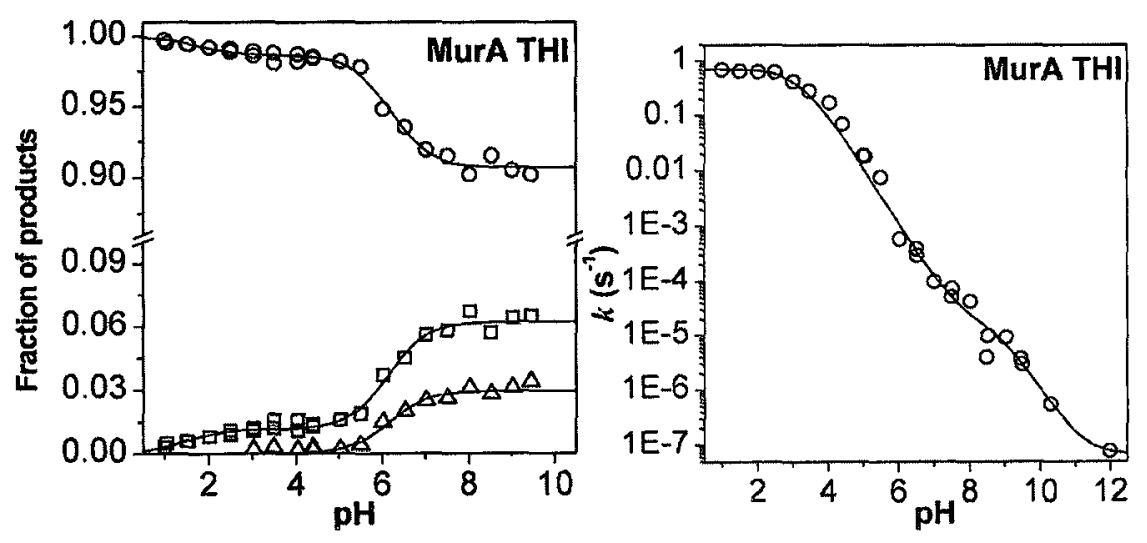

Figure 11. pH profile of MurA THI partitioning and breakdown (30). 


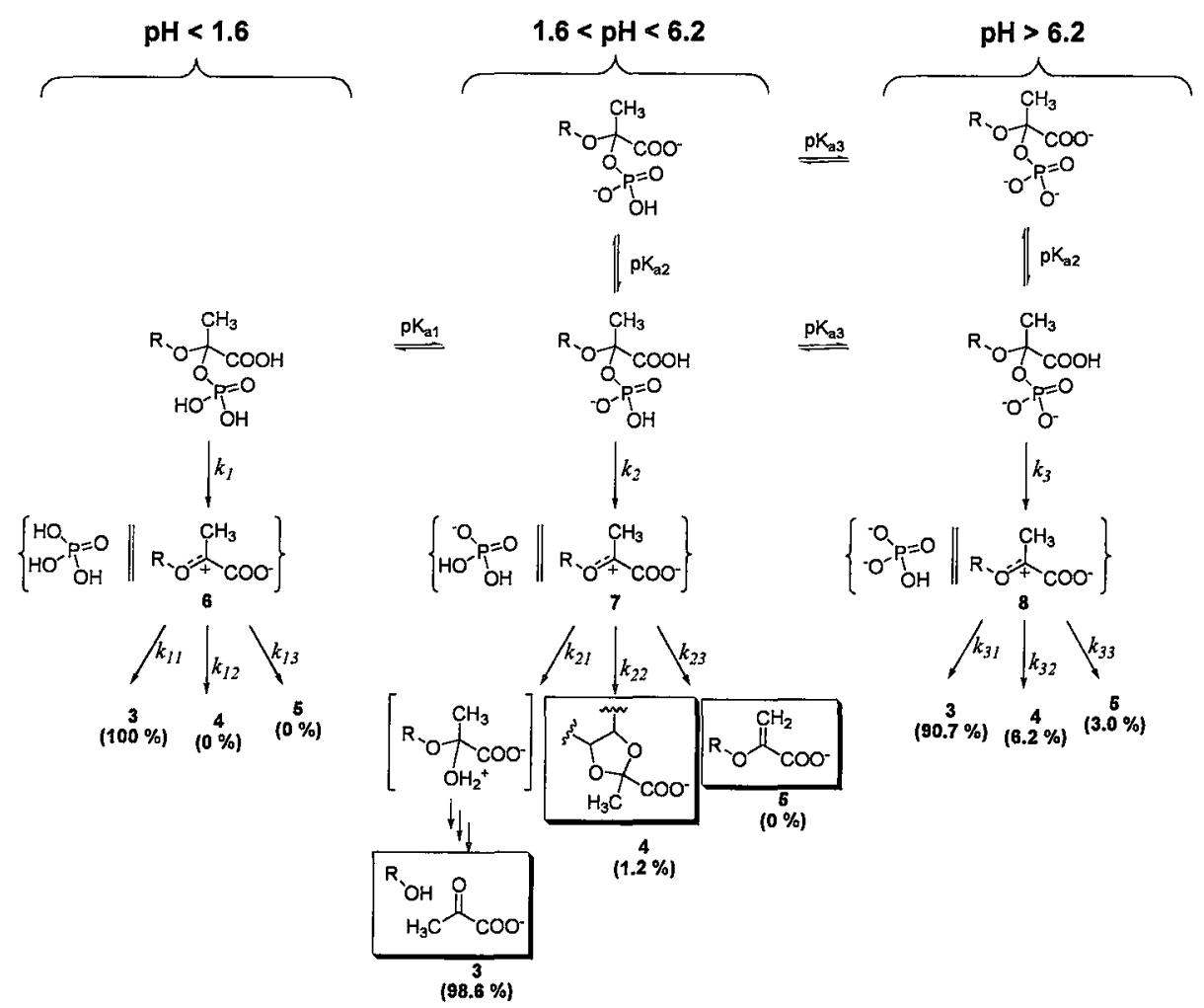

Figure 12. Mechanism of MurA THI non-enzymatic breakdown (42).

\subsection{Phosphate analogues}

Several molecules have been used as phosphate analogues in various studies. Among them, arsenate is probably the most common one. It is frequently accepted by enzymes, forming arsenate esters, which are quickly hydrolyzed to give inorganic arsenate and an alcohol (43). In glucose-6-phosphate isomerase (44), glucose and arsenate can reach a rapid equilibrium with glucose-6-arsenate, with equilibrium favouring dissociation (Fig. 13a). Glucose-6-arsenate is converted to fructose-6arsenate and then hydrolyzed to fructose and arsenate. Glycerophosphate 
dehydrogenase (45) reversibly catalyzes the oxidation of glycerol-3phosphate to dihydroxyacetone phosphate (DHAP) using NAD ${ }^{+}$. Incubation of dihydroxyacetone together with $\mathrm{NADH}$ in the presence of arsenate yields glycerol and $\mathrm{NAD}^{+}$(Fig. 13b). The mechanism was proposed to involve formation of dihydroxyacetone arsenate (a DHAP analogue) followed by conversion to glycerol-3-arsenate. This arsenate ester is later hydrolyzed by water non-enzymatically.

(a)
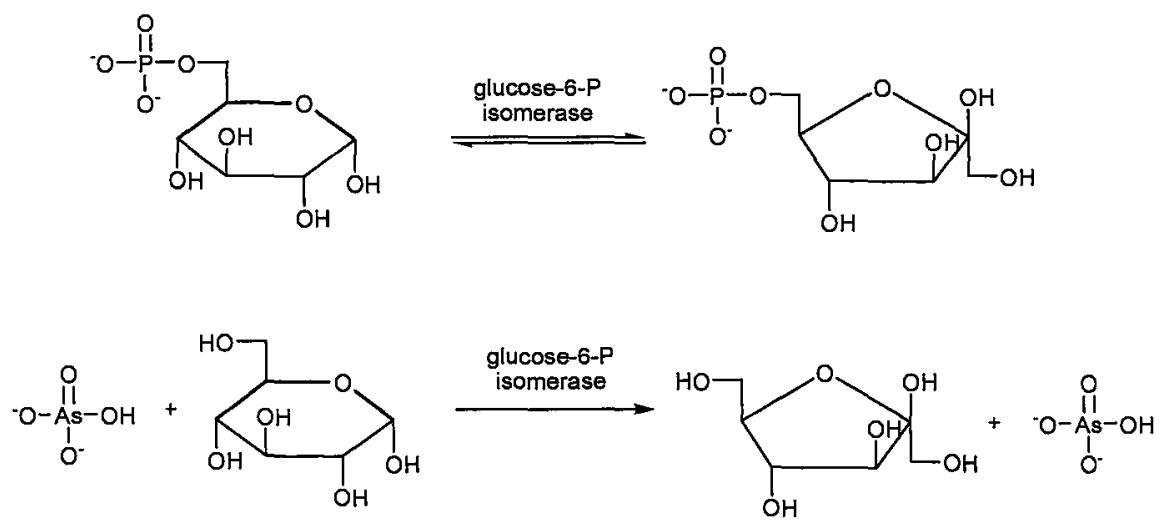

(b)
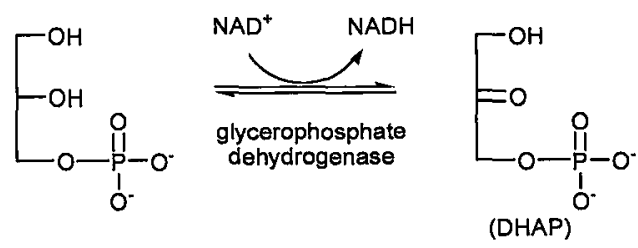

$$
\prod_{\substack{\mathrm{As}-\mathrm{OH} \\ \mathrm{O}^{-}}}+\sum_{\mathrm{OH}}^{\mathrm{OH}}
$$
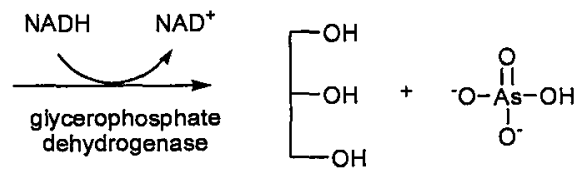

Figure 13. Arsenate as a phosphate analogue. (a) Reaction catalyzed by 
glucose-6-P isomerase, and arsenolysis reaction. (b) Reaction catalyzed by glycerophosphate dehydrogenase and arsenate reaction.

In addition to arsenate, other phosphate analogues have been used. As with arsenate, substitution of phosphorus with element from transition metal vanadium yields another good analogue, vanadate. Vanadate inhibits many enzymes which catalyze phosphoryl transfer reactions, including mitochondrial ATPase (46). In glucose-6-phosphate dehydrogenase, it activates the oxidation of glucose by NADP $^{+}$through formation of a transient glucose-6-vanadate (47) (Fig. 14). Tungstate, having the same tetrahedral geometry with phosphate was used to cocrystallize with protein-tyrosine phosphatase (48). Aluminum fluoride (AIF ${ }_{x}$ is another commonly used phosphate analogue, especially in phosphoryl transferases as the transition state analog. A number of crystal structures of nucleotide binding proteins complexed with $\mathrm{AlF}_{\mathrm{X}}$ have been determined in either $\mathrm{AlF}_{4}^{-}$or $\mathrm{AlF}_{3}$ (49)' (50). Other, less commonly used phosphate analogues, including methyl phosphonic acid, methyl phosphate, thiophosphate and fluorophosphates, can also be useful in probing enzyme mechanisms. 
(a)<smiles>O=P([O-])([O-])OCC1OC(O)C(O)C(O)C1O</smiles>

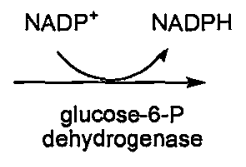<smiles></smiles>

(b)

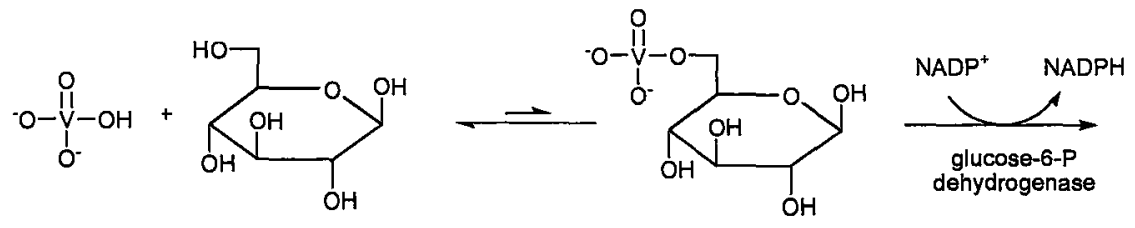<smiles>CC=CC(=O)OC(O)C1C(O)C(O)C(O)C(O)C1OC(=O)[O+]=O</smiles>

Figure 14. Vanadate as a phosphate analogue. (a) Reaction catalyzed by glucose-6-P dehydrogenase. (b) Vanadate assisted oxidation of glucose. 


\section{Experimental}

\subsection{General}

UDP-GlcNAc, shikimic acid, and PEP were purchased from Sigma. Pyruvic acid, fosfomycin, kanamycin, isopropyl-thiogalactopyranoside (IPTG), phenylmethylsulfonyl fluoride (PMSF), and benzamidine were purchased from Bioshop Canada (Burlington, Ontario). $\left[1-{ }^{14} \mathrm{C}\right]$ pyruvate and THO $(1 \mathrm{mCi} / \mathrm{mL})$ were purchased from Amersham Bioscience, $\mathrm{H}_{2}{ }^{18} \mathrm{O}$ from Cambridge.

UV/Nis spectroscopy was performed using $1 \mathrm{~cm}$ quartz cuvettes and a Cary 100 Bio spectrophotometer. Protein purification was performed at 4 ${ }^{\circ} \mathrm{C}$ on an FPLC chromatographic system (Amersham Biosciences). Mini-PROTEAN 3 (Bio-Rad) was used for SDS-PAGE analysis (4\% stacking gel and a $10 \%$ resolving gel) with electrode running buffer (25 mM Tris $\cdot H C l, 192 \mathrm{mM}$ glycine, and $0.1 \%$ sodium dodecyl sulphate (SDS) and SDS reducing buffer ( $\leq 42 \mathrm{mM}$ Tris $\bullet \mathrm{HCl}, \mathrm{pH} 6.8, \leq 17 \%$ glycerol, $\leq 0.7 \%$ SDS, $\leq 0.07 \%$ bromophenol blue, and $\leq 3 \%$ $\beta$-mercaptoethanol). Preparative and analytical HPLC were performed using Waters 616 or 626 LC systems equipped with dual wavelength UV detectors. All liquid scintillation counting was done on a Beckman LS 6500 liquid scintillation counter. Aqueous solutions were freeze 
dried using a Centrivap Concentrator (Labconco Corporation). NMR spectra were acquired on a Bruker AV 600 spectrometer. Mass spectra (MS) were collected using negative electrospray ionization (ESI) and a Micromass Quattro-LC Triple Quadrupole mass spectrometer.

\subsection{Enzyme purification and compounds synthesis}

\subsubsection{E. coli MurA expression and purification}

E.coli MurA were over-expressed using a pET41a (Novagen, inc.) vector in $\mathrm{BL} 21^{*}(\mathrm{DE} 3)$ cells (Invitrogen). In detail, a pET41a plasmid with the E.coli murA gene inserted between the BamHI and $\mathrm{Ndel}$ restriction sites was minipreped from an E.coli $\mathrm{DH} 5 \alpha$ preservation culture. The insert was sequenced. The murA-containing plasmid was transformed into BL21*(DE3) electro-competent cells by electroporation. LB broth (4 L) containing $30 \mu \mathrm{g} / \mathrm{mL}$ kanamycin and $4 \%(\mathrm{v} / \mathrm{v})$ of overnight culture was incubated at $37^{\circ} \mathrm{C}$ until $O D_{600}=0.6$. Expression was induced by $1 \mathrm{mM}$ IPTG, and after a 4 hour incubation at $37^{\circ} \mathrm{C}$ cells were harvested by centrifugation at $5000 \times \mathrm{g}, 4^{\circ} \mathrm{C}$ for $10 \mathrm{~min}$, yielding $3-4 \mathrm{~g} / \mathrm{L}$. The pellet was then suspended in $50 \mathrm{~mL}$ Buffer $\mathrm{A}(50 \mathrm{mM}$ Tris• $\mathrm{HCl}$ at $\mathrm{pH} 7.5,1 \mathrm{mM}$ EDTA, 1 mM DTT).

All the purification steps were carried out at $4^{\circ} \mathrm{C}$. Just before lysing the cells, PMSF and benzamidine were added to a final concentration of 
$1 \mathrm{mM}$, DNase and RNase were added to a final concentration of $100 \mu \mathrm{g} / \mathrm{mL}$. Then cells were lysed with a French Press for 3 passes at 10000 psi. After lysis, cell debris was removed by centrifugation at 10000 $\mathrm{xg}$ for $10 \mathrm{~min}$. $\left(\mathrm{NH}_{4}\right)_{2} \mathrm{SO}_{4}$ was then added to $70 \%$ saturation, and precipitated protein was collect by centrifugation at $50000 \times \mathrm{g}$ for $10 \mathrm{~min}$. The protein was then redissolved in Buffer $\mathrm{B}$ (Buffer $\left.\mathrm{A}, 1 \mathrm{M}\left(\mathrm{NH}_{4}\right)_{2} \mathrm{SO}_{4}\right)$ by shaking for $1 \mathrm{~h}$, and centrifuged again at $50000 \times \mathrm{g}$ for $10 \mathrm{~min}$ to remove insoluble precipitate. The supernatant was loaded on to a Phenyl-Sepharose High-Sub column (40 mL, Amersham Biosciences) and equilibrated with Buffer B until the absorbance returned to baseline. The protein was eluted at $5 \mathrm{~mL} / \mathrm{min}$ with a gradient from Buffer $B$ to Buffer $A$ over $40 \mathrm{~min}$. Fractions containing MurA were collected and buffer was changed to Buffer A by ultra-filtration using a YM-10 membrane. Protein was then applied to Q-Sepharose FF column (40 mL, Amersham Biosciences) and eluted in a 40 min gradient from Buffer $A$ to Buffer $C$ (Buffer $\mathrm{A}, 1 \mathrm{M} \mathrm{KCl}$ ). MurA was collected and stored at $-80^{\circ} \mathrm{C}$ freezer. Yield was $64-76 \mathrm{mg} / \mathrm{L}$ of LB culture.

Some MurA was made PEP free, where the covalently linked PEP (phospholactoyl-enzyme adduct) was removed. To one equivalent of MurA, 2 equivalents of UDP-GIcNAc was added. After incubation for 30 min at $4^{\circ} \mathrm{C}, 8 \mathrm{M}$ freshly prepared urea was added to a final concentration of $6 \mathrm{M}$ 
and the solution was shaken gently at $4^{\circ} \mathrm{C}$ for $2 \mathrm{~h}$. The urea-containing buffer was then exchanged to $1 \mathrm{mM} \mathrm{DTT,} 50 \mathrm{mM}$ Tris $\bullet \mathrm{HCl}$ at $\mathrm{pH} 7.5$ by ultra-filtration using a YM-10 membrane to final urea concentration less than $0.1 \mathrm{mM}$.

\subsubsection{E. coli Aro $_{\mathrm{H} 6}$ expression and purification}

Plasmid pET23a containing the aroA gene with a His6 at the Cterminal, Aro $A_{H 6}$, was transformed into $B L 21^{*}(D E 3)$ cells. The cells were grown, induced, harvested and lysed the same as MurA, except $40 \mathrm{~mL}$ Buffer D (50 mM Tris $\bullet \mathrm{HCl}$ at $\mathrm{pH} 7.5,300 \mathrm{mM} \mathrm{NaCl}, 20 \mathrm{mM}$ imidazole) was used to resuspend the cell pellet. Cell debris was removed by centrifugation at $20000 \times \mathrm{g}$ for $30 \mathrm{~min}$. The supernatant was then applied to $\mathrm{NiSO}_{4}$ Chelating Sepharose column (30 mL, Amersham Biosciences) at $3 \mathrm{~mL} / \mathrm{min}$. Each time, $15 \mathrm{~mL}$ of cell lysate from $6 \mathrm{~L}$ culture was loaded and washed with Buffer D until absorbance returned to the baseline. Buffer $\mathrm{E}(50 \mathrm{mM}$ Tris $\bullet \mathrm{HCl}$ at $\mathrm{pH} 7.5,300 \mathrm{mM} \mathrm{NaCl}, 500 \mathrm{mM}$ imidazole) was used to elute AroA $_{\mathrm{HG}}$. The buffer was exchanged by ultrafiltration to $50 \mathrm{mM}$ Tris $\cdot \mathrm{HCl}$ at $\mathrm{pH} 7.5,50 \mathrm{mM} \mathrm{KCl}, 1 \mathrm{mM} \mathrm{DTT}$. Yield was 50 to $80 \mathrm{mg} / \mathrm{L}$ of LB culture.

\subsubsection{E. coli PPDK expression and purification}

PACYC plasmid containing the pyruvate phosphate dikinase 
(PPDK) gene was transformed into E.coli strain JM101 cells (Stratagene) by electroporation. Cells were grown up in 9L LB broth containing $20 \mu \mathrm{g} / \mathrm{mL}$ tetracycline and $4 \%(\mathrm{v} / \mathrm{v})$ of overnight culture at $37^{\circ} \mathrm{C}$. The cells were then induced, harvested, and lysed as with MurA. The protein was subjected to $50 \%$ saturated $\left(\mathrm{NH}_{4}\right)_{2} \mathrm{SO}_{4}$ precipitation, and centrifuged at $50000 \times \mathrm{g}$ for $10 \mathrm{~min}$. To the supernatant, $\left(\mathrm{NH}_{4}\right)_{2} \mathrm{SO}_{4}$ was added to $62 \%$ saturation to precipitate PPDK, and the solution was then centrifuged at $50000 \times \mathrm{g}$ for $10 \mathrm{~min}$. The precipitate was dissolved in Buffer $\mathrm{F}(20 \mathrm{mM}$ imidazole- $\mathrm{HCl}$ at $\mathrm{pH} 6.4,2.5 \mathrm{mM}$ EDTA, $0.6 \mathrm{mM} \beta$-mercaptoethanol, $88 \mathrm{mM} \mathrm{KCl})$, and loaded on to a DEAE-Sephadex column ( $20 \mathrm{~mL}$ packed from $2 \mathrm{~g}$ of dry DEAE-Sephadex resin (Amersham Bioscience)). The protein was eluted with a gradient from Buffer $F$ to Buffer $G(20 \mathrm{mM}$ imidazole- $\mathrm{HCl}$ at $\mathrm{pH}$ 6.4, $2.5 \mathrm{mM}$ EDTA, $0.6 \mathrm{mM} \beta$-mercaptoethanol, $500 \mathrm{mM} \mathrm{KCl}$ ) over $40 \mathrm{~min}$ at $0.8 \mathrm{~mL} / \mathrm{min}$.

\subsection{4 $\left[1-{ }^{14} \mathrm{C}\right] \mathrm{PEP}$ and $\left[{ }^{13} \mathrm{C}\right] \mathrm{PEP}$ synthesis}

A $100 \mathrm{uL}$ solution containing $\left[1-{ }^{14} \mathrm{C}\right]$ pyruvate $(3.67 \mathrm{mM}, 10 \mu \mathrm{Ci})$ or $4 \mathrm{mM}$ of $\left[{ }^{13}\right.$ C]pyruvate, $6 \mathrm{mM}$ ATP, $10 \mathrm{mM} \mathrm{MgCl}_{2}, 5 \mathrm{mM} \mathrm{KCl}, 5 \mathrm{mM} \mathrm{Pi}$, $10 \mu \mathrm{M}$ PPDK was incubated together with $10 \mathrm{U}$ inorganic pyrophosphatase (PPiase) for 6 hours. After quenching by adding $\mathrm{KOH}$ to $200 \mathrm{mM}$ and extracting with chloroform, PEP was purified by Mono-Q (Amersham Biosciences) anion exchange column with a 
gradient from $10 \mathrm{mM} \mathrm{NH}_{4} \mathrm{HCO}_{3}$ to $500 \mathrm{mM} \mathrm{NH}_{4} \mathrm{HCO}_{3}$ over 30 min at $\mathrm{pH}$ 10.0. Large scale purifications were used for some $\left[{ }^{13} \mathrm{C}\right] \mathrm{PEP}$ syntheses. The reaction mixture was purified on a $20 \mathrm{~mL}$ Q-Sepharose column with a gradient from $250 \mathrm{mM}$ to $400 \mathrm{mM} \mathrm{NH}_{4} \mathrm{HCO}_{3}$ at $\mathrm{pH} 10.0$ over $50 \mathrm{~min}$. PEP was collected and freeze-dried. Yields were typically $38 \%$ to $46 \%$ relative to pyruvate.

\subsubsection{EP-UDP-GICNAc and EPSP synthesis}

Reaction mixture (up to $1 \mathrm{~mL}$ ) containing $10 \mathrm{mM}$ UDP-GIcNAc (or S3P in EPSP synthesis), $10 \mathrm{mM}$ PEP, $50 \mathrm{mM}$ Tris $\bullet \mathrm{HCl}, 1 \mu \mathrm{M}$ of MurA (AroA in EPSP synthesis) was prepared and incubated at room temperature for more than $1 \mathrm{~h}$. After quenched with $200 \mathrm{mM} \mathrm{KOH}$ and extracting with $\mathrm{CHCl}_{3}$, the product was separated on a Q-Sepharose column with a gradient from $100 \mathrm{mM}$ to $700 \mathrm{mM} \mathrm{NH}_{4} \mathrm{HCO}_{3}$ at $\mathrm{pH} 10.0$ over $60 \mathrm{~min}$. After the products were collected, they were freeze-dried as described in $\left[1-{ }^{14} \mathrm{C}\right]$ PEP synthesis. The yield for EP-UDP-GIcNAc was usually 50 to $65 \%$ and EPSP $>95 \%$.

In $\left[{ }^{13} \mathrm{C}\right]$ EP-UDP-GIcNAc synthesis, three-fold excess of UDPGlcNAc was added to drive most of the $\left[{ }^{13} \mathrm{C}\right]$ PEP to $\left[{ }^{13} \mathrm{C}\right] \mathrm{EP}-U D P-G I c N A c$. The yield for these isotope labeled EP-UDP-GlcNAc was usually $>90 \%$ calculated relative to labeled PEP. 
2.2.6 $\left[1-{ }^{14} \mathrm{C}\right] \mathrm{THI}$ (MurA) synthesis

A $300 \mu \mathrm{L}$ reaction mixture containing $0.2 \mathrm{mM}\left[1-{ }^{14} \mathrm{C}\right] \mathrm{PEP}(0.5 \mu \mathrm{Ci})$, $2 \mathrm{mM}$ UDP-GlcNAc, $50 \mathrm{mM}$ phosphate, $50 \mathrm{mM}$ Tris $\bullet \mathrm{HCl}$, pH 7.5 were prepared, and MurA was added to $2 \mathrm{mM}$ and quenched within 5 seconds by $200 \mathrm{mM} \mathrm{KOH}$. The reaction mixture was extracted with $\mathrm{CHCl}_{3}$ repeatedly until no more protein precipitated, and then injected to Mono-Q column with a gradient from $10 \mathrm{mM} \mathrm{KCl}, 10 \mathrm{mM} \mathrm{NH}_{4} \mathrm{Cl}$, to $500 \mathrm{mM} \mathrm{KCl}$, $10 \mathrm{mM} \mathrm{NH}_{4} \mathrm{Cl}$ at pH 10.0 over $30 \mathrm{~min}$. The yield was 14 to $25 \%$ relative to $\left[1-{ }^{14} \mathrm{C}\right]$ PEP. $\left[1-{ }^{14} \mathrm{C}\right] \mathrm{EP}-$ UDP-GICNAc was also purified as a byproduct and the yield was 40 to $50 \%$.

\subsection{MurA THI enzymatic breakdown}

Partitioning analysis of MurA THI reaction with MurA was carried out by incubating $\left[{ }^{14} \mathrm{C}\right] \mathrm{TH} I$ with different MurA concentrations, and quenching at the same time. This reaction was coupled with two other enzymatic reactions in order to prevent any overall reaction from PEP to EP-UDP-GIcNAC. PEP was reacted with ADP to convert to pyruvate by pyruvate kinase (PK) and phosphate was consumed using by MESG with purine nucleoside phosphorylase (PNP) (Fig. 15). In detail, a 200uL reaction mixture was prepared containing $4.4 \mu \mathrm{M}\left[1-{ }^{14} \mathrm{C}\right] \mathrm{THI}(7000 \mathrm{cpm})$, $1 \mathrm{mM}$ ADP, $0.13 \mathrm{mM}$ MESG, $100 \mathrm{mM} \mathrm{MgCl} 2,300 \mathrm{mM} \mathrm{KCl}, 50 \mathrm{mM}$ 
Tris $\bullet \mathrm{HCl}$ at $\mathrm{pH} 7.5,0.5 \mathrm{U}$ PK (Sigma), 0.3 U PNP (Sigma) and MurA (from 20 to $200 \mu \mathrm{M}$ ) were added. The reactions were quenched after 15 to $45 \mathrm{~min}$ by adding $200 \mathrm{mM} \mathrm{KOH}$ and then extracting with $\mathrm{CHCl}_{3}$ until no more protein precipitated. The quenched reaction mixture was separated by Mono-Q column with the same condition as in $\left[1-{ }^{14} \mathrm{C}\right] \mathrm{THI}$ synthesis. One minute fractions were collected into scintillation vials. To each fraction, $20 \mathrm{~mL}$ Liquiscint scintillation fluid (National Diagnostics) was added and radioactivity was counted for $2 \times 5 \mathrm{~min}$. The partitioning was calculated as $f(P E P)=\left[\left[1-{ }^{14} C\right] P E P\right] /\left(\left[\left[1-{ }^{14} C\right] P E P\right]+\left[\left[1-{ }^{14} C\right] E P U\right]\right)$, where $\left[\left[1-{ }^{14} \mathrm{C}\right] \mathrm{PEP}\right]$ was calculated from $\left[\left[1-{ }^{14} \mathrm{C}\right]\right.$ pyruvate $]$. These experiments were conducted under different pHs. Partitioning experiments at different pHs followed the same method, except using $50 \mathrm{mM}$ CAPS as buffer at $\mathrm{pH} 10.0$ and $50 \mathrm{mM}$ ammonium acetate at $\mathrm{pH} 5.0$.

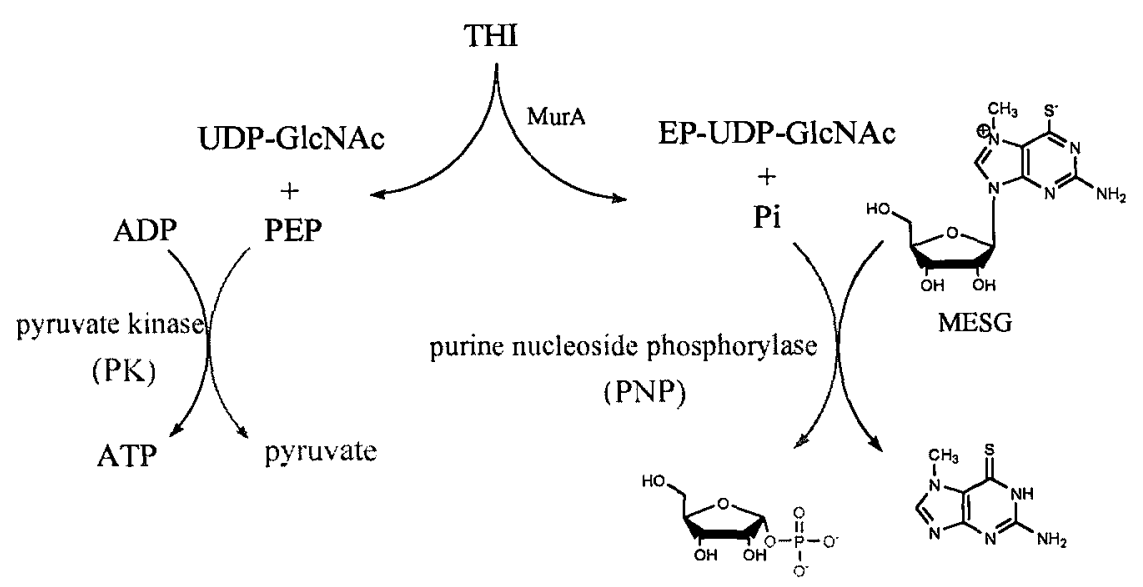

Figure 15. MurA THI enzymatic breakdown reaction. THI breakdown was coupled with PK and PNP reactions to exhaust PEP and phosphate. 


\subsection{Phosphate analogue/enzyme-catalyzed EP-OR hydrolysis products}

\subsubsection{Products characterization by HPLC}

To a $200 \mu \mathrm{L}$ reaction mixture containing $0.75 \mathrm{mM}$ of EP-OR, $8.5 \mu \mathrm{M}$ of enzyme, in $50 \mathrm{mM}$ Tris $\cdot \mathrm{HCl}$ at $\mathrm{pH} 7.5$, arsenate was added to $40 \mu \mathrm{M}$. After $1 \mathrm{~h}$, the reaction mixture was separated by Mono-Q anion exchange chromatography as in $\left[1-{ }^{14} \mathrm{C}\right] \mathrm{THI}$ synthesis and detected by dual wavelength UV absorbance detector at $260 \mathrm{~nm}$ and $240 \mathrm{~nm}$. UDP-GlcNAc and EP-UDP-GIcNAc have different retention times and different area ratio at the two wavelengths. Under these separation conditions, S3P eluted earlier than EPSP. Standard UDP-GIcNAc, EPU, S3P, EPSP were injected and compared. Control experiments without enzyme or arsenate were done under the same conditions.

\subsubsection{Products characterization by Radioactivity assay}

A final concentration of $200 \mu \mathrm{M}$ arsenate was added to $0.33 \mu \mathrm{M}$ of $\left[1-{ }^{14} \mathrm{C}\right] \mathrm{EP}-\mathrm{OR}$ (with specific activity of $27 \mathrm{mCi} / \mathrm{mmol}$ ), $20 \mu \mathrm{M}$ of AroA or MurA, $50 \mathrm{mM}$ Tris $\cdot \mathrm{HCl}$ at $\mathrm{pH}$ 7.5. The final volume was $100 \mu \mathrm{L}$. The reaction was incubated for $30 \mathrm{~min}$, then separated as with $\left[1-{ }^{14} \mathrm{C}\right] \mathrm{THI}$ synthesis, but taking $45 \mathrm{~s}$ fractions and counting ${ }^{14} \mathrm{C}$ in each fraction. 


\subsubsection{Lactate Dehydrogenase reaction assay}

In order to confirm that the presumed pyruvate product was indeed being formed, lactate dehydrogenase was used in a spectrophotometric assay to reduce pyruvate to lactate. Arsenate/enzyme-catalyzed EP-OR breakdown reactions were set up with $0.4 \mathrm{mM}$ EP-OR, $2 \mathrm{mM}$ arsenate, $0.2 \mu \mathrm{M}$ enzyme, $50 \mathrm{mM}$ Tris $\bullet \mathrm{HCl}, \mathrm{pH} 7.5$ in $500 \mu \mathrm{L}$. After $30 \mathrm{~min}$, the reaction was quenched and extracted with $\mathrm{CHCl}_{3} 3$ times. A $10 \mu \mathrm{L}$ aliquot of quenched reaction mixture was analyzed by HPLC to ensure EP-OR breakdown was complete. To the remaining reaction solution, $0.1 \mathrm{mM}$ $\mathrm{NADH}$ was added to a total volume of $1 \mathrm{~mL}$ in a cuvette. Lactate dehydrogenase $(1 \mathrm{U})$ was added, and $A_{340}$ was monitored.

\subsubsection{Products characterization by Mass spectrometry}

The products of EP-OR hydrolysis by arsenate/enzyme was identified by mass spectrometry. To a reaction mixture containing $0.5 \mathrm{mM}$ EP-OR, $0.25 \mathrm{mM}$ arsenate at $\mathrm{pH} 7.5$, MurA or AroA was added to final concentrations of $34 \mu \mathrm{M}$ or $48 \mu \mathrm{M}$ in $100 \mu \mathrm{L}$. After 5 to $28 \mathrm{~min}$, the reaction was quenched with $200 \mathrm{mM} \mathrm{NH}_{4} \mathrm{OH}$, followed by $\mathrm{CHCl}_{3}$ extraction. The aqueous layer was lyophilized and analyzed by mass spectrometry.

\subsection{Kinetics of phosphate analogues/enzyme-catalyzed EP-OR}




\section{hydrolysis}

In order to estimate the specificity constants, $k_{\text {cat }} / K_{\mathrm{M}}$, of phosphate analogue-promoted reactions, EP-OR was incubated with AroA or MurA, then the phosphate analogues were added to initiate the reaction. Initial rates, $v_{0}$ 's, were measured and apparent $k_{\text {cat }} / K_{M}$ 's were calculated using equation 1:

$$
v_{0}=\frac{k_{c a t}}{K_{M}}[\text { analogue }][\mathrm{E}]
$$

In detail, $100 \mu \mathrm{L}$ reaction mixture containing $333 \mu \mathrm{M}$ of EP-UDPGlcNAc or $750 \mu \mathrm{M}$ of EPSP, 8.5 or $34 \mu \mathrm{M}$ of enzyme, and 75 to $150 \mu \mathrm{M}$ phosphate analogues, in $50 \mathrm{mM}$ Tris $\bullet \mathrm{HCl}, \mathrm{pH} 7.5$, was incubated for up to $80 \mathrm{~min}$. The products were then separated by anion exchange chromatography, as above, and peaks were quantitated. For some reactions, 0.2 to $2 \mu \mathrm{M}$ of $\left[1-{ }^{14} \mathrm{C}\right] \mathrm{EPSP}$ was added, and radioactivity in pyruvate and EPSP was calculated.

\subsection{Mechanism of arsenate/enzyme-catalyzed EP-OR hydrolysis}

2.6.1 Phosphate analogue/enzyme-catalyzed EP-OR C3 proton solvent exchange

With enzyme only, the two EP-OR ethylene protons were not 
exchangeable. Solvent exchange of these protons under phosphate analogue/enzyme system was studied by incubating the reaction in $\mathrm{D}_{2} \mathrm{O}$.

In the arsenate/MurA-catalyzed reaction, EP-UDP-GIcNAc and arsenate were freeze dried redissolved in $190 \mu \mathrm{L} \mathrm{D}_{2} \mathrm{O}$, then enzyme and volatile buffer $\mathrm{NH}_{4} \mathrm{HCO}_{3}$ at $\mathrm{pH} 7.5$ were added with final concentrations of $90 \mu \mathrm{M}$ EP-UDP-GlcNAc, $62.5 \mu \mathrm{M}$ arsenate, $1.25 \mu \mathrm{M}$ MurA, $50 \mathrm{mM}$ $\mathrm{NH}_{4} \mathrm{HCO}_{3}$ in $95 \% \mathrm{D}_{2} \mathrm{O}$. The reaction was quenched by $50 \% \mathrm{NH}_{4} \mathrm{OH}$ at $50 \%$ completion as monitored by HPLC. The enzyme was then precipitated with $\mathrm{CHCl}_{3}$. The aqueous layer was freeze dried and redissolved in $\mathrm{H}_{2} \mathrm{O}$ for at least 5 times in order to exchange all the active protons in EP-UDP-GIcNAc. Finally, the mixture was dissolved in $50 \%$ $\mathrm{MeOH} / \mathrm{H}_{2} \mathrm{O}$ containing $2.5 \%$ formic acid and injected onto MS to analyze EP-UDP-GIcNAc isotope peaks. The vanadate/MurA-catalyzed reaction was carried out in the same way except using $225 \mu \mathrm{M}$ EP-UDP-GlcNAc, $125 \mu \mathrm{M}$ vanadate and $8.5 \mu \mathrm{M}$ MurA.

The solvent exchange rates of analogue/AroA-catalyzed reactions were measured by dissolving EPSP and phosphate analogues in $95 \%$ $\mathrm{D}_{2} \mathrm{O}$ with final concentrations of $375 \mu \mathrm{M}$ EPSP, 25 to $333 \mu \mathrm{M}$ of phosphate analogue, 5.3 to $15 \mu \mathrm{M}$ of AroA in $50 \mathrm{mM} \mathrm{NH}_{4} \mathrm{HCO}_{3}$ buffer at $\mathrm{pH}$ 7.5. The reaction was quenched with $50 \% \mathrm{NH}_{4} \mathrm{OH}, 50 \%$ D2O at different time 
points varied from $1 \mathrm{~min}$ to $12 \mathrm{~h}$. After $\mathrm{CHCl}_{3}$ extraction, the mixture was lyophilized and active protons were exchanged with $\mathrm{H}_{2} \mathrm{O}$. The sample was finally dissolved in $50 \% \mathrm{MeOH} / \mathrm{H}_{2} \mathrm{O}$ and EPSP isotope peaks were analyzed by MS. In the vanadate, tungstate, and sulphate containing reactions, in order to suppress any contaminant phosphate-catalyzed solvent exchange, $50 \mu \mathrm{M}$ of $\mathrm{KCl}, 50 \mu \mathrm{M} \mathrm{MgCl}_{2}, 300 \mu \mathrm{M}$ of ADP and $0.2 \mathrm{U}$ of PK were added to remove phosphate by forming ATP.

\subsection{2 $\left[3-{ }^{3} \mathrm{H}\right] \mathrm{EP}-\mathrm{OR}$ hydrolysis}

In MurA-catalyzed reactions, a final concentration of $12 \mathrm{mM}$ EP-UDP-GlcNAc containing $500 \mathrm{cpm}$ [3--3]EP-UDP-GIcNAc, $20 \mathrm{mM}$ arsenate, $40 \mu \mathrm{M}$ MurA, $14 \mathrm{mM} \mathrm{NADH}$, and $0.05 \mathrm{mg} \cdot \mathrm{mL}^{-1} \mathrm{LDH}$ was incubated in $50 \mathrm{mM}$ Tris $\bullet \mathrm{HCl}$ at $\mathrm{pH}$ 7.5. NADH and LDH were used to drive the pyruvate formed to lactate in order to prevent any tritium release from the enol form of pyruvate. A control experiment with everything except arsenate was carried out in parallel. The reactions were quenched after 15 min with $120 \mathrm{mM} \mathrm{HCl}$ and extracted with $\mathrm{CHCl}_{3}$ three times. The aqueous solution was then diluted to $4 \mathrm{~mL}$ and evenly divided to two scintillation vials. One vial was lyophilized by adding regular water repeatedly. Radioactivity in both the two vials was then counted for $10 \mathrm{~min}$ and radioactivity losses in the lyophilized vial were compared. 
AroA-catalyzed reactions were followed in the same way except that $1.6 \mathrm{mM}$ EPSP containing $500 \mathrm{cpm}\left[3{ }^{3} \mathrm{H}\right] \mathrm{EPSP}$, and $100 \mu \mathrm{M}$ AroA were need, and the reactions were quenched after $6 \mathrm{~min}$ (100\% in completion).

\subsubsection{EP-OR hydrolysis in $\mathrm{H}_{2}{ }^{18} \mathrm{O}$}

Hydrolysis of EP-OR by arsenate/enzyme was initiated in $\mathrm{H}_{2}{ }^{18} \mathrm{O}$ to determine the site of nucleophilic attack by water. To a reaction mixture containing $0.5 \mathrm{mM}$ EP-OR, $0.25 \mathrm{mM}$ arsenate in $86 \mu \mathrm{L}$ of $\mathrm{H}_{2}{ }^{18} \mathrm{O}$ at $\mathrm{pH} 7.5$, MurA or AroA was added to final concentrations of $34 \mu \mathrm{M}$ and $48 \mu \mathrm{M}$ separately in $100 \mu \mathrm{L}$. After 5 to $28 \mathrm{~min}$, the reaction was quenched by $\mathrm{CHCl}_{3}$ extraction and analyzed by mass spectrometry immediately. Control experiments were carried out in the same conditions but without EP-OR or enzyme, or in $\mathrm{H}_{2}{ }^{16} \mathrm{O}$.

\subsection{Fluorescence titration experiments}

Dissociation constants $\left(K_{d}\right)$ for phosphate analogues with Aro $A_{H 6}$ were determined using steady state fluorescence titrations in a $2 \mathrm{~mL}$ quartz cuvette at $25^{\circ} \mathrm{C}$, with $280 \mathrm{~nm}$ excitation wavelength and $360 \mathrm{~nm}$ emission wavelength. In a typical titration experiment, aliquots of 0.5 to $10 \mu \mathrm{L}$ of ligand (phosphate or an analogue) were added to an either 0.5 or $1 \mu \mathrm{M}$ enzyme solution in $50 \mathrm{mM}$ Tris $\bullet \mathrm{HCl}, \mathrm{pH} 7.5,1 \mathrm{mM}$ DTT. The solution 
was stirred and equilibrated for $20 \mathrm{~min}$ before readings $(60 \times 0.5 \mathrm{~s})$ were taken and averaged. Ligand was added until no further fluorescence change was observed. After correction for dilution, fluorescence intensity was plotted versus total ligand concentration, [L], and fitted to equation 2:

$$
F=F_{0} \frac{\left(F_{0}-F_{\text {inf }}\right)\left\{\frac{\left([\mathrm{E}]_{0}+[\mathrm{L}]+K_{d}\right)-\sqrt{\left([\mathrm{E}]_{0}+[\mathrm{L}]+K_{d}\right)^{2}-4[\mathrm{E}]_{0}[\mathrm{~L}]}}{2}\right\}}{[\mathrm{E}]_{0}}
$$

where $F$ were the observed fluorescence data, $F_{0}$ and $F_{\text {inf }}$ were fitted fluorescence at zero and infinite $[L],[E]_{0}$ was the total enzyme concentration, and $K_{d}$ was the fitted dissociation constant for the ligand. Titrations of the AroA mutant D313A, with EPSP and phosphate were performed the same way.

For thiophosphate and methylphosphate, the competitive inhibition of EPSP binding was also studied by fluorescence titration. In detail, different concentrations of analogue, 0.5 to $2 \mathrm{mM}$ for thiophosphate and 11.5 to $115 \mathrm{mM}$ for methylphosphate, were incubated with Aro $_{\mathrm{H} \sigma}$ for 30 min. The mixture was then titrated with EPSP as described as before. Apparent binding constants at each analogue concentration were fitted, and $K_{d}$ for each analogue was fitted to equation 3: 


$$
K_{\text {d,EPSP }}(\text { apparent })=K_{\text {d,EPSP }}\left(1+\frac{[\text { analogue }]}{K_{\text {d,analogue }}}\right)
$$

\subsection{Phosphate analogues charge calculation}

The atomic charge of each deprotonated oxygen in each phosphate analogue was calculated by using the RB3PW $91 / 6-31+G^{* *}$ level of theory; that is, density functional theory with Becke's exchange functional (51) and Perdew and Wang's correlation functional (52), as implemented in Gaussian 98 (53), with charges calculated using natural population analysis (NPA) (54). 


\section{Results}

\subsection{Enzyme purity, concentration and specific activity measurement}

Protein purity measured by SDS/PAGE, showed $>95 \%$ pure for MurA, $>98 \%$ for AroA and $90 \%$ for PPDK. Enzyme identity was confirmed by DNA-sequencing, and mass spectrometry for MurA and AroA (data not shown). Protein concentrations were determined using $\varepsilon_{280}=2.45 \times 10^{4} \mathrm{M}^{-}$ ${ }^{1} \mathrm{~cm}^{-1}$ for MurA, $\varepsilon_{280}=3.06 \times 10^{4} \mathrm{M}^{-1} \mathrm{~cm}^{-1}$ for AroA and $\varepsilon_{280}=7.50 \times 10^{4} \mathrm{M}^{-1} \mathrm{~cm}^{-}$ ${ }^{1}$ for PPDK, which were determined by the method of Edolhoch ${ }^{18}$. The active concentration of MurA was determined by titrating its activity with fosfomycin in a kinetic assay using Malachite Green/ ammonium molybdate to detect phosphate. It showed $>90 \%$ specific activity.

E.coli MurA contained approximately $10 \%$ covalently linked PEP. In order to remove this phospholactoyl-enzyme adduct, UDP-GlcNAc was added to react with PEP. They were converted into EP-UDP-GIcNAc and phosphate. Reaction between covalently linked PEP and UDP-GIcNAc was fast. The EP-UDP-GIcNAc formed was observed 30s after UDPGlcNAc was added after HPLC purification (Fig.16a). Leaving the reaction too long led to EP-UDP-GIcNAc hydrolysis by the excess enzyme. The EP-UDP-GIcNAc peak can not be observed after incubation for overnight. The completion of the chasing reaction was tested by HPLC. The products 
together with unreacted UDP-GIcNAc, and non-covalently linked UDP-

MurNAc were removed by denaturing the enzyme with urea. By removing the urea, MurA regained $10-60 \%$ activity as compared with untreated MurA. Treated MurA was shown to be ligand free by HPLC (Fig. 16b).
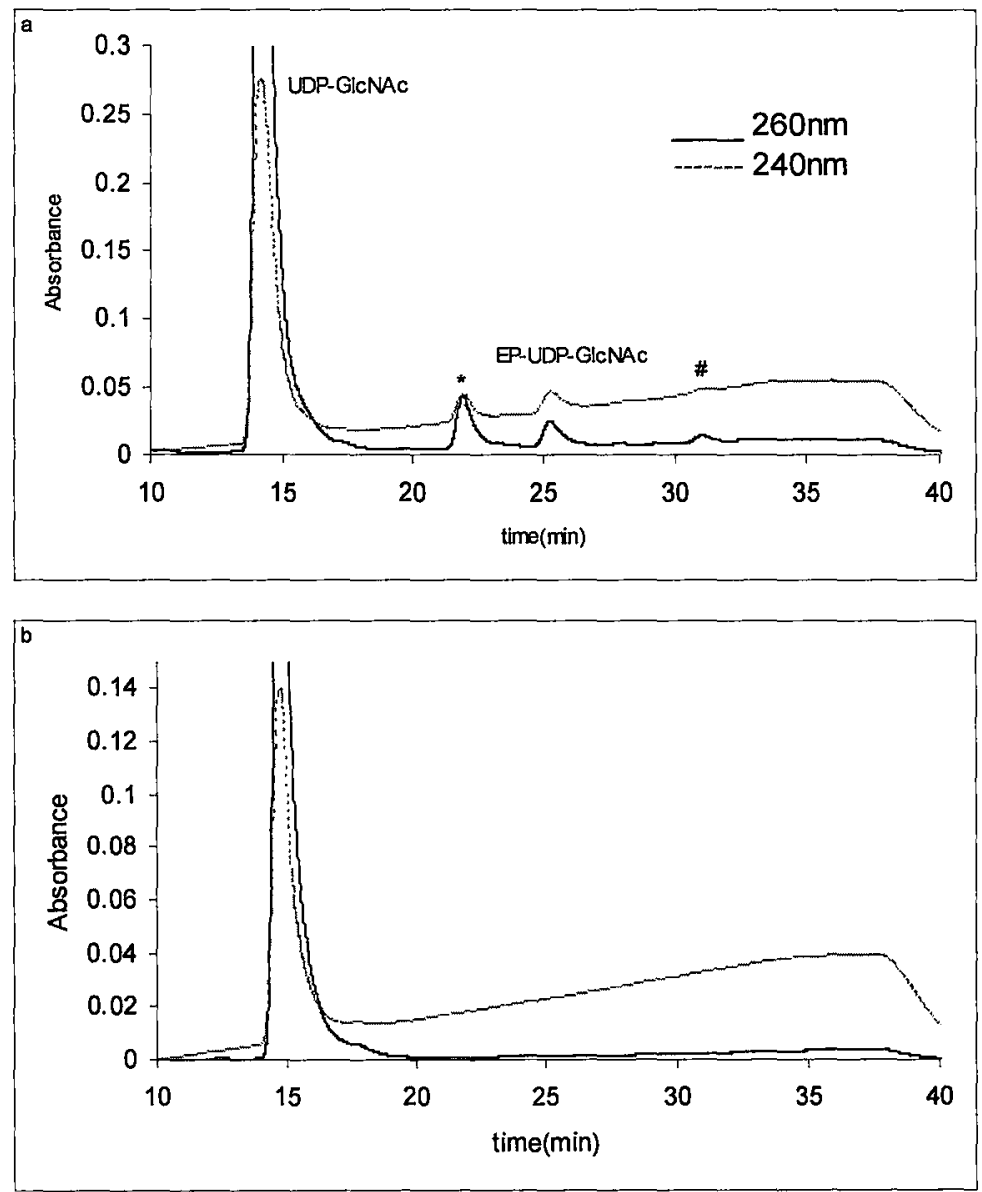

Figure 16. (a)Two equivalents of UDP-GICNAc were added to MurA directly after purification. Covalently linked PEP was chased to EP-UDP-GICNAC and eluted at 25.2 min. * non-covalently linked UDP-MurNAc. \# MurA THI formed under excess enzyme. (b) Two equivalents of UDP-GicNAc were added to treated PEP-free MurA. The HPLC chromatograph did not have EP-UDP-GIcNAc or UDP-MurNAc peaks showing the PEP chase was effective.

\subsection{Ligands synthesis}


PEP synthesis from pyruvate as catalyzed by PPDK is reversible, favouring pyruvate. Inorganic pyrophosphatase (PPiase) was added to hydrolyze inorganic pyrophosphate and drive the equilibrium forward (Fig. 17a).

EP-UDP-GICNAC and EPSP were synthesized many times. The purification method (elution buffer concentration and gradient length) varied with injection volume and the reaction mixture (Fig. $7 b, c)$. Concentrations of newly synthesized PEP, EP-UDP-GIcNAc and EPSP were determined by comparing HPLC peak areas with standard injection of PEP and UDP-GICNAc. EP-UDP-GIcNAc had the same molar absorptivity as UDP-GICNAc at $260 \mathrm{~nm}$. The area ratios of PEP/EPSP (determined from ${ }^{14} \mathrm{C}$-labeled sample with same specific radioactivity) at 240nm was used to determine EPSP concentration. PEP/S3P area ratio at $240 \mathrm{~nm}$ was measured from the reverse reaction. It was 1:0.59:2.1 for PEP:S3P:EPSP. Compound purities were $95 \%$ to $99 \%$, as determined by HPLC. Both EP-OR's were stable at neutral and slightly basic $\mathrm{pH}(<12)$ at $4^{\circ} \mathrm{C}$, which is how they were stored, but not at acidic pH. EP-UDP-GIcNAc was hydrolyzed through $\mathrm{P}-\mathrm{O}$ bond cleavage in $1 \mathrm{M} \mathrm{HCl}$ or $\mathrm{KOH}$ after 2hours, yielding UMP and the other moiety (examined by MS, data not shown). 

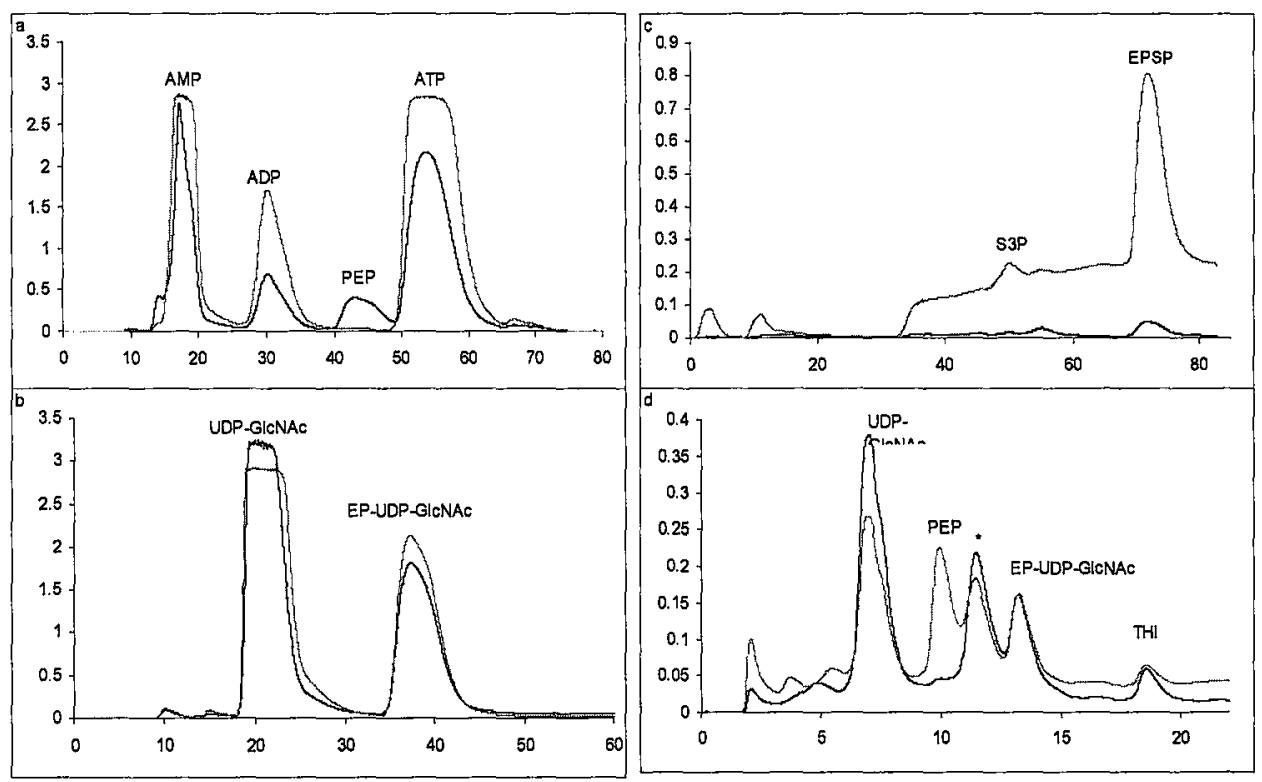

Figure 17 (a) A typical HPLC chromatogram of PEP purification on a Q-Sepharose column. (b) Labeled EP-UDP-GIcNAc purification on a Q-Sepharose column. Excess UDP-GICNAc was used to consume all the labeled PEP. (c) EPSP purification on a Q-Sepharose column. (d) MurA THI purification on a Mono-Q column.

MurA THI is stable in basic conditions with a lifetime of 49 days at $\mathrm{pH} 12,14$ days at $\mathrm{pH} 10$, and labile in acidic conditions with a lifetime of 4s at $\mathrm{pH}$ 4.0. Its nonenzymatic breakdown products are pyruvate, phosphate and UDP-GICNAc. Chromatography from THI purification is shown in Fig. 17d. Identity of THI was confirmed by bringing MurA THI to $\mathrm{pH} 4.0$, after $10 \mathrm{~s}$ bringing it back to $\mathrm{pH} 10.0$; then its components was examined by HPLC. Most of THI broke down to pyruvate and UDP-GICNAc, with $<5 \%$ residual THI from $260 \mathrm{~nm}$ UV detection, which could be some impurity having the same retention time with THI (data not shown). There was no remaining radioactivity at the $\mathrm{THI}$ retention time when ${ }^{14} \mathrm{C}$-labeled THI was used. 


\subsection{MurA THI enzymatic breakdown}

The initial rate of MurA-catalyzed THI breakdown was measured. Its $k_{\text {cat }} / K_{\mathrm{m}}$ was $4 \times 10^{3} \mathrm{M}^{-1} \mathrm{~s}^{-1}, 3 \times 10^{4}$-fold slower than AroA-catalyzed THI breakdown (30). Presumably this was due to slower binding. Trying to increase the flexibility of the active site with up to $300 \mathrm{mM}$ urea did not increase the reaction rate (data not shown). Higher urea concentrations led to decreasing enzyme activity, from $48 \%$ at $600 \mathrm{mM}$ urea to $<0.1 \%$ activity at $2 \mathrm{M}$ urea. THI breakdown was slow enough that its products, [UDP-GIcNAc + PEP] and [EP-UDP-GlcNAc + Pi], would have reacted with MurA unless steps were taken to prevent this. Two coupled enzymatic reactions were used to consume PEP and phosphate, and stop any overall equilibrium reaction (Fig. 15). Pyruvate kinase (PK) is $\mathrm{pH}$ dependent, with lower activity at low pH (55). Large amounts were used in order to make sure all PEP can be converted to pyruvate at $\mathrm{pH} 5.0$. Lower $\mathrm{pH}$ was not tried due to low PK activity. Initially, the purine nucleoside phosphorylase (PNP) coupled reaction with inosine failed because equilibrium favoured to Pi with equilibrium constant $\sim 0.05$ (56). 7-methyl-6thioguanosine (MESG) was chosen for this reaction. MESG is not stable under basic conditions, so large amounts were used at $\mathrm{pH} 10.0$, and higher pH's were not tried.

In order to accurately measure the breakdown products, at each 
$\mathrm{pH}$, increasing amounts of MurA were used and all reactions were quenched at the same time. Increasing amounts of each product, PEP and EP-UDP-GIcNAc, were detected. The $\mathrm{f}(\mathrm{PEP})$ was averaged at different enzyme concentrations. The partitioning experiments were repeated at $\mathrm{pH} 5.0,7.5$ and 10.0. As shown in Fig. 18, there is no obvious $\mathrm{pH}$ dependence and $f(P E P)$ fluctuated from 0.20 to 0.26 . The average was $0.22 \pm 0.01$
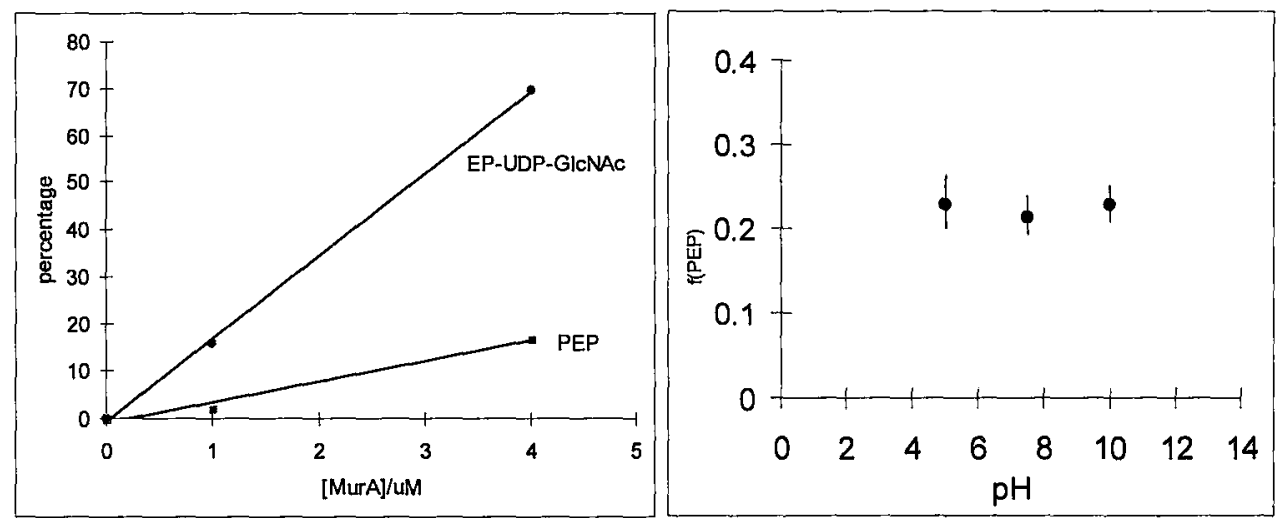

Figure 18. MurA THI partitioning versus $\mathrm{pH}$. (a) Breakdown products at different MurA concentrations. (b) $f(P E P)$ at different pHs.

\subsection{Phosphate analoguelenzyme-catalyzed EP-OR hydrolysis} products

\subsubsection{Products characterization by HPLC}

EP-OR was relatively stable in the presence of enzyme only, with 
$k_{\text {cat }(\text { AroA })}=4.7 \times 10^{-4} \mathrm{~s}^{-1}$, and $k_{\text {cat(MurA })}=4.2 \times 10^{-4} \mathrm{~s}^{-1}$, compared with a literature value of $k_{\text {cat(AroA })}=4.1 \times 10^{-4} \mathrm{~s}^{-1}(57)$, which means there would be only $1.5 \%$ of EP-UDP-GICNAc hydrolyzed under the experimental conditions in the absence of arsenate (0.75 mM of EP-UDP-GlcNAc, $8.5 \mu \mathrm{M}$ of enzyme, in $50 \mathrm{mM}$ Tris $\cdot \mathrm{HCl}$ at $\mathrm{pH} 7.5$ reacted for $1 \mathrm{~h}$ ). In the presence of $40 \mu \mathrm{M}$ arsenate, the EP-OR peak completely disappeared in anion exchange chromatograms. A new peak was eluted at the same elution time and $\mathrm{A}_{260} / \mathrm{A}_{240}$ ratio as standard UDP-GICNAc. The area ratio under dual wavelength UV detection provides a simple and fast way to identify each species in this reaction system. With a uridine ring only and no $\mathrm{C}=\mathrm{C}$ bond, the area ratio of $A_{260} / A_{240}$ for UDP-GlcNAc was $\sim 1.7$. EP-UDP-GlcNAc has both uridine and $C=C$; its $A_{260} / A_{240}$ ratio was 1.0 . PEP with only one $C=C$ had an $A_{260} / A_{240}$ ratio of 0.04 . A small peak at $240 \mathrm{~nm}$ with same elution time as pyruvate was visible in enlarged chromatograms.

When arsenate was added to AroA and EPSP, and the reaction stopped before EPSP was completely hydrolyzed, S3P was observed in the HPLC chromatograph (Fig. 20). 


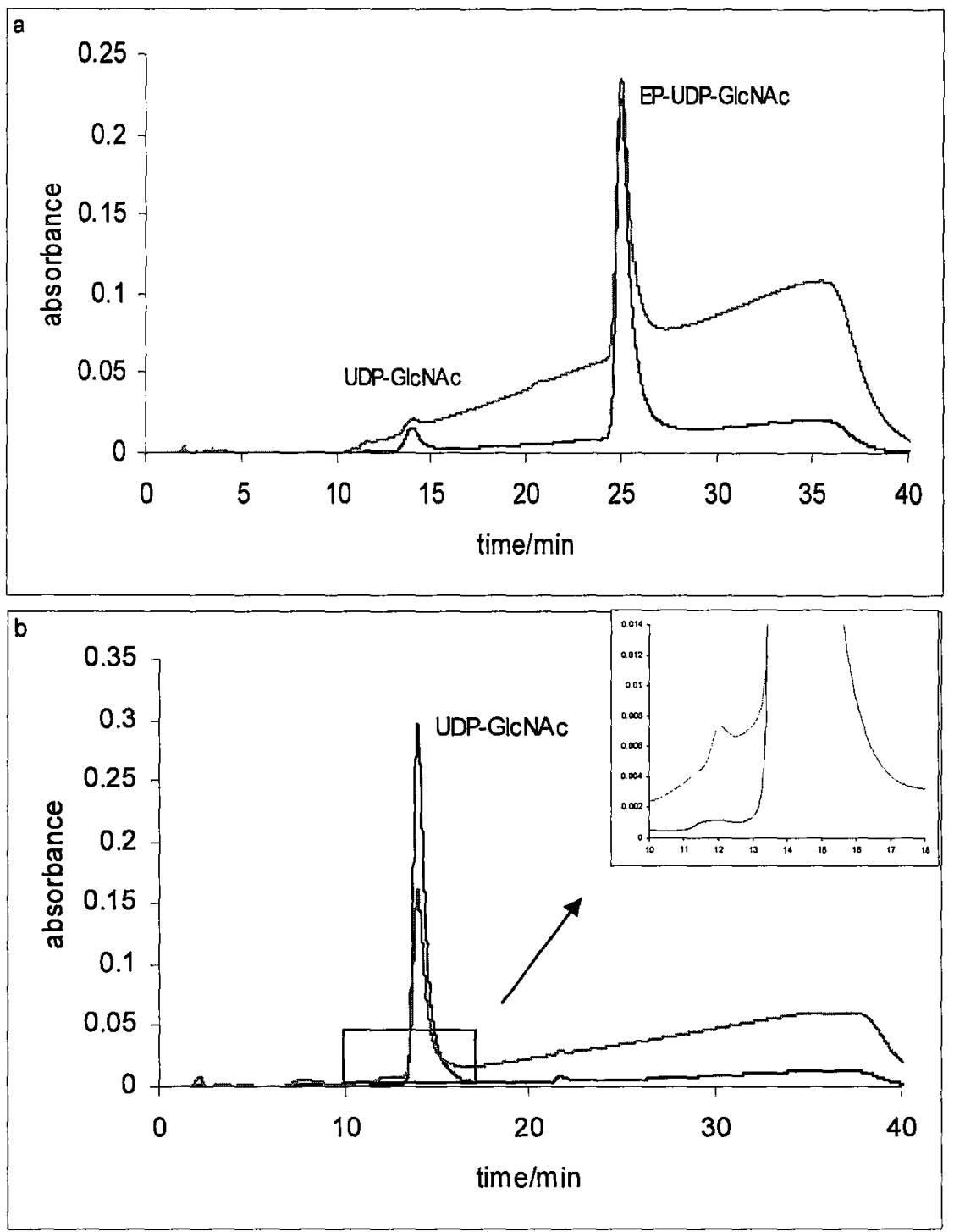

Figure 19. HPLC chromatography of arsenate/MurA-catalyzed EP-UDP-GICNAC hydrolysis. (a) Standard EP-UDP-GICNAC injection with contaminating UDP-GICNAc from EP-UDP-GICNAc synthesis. Blue line: $A_{260}$; red line: $A_{240}$. (b) After reaction to completion, with a new peak at the UDP-GICNAc elution time. The inset is the enlarged box area. The small peak at 13 min was believed to be pyruvate. 

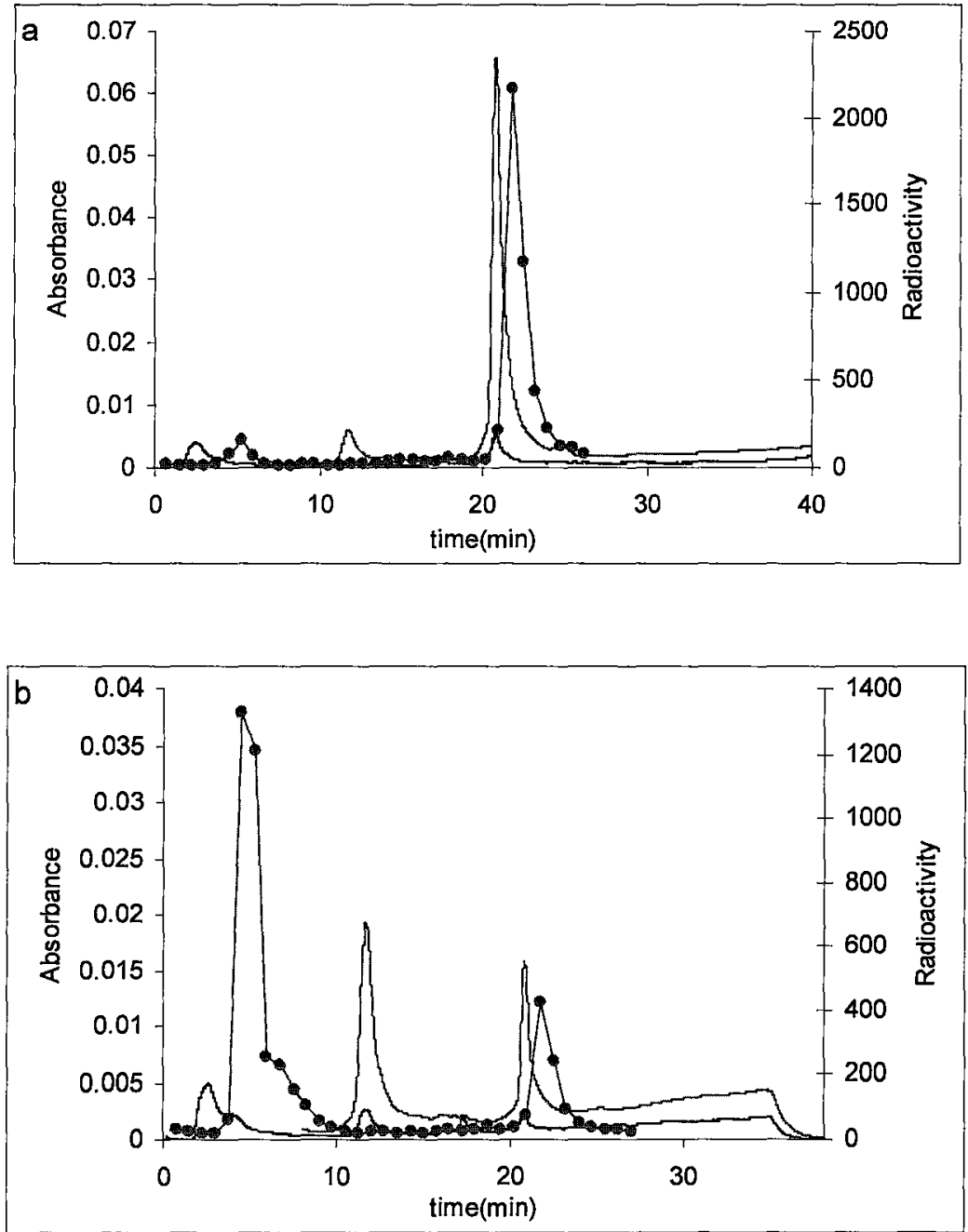

Figure 20. HPLC chromatography of AroAarsenate-catalyzed EPSP hydrolysis. Green line, $A_{240}$; blue line, $A_{260}$; red line, radioactivity taken for 1 min fractions. (a) Reaction without arsenate. The small red peak at 5 min and small green peak at 12 min was contaminant pyruvate and S3P from EPSP stock solution. (b) Reaction with arsenate stopped before EPSP was completely hydrolyzed.

\subsubsection{Products characterization by radioactivity assay}

${ }^{14} \mathrm{C}$ labeled EP-OR was used to further identify pyruvate. Position $\mathrm{C} 1$ of the carboxyvinyl group was labeled with ${ }^{14} \mathrm{C}$, so that the radioactive material would elute at the pyruvate retention time upon HPLC purification. 
The results indicated pyruvate formation with MurA (Fig. 21) and AroA (Fig. 20).

The small radioactive peak at $17-18 \mathrm{~min}$ is believed to be PEP from covalently linked PEP in MurA (Fig. 21). The cold enzyme adduct reacted with UDP-GICNAc and reached equilibrium with EP-UDP-GIcNAc. This experiment was performed before it became routine to treat MurA with UDP-GICNAC and urea before experiment. There were several pieces of evidence for the formation of $\left[1-{ }^{14} \mathrm{C}\right] \mathrm{PEP}$. First, there was no absorbance at $260 \mathrm{~nm}$, and a single absorbance peak at $240 \mathrm{~nm}$, with elution time consistence with PEP. Second, higher MurA concentrations led to increased amounts of the putative PEP peak. When catalytic amounts of enzyme were used, the peak was very small or even disappeared. Third, when pyruvate kinase and ADP was added, the putative PEP peak disappeared, which was consistent with the reaction catalyzed by pyruvate kinase (data not shown). 


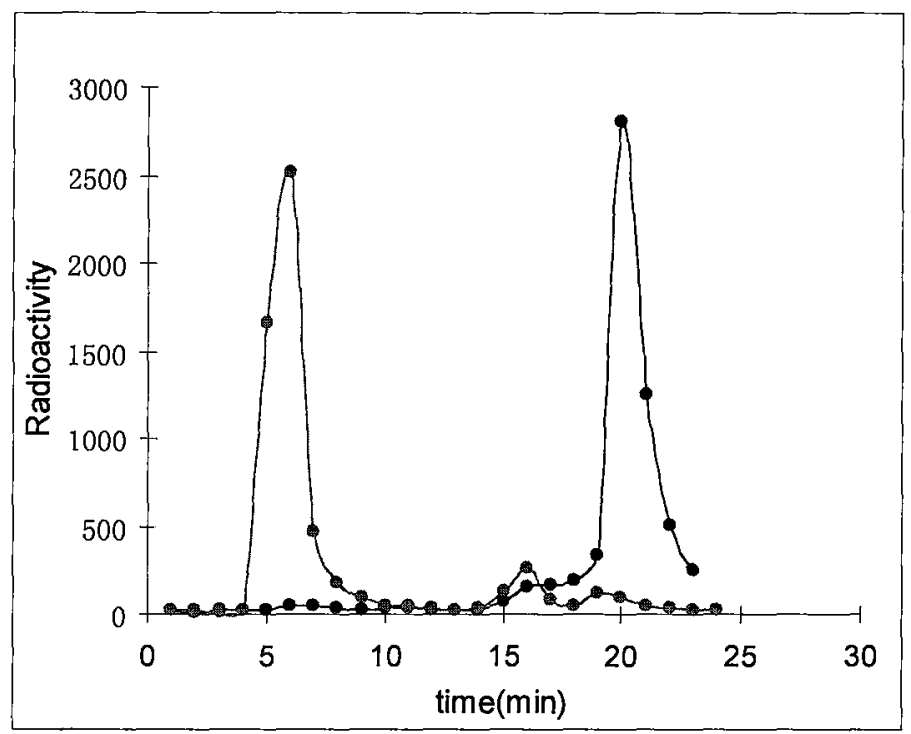

Figure 21. Evidence of pyruvate formation from EP-OR hydrolysis. The radioactivity peak shifted from EP-UDP-GICNAc elution time (blue line) to pyruvate elution time (red line) after arsenate was added.

\subsubsection{Lactate Dehydrogenase reaction assay}

To further confirm one of the products was pyruvate, an enzymatic reaction was used to reduce pyruvate to lactate with NADH and lactate dehydrogenase ( $(\mathrm{DH})$, concomitant with $\mathrm{A}_{340}$ decreasing. It confirmed that pyruvate was present, with a concentration of $97 \mu \mathrm{M}$, compared to an expected value of $100 \mu \mathrm{M}$. 


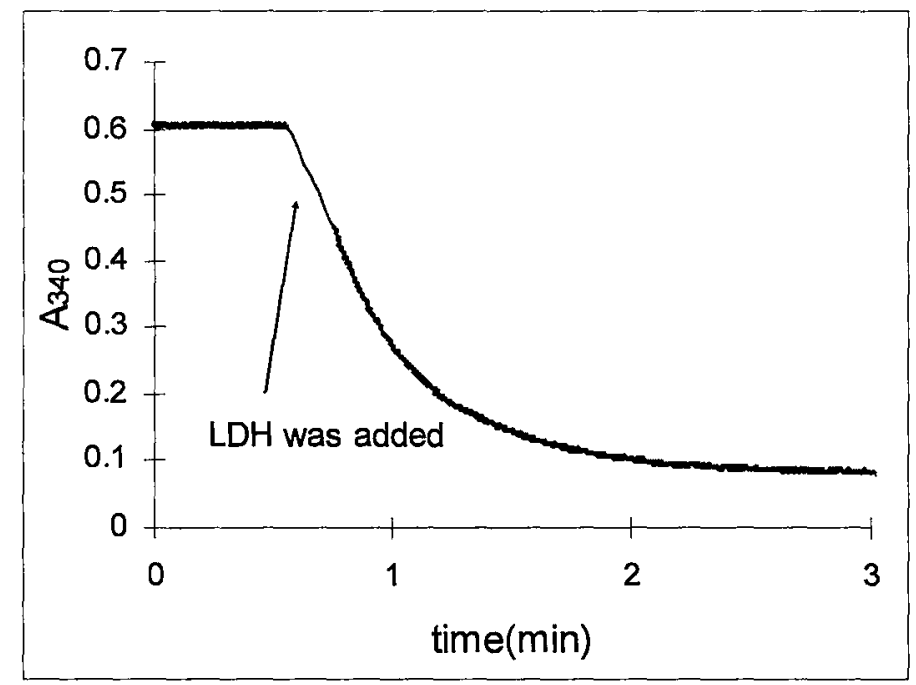

Figure 22. Evidence of pyruvate formation from LDH reaction.

3.4.4 Products characterization by mass spectrometry

To further identify the products, the reaction mixture was analyzed by mass spectrometry. Masses corresponding to UDP-GIcNAc and S3P were observed from EP-OR hydrolysis (data not shown). Pyruvate is a small molecule located in a noisy region in mass spectrum and its peak was not visible. However, from both radioactive identification and LDH coupled reaction, there was already strong evidence for pyruvate formation.

\subsection{Kinetics of phosphate analogue/enzyme-catalyzed EP-OR} hydrolysis

The apparent second order rate constants, $k_{\mathrm{cat}} / K_{\mathrm{M}}$, for phosphate 
analogue-promoted EP-OR breakdown at specific EP-OR concentration were determined from the observed initial velocities. Phosphate analogue concentrations were $<4 \%$ of their $K_{d}$ 's as determined by fluorescence titrations, which made it possible to estimate values of apparent $\left(k_{\text {cat }} / K_{\mathrm{M}}\right)_{\text {analogue }}$ using equation 1. AroA normally follows a sequential $\mathrm{Bi} \mathrm{Bi}$ mechanism with random substrate binding; we assume it follows the same mechanism when phosphate analogues were used, and in MurA-catalyzed reactions. The apparent $k_{\text {cat }} / K_{\mathrm{M}}$ approaches the true $k_{\text {cat }} / K_{\mathrm{M}}$ as EP-OR concentration become much higher than $K_{d}$ 's. Under the conditions used, EP-OR concentrations (333 $\mu \mathrm{M}$ EP-UDP-GIcNAc, $750 \mu \mathrm{M}$ EPSP) were much higher than $K_{d}$, which is $1 \mu \mathrm{M}$ for both of MurA-EP-UDP-GIcNAc (58) and AroA•EPSP (21).

Of the thirteen analogues tested, only three promoted EP-OR hydrolysis, both in MurA and AroA. They were arsenate, vanadate and fluorophosphate. Their rates were measured and compared with phosphate in the reverse reaction (Table 1). Arsenate was the most efficient analogue, only 58 times slower with AroA, and 133 times slower with MurA. This molecule was chosen for detailed study of the mechanism. 
Table1. Rate constants for phosphate-analogue promoted EP-OR hydrolysis.

\begin{tabular}{lllll} 
& $\mathrm{HPO}_{4}{ }^{2-}$ & $\mathrm{HAsO}_{4}{ }^{2-}$ & $\mathrm{HVO}_{4}{ }^{2-}$ & $\mathrm{FPO}_{3}{ }^{2-}$ \\
\hline MurA k ${ }_{\text {cat }} / \mathrm{K}_{\mathrm{M}}\left(\mathrm{s}^{-1} \mu \mathrm{M}^{-1}\right)$ & 0.02 & $1.5 \times 10^{-4}$ & $9.4 \times 10^{-5}$ & $3.3 \times 10^{-6}$ \\
AroA $\mathrm{k}_{\text {cat }} / \mathrm{K}_{\mathrm{M}}\left(\mathrm{s}^{-1} \mu \mathrm{M}^{-1}\right)$ & $4.5 \times 10^{-3}$ & $7.7 \times 10^{-5}$ & $2.0 \times 10^{-5}$ & $1.2 \times 10^{-6}$ \\
Relative rate to $\mathrm{Pi}(\mathrm{MurA})$ & 1 & 133 & 213 & $6.0 \times 10^{3}$ \\
& & & & \\
Relative rate to $\mathrm{Pi}($ AroA $)$ & 1 & 58 & 225 & $3.8 \times 10^{3}$ \\
\hline
\end{tabular}

\subsection{Isotope labeling experiments}

In order to probe the mechanism of carboxyvinyl transferasescatalyzed reactions, isotope labeling techniques were used.

Considering the low $\mathrm{pK}_{\mathrm{a}}$ value of the EP-OR C3, one challenge for the enzyme is to protonate it into a methyl, and then deprotonate $\mathrm{C} 3$ back to ethylene (Fig. 23a). These unfavorable steps exist in both the forward and reverse directions. In the forward direction, incubating PEP with the enzymes does not lead to $\mathrm{C} 3$ protonation as there is no ${ }^{3} \mathrm{H}$ incorporation when ${ }^{3} \mathrm{H}_{2} \mathrm{O}$ was used (27). However, this PEP C3 ethylene can be protonated in the presence of dideoxyS3P (see Section 1.4 for more detail). This indicated that binding of both substrates to the enzyme was required to generate the catalytic machinery. In the phosphate analogue-catalyzed reverse direction, C3 of EP-OR was protonated, and 
was converted to pyruvate. There is no doubt that protonation occurs (Fig. 23b). The question was if there was also a deprotonation step involved. This is an important question because EP-OR breakdown without C3 deprotonation was possible, but not relevant to the true reaction. If there was a deprotonation step, what did this step contribute to the overall reaction? Is there any tetrahedral intermediate formed in the arsenate reaction that is analogous to the $\mathrm{THI}$ in the natural reaction?

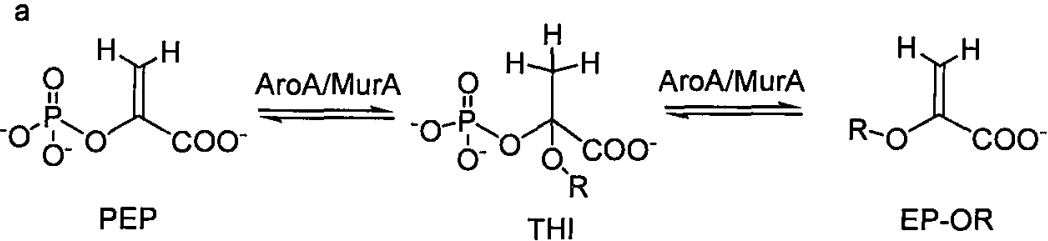

b

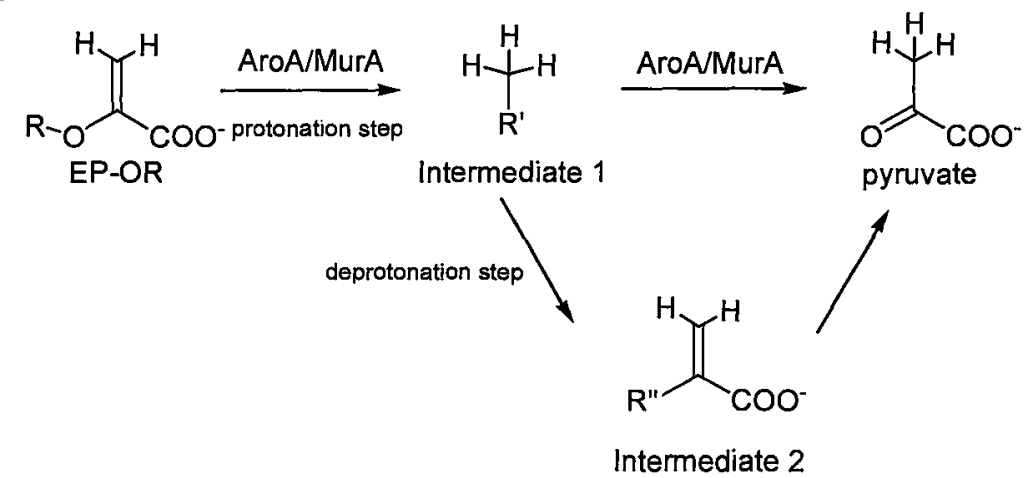

Figure 23. Reaction pathways. (a) AroA or MurA-catalyzed natural reaction. (b) Possible reaction pathways in phosphate analogue-catalyzed EP-OR hydrolysis.

\subsubsection{Phosphate analogue/enzyme-catalyzed EP-OR C3 proton solvent exchange}


The first experiment was designed to detect any deuterium incorporation from solvent $\mathrm{D}_{2} \mathrm{O}$ into $\mathrm{C} 3$ of EP-OR. Electrospray mass spectrometry was used to monitor the formation of D-labeled EP-OR. Only D-labelling at C3 would be detected. Active protons in EP-OR could contain deuterium, in the $\mathrm{D}_{2} \mathrm{O}$ solution, but would exchange with protium by repeatedly lyophilizing from $\mathrm{H}_{2} \mathrm{O}$. The D-labeled site was confirmed to be $\mathrm{C} 3$ by $\mathrm{H}-\mathrm{NMR}$ (decreasing intensity of $\mathrm{C} 3$ proton signals, data not shown). Reactions were set up in volatile buffer $\mathrm{NH}_{4} \mathrm{HCO}_{3}$ in order to study by ESI mass spectrometry.

Of the thirteen analogues, arsenate, vanadate, tungstate and phosphate were chosen for this experiment. Reaction with $\mathrm{KCl}$ at the same concentration as analogues was used as a control.

Table 2. EPSP C3 proton solvent exchange rate compared with hydrolysis rate with AroA. $n d=$ not detectable, $\mathrm{nm}=$ not measured.

\begin{tabular}{lllll} 
& $\mathrm{HAsO}_{4}{ }^{2-}$ & $\mathrm{HVO}_{4}{ }^{2-}$ & $\mathrm{WO}_{4}{ }^{2-}$ & $\mathrm{SO}_{4}{ }^{2-}$ \\
\hline $\begin{array}{l}\text { AroA } \\
k_{\text {ex }} / k_{\text {cat }}\end{array}$ & 4.6 & 4.9 & nd & nd \\
\hline $\begin{array}{l}\text { MurA } \\
k_{\text {ex }} / k_{\text {cat }}\end{array}$ & 6.4 & 0.028 & $n m$ & $\mathrm{~nm}$ \\
\hline
\end{tabular}

In AroA reactions, there was no detectable $\left[3{ }^{2} \mathrm{H}\right] \mathrm{EPSP}$ when tungstate and sulphate were used. However, arsenate and vanadate could promote deuterium incorporation. The kinetic formation of singly and doubly labeled EPSP formation was monitored by measuring each isotope 
at different time points. $k_{\mathrm{ex}}$ was calculated as $k_{\mathrm{ex}}=k_{(\mathrm{D}, \mathrm{H}-\text { labelled })}+2 \times k_{(\mathrm{D}, \mathrm{D}-}$ labelled), where all the rate constants were measured for initial rate. The exchange rate was compared with hydrolysis rate as $k_{\text {ex }} / k_{\text {cat }}($ Table 2$)$. The $\mathrm{D} / \mathrm{H}$ ratio was calculated as $\mathrm{D} / \mathrm{H}=(2 \times \mathrm{D}, \mathrm{D}$-labelled $+\mathrm{D}, \mathrm{H}$-labelled $) /(\mathrm{D}, \mathrm{H}-$ labelled $+2 \times \mathrm{H}, \mathrm{H}$-labelled), and compared with the hydrolysis rate (Fig. 24).
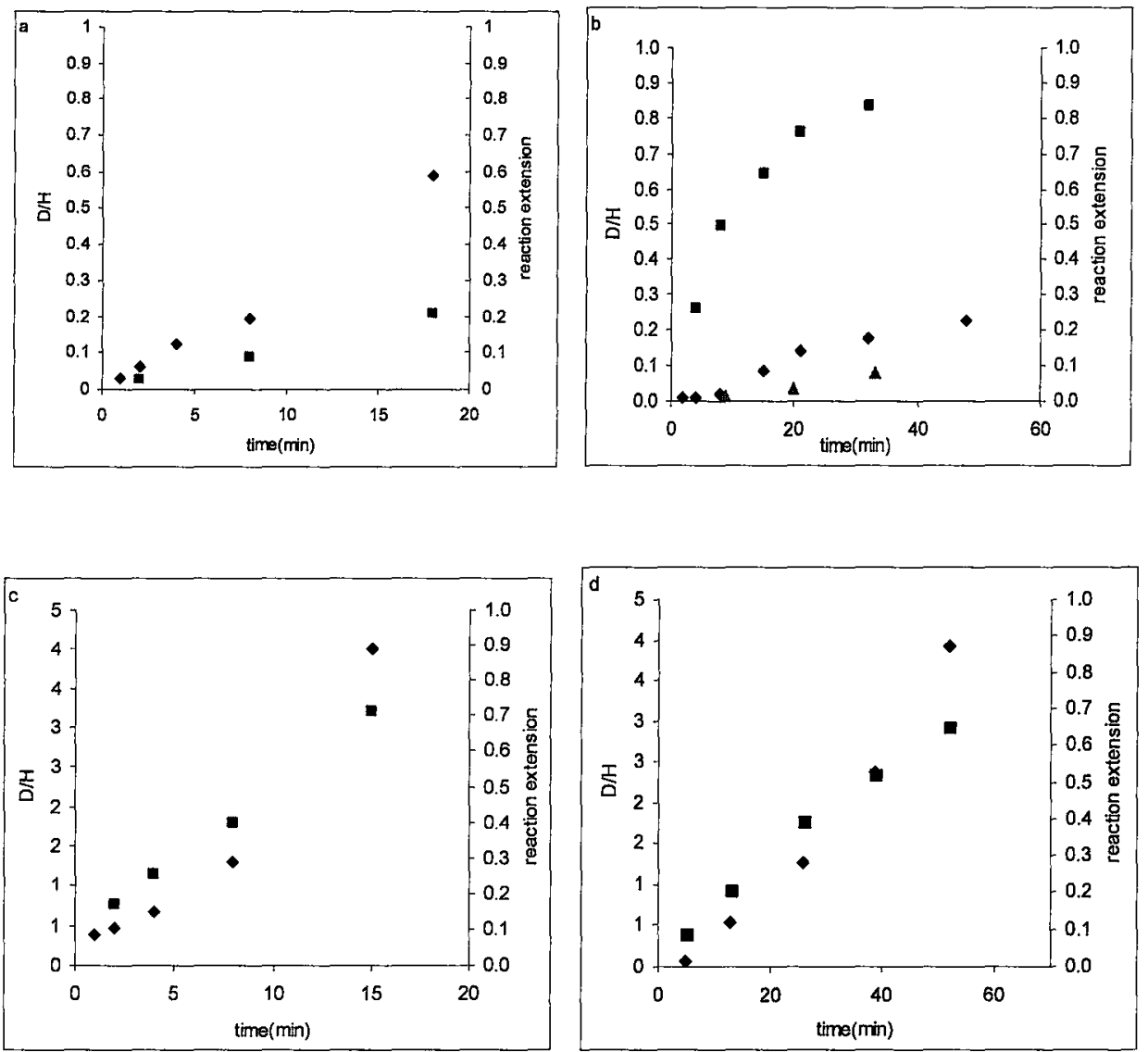

Figure 24. Phosphate analogue/enzyme catalyzed EP-OR C3 proton exchange. (a) Kinetics of EPSP proton $\mathrm{C} 3$ exchange and hydrolysis under arsenate/AroA. EP-OR D/H ratio is represented by $(\downarrow)$, and hydrolysis is represented by ( $\boldsymbol{m})$. (b) Vanadate/MurA catalyzed EP-UDP-GlCNAC hydrolysis and C3 proton exchange.(4) represented for the EP-UDP-GICNAC C3 D/H ration in the control experiment under the same condition except without vanadate (c) Reaction catalyzed by Arsenate/MurA and MurA alone (d). 
MurA alone catalyzed EP-UDP-GIcNAc hydrolysis showed the same $k_{\text {ex }} / k_{\text {cat }}$ ratio as in arsenate/MurA catalyzed hydrolysis, which is $k_{\text {ex }} / k_{\text {cat }}=6.3$. However this ratio is $\sim 300$ time smaller in vanadate/MurA catalyzed reaction, where after $50 \%$ of EP-UDP-GlcNAc was hydrolyzed, the $\mathrm{D} / \mathrm{H}$ ratio of $\left[3-{ }^{2} \mathrm{H}\right] \mathrm{EP}-\mathrm{UDP}-\mathrm{GlcNAc}$ was $>2 \%$.

\subsection{2 $\left[3{ }^{3} \mathrm{H}\right] \mathrm{EP}-\mathrm{OR}$ hydrolysis}

Another probe of mechanism was the fate of ${ }^{3} \mathrm{H}$ in $\left[3-{ }^{3} \mathrm{H}\right] \mathrm{EP}-\mathrm{OR}$ upon reaction with MurA or AroA. ${ }^{3} \mathrm{H}$ will be released only if $\mathrm{C} 3$ is protonated then deprotonated. This would happen in reversible formation of an oxacarbenium intermediate or formation of arsenoenolpyruvate.

Deprotonation was studied by measuring tritium release from [3- $\left.{ }^{3} \mathrm{H}\right]$ EP-OR. $\left[3-{ }^{3} \mathrm{H}\right] \mathrm{EP}-\mathrm{OR}$ was synthesized from tritium water. Due to the low specific radioactivity of tritiated water, the reaction had to be carried out parallel with a control. Tritium released from EP-OR into solvent was measured. To measure the tritium water from the reaction mixture, several methods including distillation, HPLC separation and lyophilization were tried. Among them, radioactivity loss after lyophilization gave the most sensitive and reliable results from control experiments (data not shown).

In this method, when there was no arsenate added (control), there would be no radioactivity loss before and after lyophilization. As shown in 
Table 3, they were $1 \%$ for MurA and $13 \%$ for AroA reaction respectively. This could be due to contaminating tritium water from $\left[3-{ }^{3} \mathrm{H}\right] \mathrm{EP}-\mathrm{OR}$ synthesis. These numbers were used as background. When arsenate was added and $\left[3-{ }^{3} \mathrm{H}\right] \mathrm{EP}-\mathrm{OR}$ was hydrolyzed, the released tritium water was measured by comparing radioactivity in the lyophilized and unlyophilized sample. After subtracting the radioactivity loss from background, the net loss was calculated in percentage. It was $22 \%$ in MurA reaction and $20 \%$ in AroA reaction.

From ${ }^{2} \mathrm{H}$ incorporation experiments, we expect to observe more radioactivity loss than $23 \%$. The smaller number could be caused by a primary isotope effect on deprotonation, where deprotonate protium was much favoured than tritium. There was also some trace radioactivity left in the enzyme layer after $\mathrm{CHCl}_{3}$ extraction. From the data, both in MurA and AroA reactions, tritium was released into the solution.

\begin{tabular}{|l|c|c|}
\hline & \multicolumn{2}{|c|}{ fractional loss of ${ }^{3} \mathrm{H}^{a}$} \\
\hline & {$\left[3{ }^{3} \mathrm{H}\right]$ EP-UDP-GlcNAC } & {$\left[3-{ }^{3} \mathrm{H}\right] \mathrm{EPSP}$} \\
\hline $20 \mathrm{mM} \mathrm{HAsO}_{4}{ }^{2}$ & $0.23 \pm 0.02$ & $0.36 \pm 0.03$ \\
\hline no $\mathrm{HAsO}_{4}{ }^{2}$ & $0.01 \pm 0.03$ & $0.13 \pm 0.02$ \\
\hline fractional loss on reaction & $0.22 \pm 0.05$ & $0.23 \pm 0.05$ \\
\hline
\end{tabular}

Table 3. Loss of ${ }^{3} \mathrm{H}$ from $\left[3-{ }^{3} \mathrm{H}\right] \mathrm{EP}-\mathrm{OR}$ upon reaction with MurA or AroA in the presence or absence of arsenate.

${ }^{a}$ Fractional loss of ${ }^{3} \mathrm{H}$ was calculated as the decrease in ${ }^{3} \mathrm{H}$ between reaction aliquots which were lyophilized repeatedly from regular water after quenching the reaction, and those that were not lyophilized: fractional loss $\left.=\left({ }^{3} \mathrm{H}_{\text {not lyophilized }}-{ }^{3} \mathrm{H}_{\text {lyophilized }}\right)\right)^{3} \mathrm{H}_{\text {not lyophilized. }}$ 


\subsubsection{EP-OR hydrolysis in $\mathrm{H}_{2}{ }^{18} \mathrm{O}$}

The experiments were run in $86 \% \mathrm{H}_{2}{ }^{18} \mathrm{O}$ and reaction mixtures were injected directly into the electrospray mass spectrometer. Samples were not purified so as to avoid arsenate oxygen exchange with water during purification. It has been reported that at $\mathrm{pH} 8$, the rate of water attack of arsenate is $1.2 \times 10^{-5} \mathrm{M}^{-1} \mathrm{~s}^{-1}(59-61) .{ }^{18} \mathrm{O}$ could be added to either arsenate or pyruvate, however, due to the fast hydration reaction of pyruvate under the experimental conditions, $1.0 \times 10^{-2} \mathrm{~s}^{-1}$ at $\mathrm{pH} 7.3(62,63)$, we would expect pyruvate to contain ${ }^{18} \mathrm{O}$ regardless of the mechanism. Thus, only arsenate peaks were monitored. Ideally, the more EP-OR in the reaction, the more cycles each arsenate molecule would be used as a catalyst, and the greater ${ }^{18} \mathrm{O}$ incorporation that would be observed. However, the drawback of analyzing a mixture was signal depression from salt. Too much EP-OR (multiply charged) would suppress the arsenate signal. During the reaction, EP-OR concentration was chosen to be twice that of arsenate. On average, each arsenate molecule would react twice with EP-OR.

In MurA reactions without EP-UDP-GIcNAc, MurA catalyzed fast ${ }^{18} \mathrm{O}$ exchange. Arsenate was repetitively attacked by water and isotope equilibrium was reached in arsenate oxygen after $5 \mathrm{~min}$ (Fig. 25a). In the presence of EP-UDP-GICNAc, the majority was $\mathrm{H}_{2} \mathrm{As}^{16} \mathrm{O}_{4}^{-}$. The 
small amounts of ${ }^{18} \mathrm{O}$ labeled arsenate were attributed from

MurA-arsenate complex rather than to reaction with EP-OR (Fig. 25b).

This result indicated that most of the arsenate was in the

MurA-arsenate-EP-UDP-GIcNAc, or MurA-arsenate-UDP-GIcNAc ternary

complexes after the reaction, where the EP-UDP-GIcNAc protected

arsenate from water attacked.
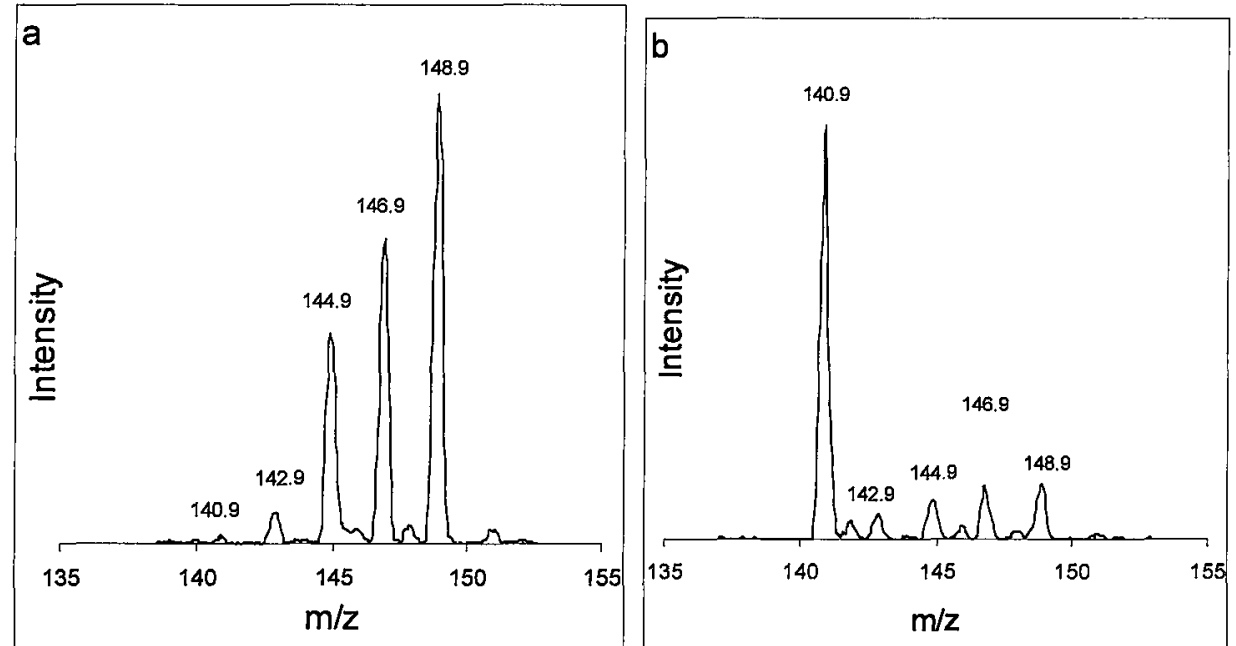

Figure 25. Mass spectra of MurA/arsenate-catalyzed EP-UDP-GIcNAc hydrolysis in $\mathrm{H}_{2}{ }^{18} \mathrm{O}$. (a) MurA-catalyzed fast ${ }^{18} \mathrm{O}$ exchange in the absence of EP-UDP-GlcNAc. Reaction containing $0.25 \mathrm{mM}$ arsenate, $34 \mu \mathrm{M}$ MurA in $86 \% \mathrm{H}_{2}{ }^{18} \mathrm{O}$ at $\mathrm{pH} 7.5$ after $28 \mathrm{~min}$, (b) Reaction conditions were the same as (a), except with $0.5 \mathrm{mM}$ EP-UDPGlcNAc, and the reaction was stopped after $5 \mathrm{~min}$, when $70 \%$ of EP-UDP-GIcNAc was hydrolyzed.

In the AroA reaction without EPSP, oxygen exchange from water to arsenate was negligible. The exchange rate increased when EPSP was added. After $\sim 70 \%$ of EPSP had been hydrolyzed, the isotope peaks $\mathrm{H}_{2} \mathrm{As}^{16} \mathrm{O}_{3}{ }^{18} \mathrm{O}^{-}$and $\mathrm{H}_{2} \mathrm{As}^{16} \mathrm{O}_{2}{ }^{18} \mathrm{O}_{2}^{-}$appeared with expected intensities, consistent with water attacked at the arsenic atom (Fig. 26). 


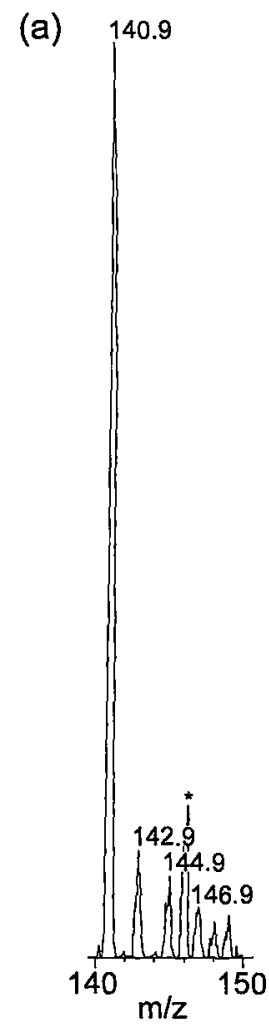

(b)

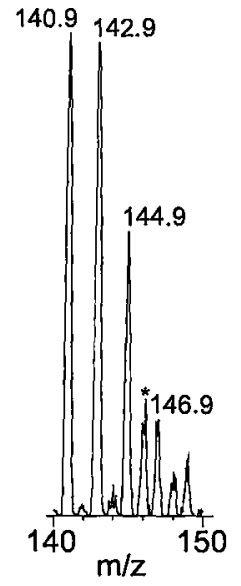

Figure 26. Mass spectra of AroA/arsenate-catalyzed EPSP hydrolysis in $\mathrm{H}_{2}{ }^{18} \mathrm{O}$. (a) Reaction containing $0.25 \mathrm{mM}$ arsenate, $48 \mu \mathrm{M}$ AroA in $86 \% \mathrm{H}_{2}{ }^{18} \mathrm{O}$ at $\mathrm{pH} 7.5$ after $18 \mathrm{~min}$, (b) AroA-catalyzed ${ }^{18} \mathrm{O}$ exchange during the hydrolysis of EPSP, when $70 \%$ of EPSP was hydrolyzed. Reaction conditions were the same as (a), except with $0.5 \mathrm{mM}$ EPSP. * contaminant peak at $\mathrm{m} / \mathrm{z} 145.9$.

\subsection{Fluorescence titration experiments}

Conformational changes when ligands bound to the proteins were studied by fluorescence titration. There are two tryptophans in AroA, one located at the protein surface, and one close to the active site. When a ligand such as S3P binds to AroA, the protein undergoes a conformational change, causing an environmental change near the active centre which can be detected by fluorescence changes. This method was previously 
used to study ligand binding constants and kinetics in AroA forward reaction (21).

\subsubsection{Free enzyme titration}

Fluorescence titrations of the free enzymes with phosphate analogues were measured. Phosphate caused $A_{r o} A_{H 6}$ fluorescence to decrease with the same titration curve as previously reported in S3P titrations (21). The value $K_{\mathrm{d}, \text { phosphate }}=4.8 \mathrm{mM}$, was similar to values measured previously with wild-type AroA, which range from $0.7 \mathrm{mM}$ (5) to $14 \mathrm{mM}$ (64) under various conditions. Phosphate analogues that caused similar fluorescence decreases as phosphate were considered to be binding to $A r o A_{H 6}$, and $K_{d}$ values were measured (Fig. 27). Vanadate absorbs at the excitation wavelength, so its binding constant was not measured. Bicarbonate and methyl phosphonic acid gave no detectable fluorescence change as compared to $\mathrm{KCl}$. Sulphate cause very small changes with a different curve shape from phosphate. They were considered as not binding to AroA (Table 4). 


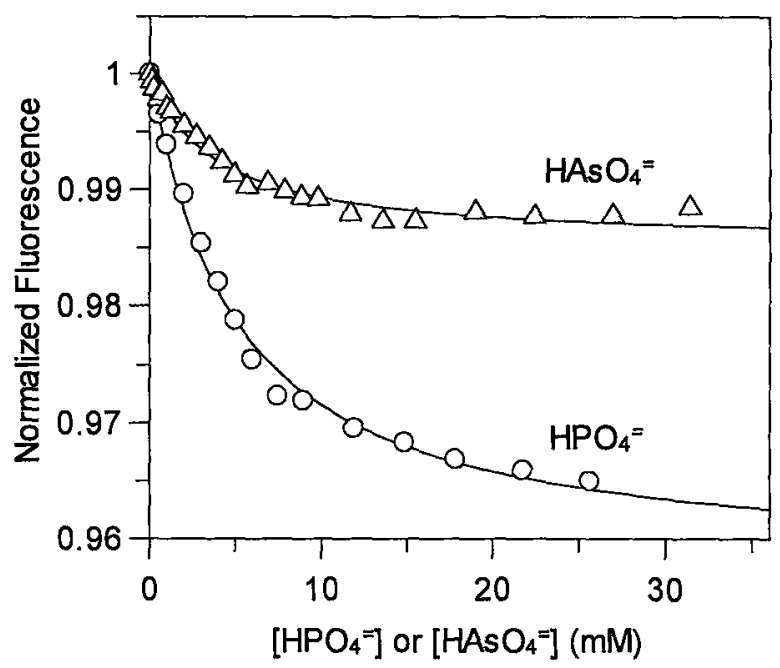

Figure 27. Fluorescence titrations of $\mathrm{HAsO}_{4}{ }^{2}$ and $\mathrm{HPO}_{4}{ }^{2}$ binding to AroA. Solid lines indicate calculated curves from fitting fluorescence data to equation 2.

Table 4. Binding constants from free AroA fluorescence titrations.

\begin{tabular}{llllll} 
& $\mathrm{HPO}_{4}{ }^{2-}$ & $\mathrm{HAsO}_{4}{ }^{2-}$ & $\mathrm{HVO}_{4}{ }^{2-}$ & $\mathrm{FPO}_{3}{ }^{2-}$ & $\mathrm{MeOPO}_{3}{ }^{2-}$ \\
\hline$K_{\mathrm{d}}(\mathrm{mM})$ & $4.8 \pm 0.5$ & $5.4 \pm 0.6$ & a & $0.6 \pm 0.2$ & $23 \pm 2$
\end{tabular}

\begin{tabular}{ccccc} 
& $\mathrm{HPSO}_{3}{ }^{2-}$ & $\mathrm{WO}_{4}{ }^{2-}$ & $\mathrm{SO}_{4}{ }^{2-}$ & $\mathrm{MePO}_{3}{ }^{2-}$ \\
\hline$K_{\mathrm{d}}(\mathrm{mM})$ & $0.21^{b}$ & $18^{c}$ & $d$ & $d$
\end{tabular}

${ }^{a}$ Vanadate strongly absorbed at the excitation wavelength, $280 \mathrm{~nm}$.

${ }^{b}$ EPSP displacement titration with variable analogue concentrations.

${ }^{c}$ Measured from phosphate inhibition constant.

${ }^{d}$ No detectable fluorescence change up to $100 \mathrm{mM}$.

Considering the high similarity of sulphate to phosphate in terms of geometry and size, the binding of sulphate to AroA was further studied by several kinetics experiments. (1) Sulphate was added to the AroA reverse reaction mixture (phosphate + EPSP $\rightarrow P E P+S 3 P$ ). If sulphate could bind with AroA, it would inhibit AroA competitively with phosphate, slowing 
the reverse reaction. The control experiment was conducted in parallel with $\mathrm{KCl}$ added to the reverse reaction in order to subtract any influence of ionic strength on AroA. Compared with $\mathrm{KCl}$, sulphate did not inhibit AroA (data not shown). (2) AroA can catalyze the EPSP hydrolysis at a rate of $k_{c a t}=4.7 \times 10^{-4} \mathrm{~s}^{-1}$. From the crystal structure, AroA has a very sterically crowded active centre. We may assume if sulphate could bind with AroA and occupy the active centre, it would prevent water molecules from approaching EPSP, thus slowing EPSP hydrolysis. The validity of this approach was demonstrated in tungstate experiments (see below). As compared with $\mathrm{KCl}$, sulphate did not inhibit EPSP hydrolysis (Fig. 28).

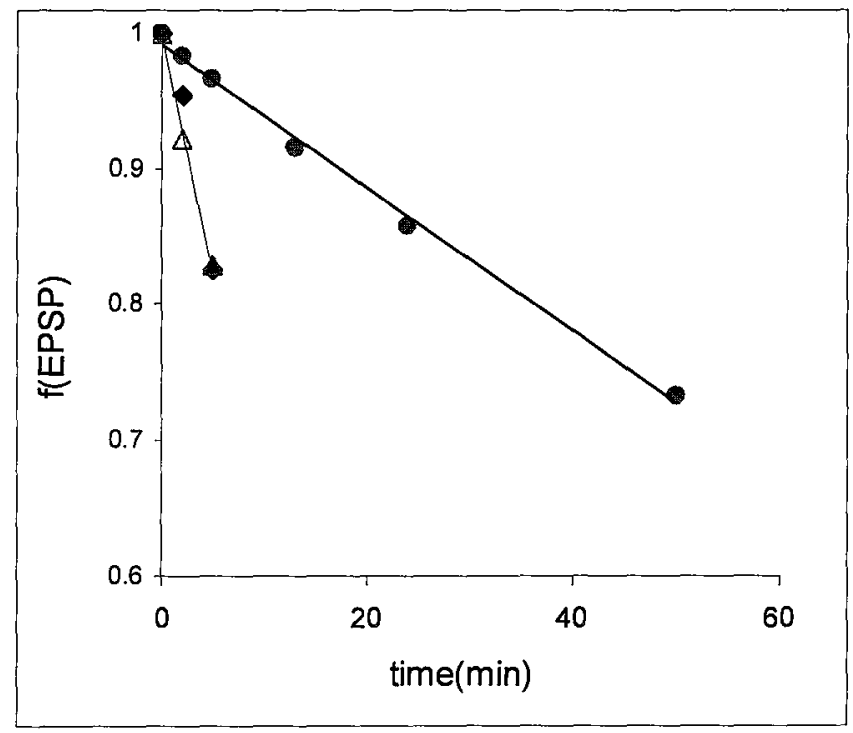

Figure 28. AroA-catalyzed EPSP hydrolysis inhibition study. To the hydrolysis reaction, $120 \mathrm{mM}$ sulphate $(\downarrow) \mathrm{KCl}(\Delta)$ or tungstate $(\bullet)$ was added. $f(P E P)$ is the fractional amount of EPSP remaining in the reaction mixture.

Tungstate quenches tryptophan fluorescence. Titration of $A$ ro $A_{H 6}$ 
with tungstate solution gave the same titration curve as free tryptophan. Kinetic studies of the reverse reaction between EPSP and phosphate in the presence of tungstate showed tungstate was a competitive inhibitor, with $K_{i}=18 \mathrm{mM}$. In detail, the reverse reaction rate was measured with different tungstate concentrations and the rates were plotted as a function of tungstate concentration as in equation 4 , where $r_{0}$ is the reverse reaction rate in the absence of tungstate, $r$ is reverse reaction rate at [tungstate]. The binding constant was calculated from the slope.

$$
\frac{1}{r}=\frac{1}{r_{0}}\left(1+\frac{[\text { tungstate }]}{K_{\mathrm{d}, \text { tungstate }}}\right)
$$

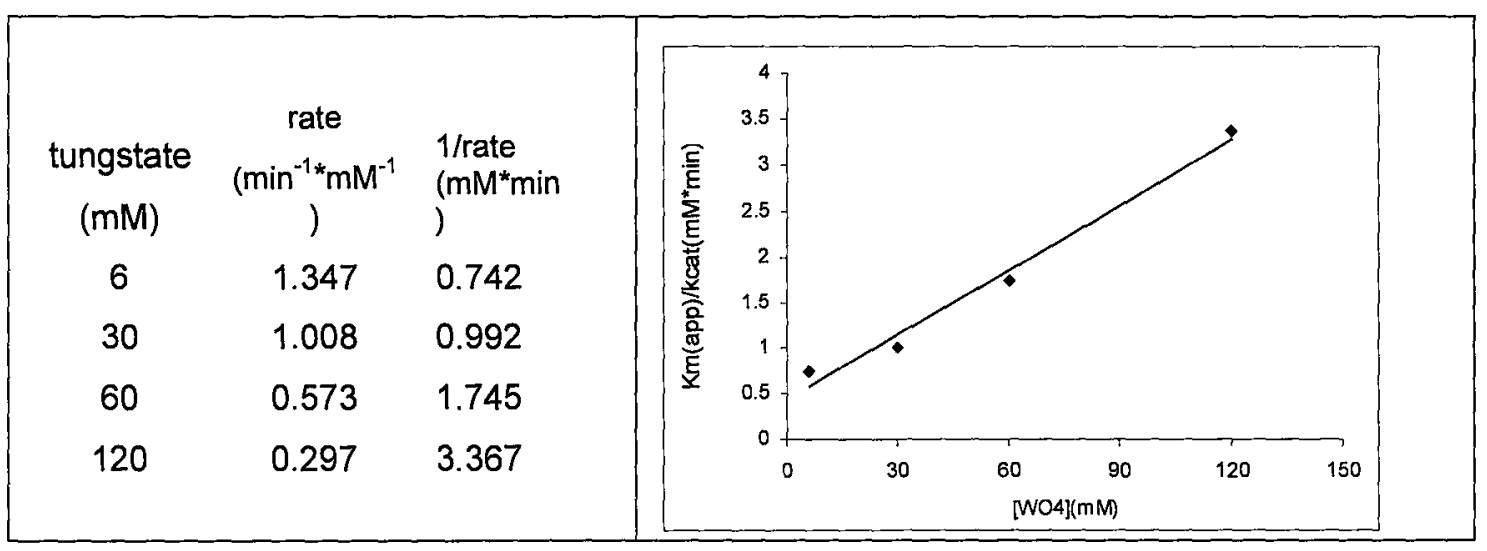

Figure 29. Tungstate inhibition of the reverse AroA reaction.

3.7.2 EPSP titration to enzyme analogue complex

EPSP binding to Aro $A_{H 6}$ decreased fluorescence, and $K_{d, E P S P}$ was 
measured. It was $1.6 \pm 0.1 \mu \mathrm{M}$ compared with $1.0 \mu \mathrm{M}$ in wild-type AroA (21). However, thiophosphate and monomethyl phosphate caused increased fluorescence when added to Aro $_{H}{ }^{\circ}$ EPSP complex, even though adding each ligand individually to $A_{r o} A_{H 6}$ caused decreased fluorescence. This indicated that these phosphate analogues displaced EPSP from the active site. In order to measure inhibition constant with EPSP, the apparent binding constant of EPSP ( $K_{d, E P S P}($ apparent)) was measured by incubating $\mathrm{ArOA}_{\mathrm{H} 6}$ with different concentrations of these analogues, then titrated with EPSP. The displacement of EPSP by these phosphate analogues was further demonstrated by observing increased $K_{d, E P S P}(a p p a r e n t)$ as analogue concentration increased. $K_{d, E P S P}(a p p a r e n t)$ was plotted at various analogue concentrations and the $K_{i, \text { ligand }}$ for each ligand was calculated from equation 3 . The inhibition constant for monomethyl phosphate was $K_{i, M e O P}=22 \mathrm{mM}$, consistent with direct fluorescent titration $K_{d, M e O P}=23 \mathrm{mM}$ (Fig. 30). The inhibition constant with thiophosphate $K_{i, \text { thiophosphate }}$ was $0.21 \mathrm{mM}$. Direct titration of $\operatorname{ArOA}_{\mathrm{H} 6}$ with thiophosphate caused decreased fluorescence, but the data were hard to fit into equation2 due to the small change in fluorescence.

To test whether monomethyl phosphate binds to $A_{r O A} A_{H 6}$ in the natural phosphate binding site, rather than the site equivalent to phosphate of S3P, titration of $\mathrm{AroA}_{\mathrm{H} 6}$ with monomethyl phosphate was 
performed in the presence of $300 \mu \mathrm{M} \mathrm{S3P.} \mathrm{At} \mathrm{this} \mathrm{S3P} \mathrm{concentration,}$ most of $A_{\text {ro }} A_{H 6}$ was in the $A_{10} A_{H 6} \cdot S 3 P$ complex form $\left(K_{d}=143 \mu \mathrm{M}\right)$. The observed fluorescence decrease was similar to the free AroA $A_{H G}$ titration. The data was fitted to equation 2 with a binding constant of $37 \pm 3 \mathrm{mM}$. This was close to the monomethyl phosphate binding constant without S3P present $K_{\mathrm{d}, \mathrm{MeOP}}=23 \mathrm{mM}$.
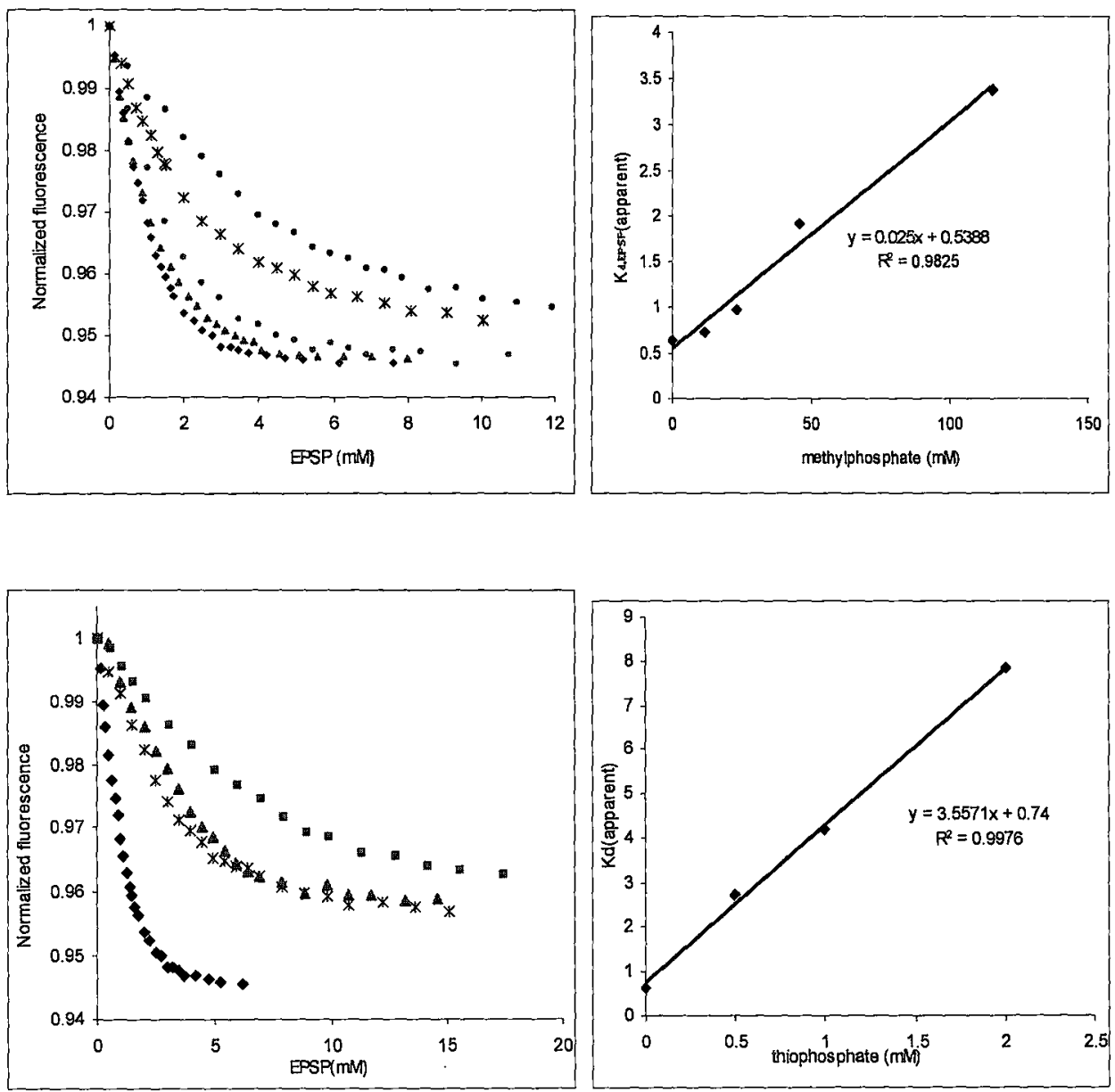

Figure 30. EPSP displacement by phosphate analogues. (a) Fluorescence titration of $1 \mu \mathrm{M}$ AroAH $\mathrm{H}_{6}$ by EPSP with different amounts of monomethyl phosphate: $(\downarrow) 0 \mathrm{mM},(\Delta)$ $0.5 \mathrm{mM},(\bullet) 1 \mathrm{mM},\left(^{*}\right) 2 \mathrm{mM},(\bullet) 5 \mathrm{mM}$. (b) $K_{d, E P S P}$ (apparent) as a function of monomethyl phosphate concentration. (c) fluorescence titration of $1 \mu \mathrm{M} \mathrm{AroAH} \mathrm{H}_{6}$ by EPSP with different 
amounts of thiophosphate: ( $\downarrow) \mathrm{mM},\left(^{*}\right) 0.5 \mathrm{mM},(\mathbf{A}) 1 \mathrm{mM},(\mathbf{m}) 2 \mathrm{mM}, \mathrm{d}$. $K_{d, E P S P}(a p p a r e n t)$ as a function of thiophosphate concentration.

\subsubsection{Second step titration with D313A}

From all the results above, in order to promote EPSP hydrolysis reaction, phosphate analogue must bind together with EPSP in enzyme active site. To study the binding of phosphate and its analogue in the presence of EPSP, and while preventing the normal reaction, a nonreactive $A r O A_{H 6}$ mutant, $D 313 A$, was used. The mutant residue D313 is far from the phosphate binding site, based on the crystal structure (33).

D313A titration with EPSP or phosphate along showed similar fluorescence decays as those in AroA $_{H G}$, with $K_{d, E P S P}=0.89 \mu \mathrm{M}$ and $K_{\mathrm{d} \text {,phosphate }}=4.2 \mathrm{mM}$ respectively. Titration of EPSP-saturated D313A with phosphate caused a fluorescence decrease similar to phosphate titration

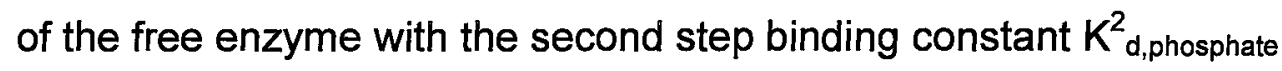
$=2.6 \mathrm{mM}$ (Fig. 31). 


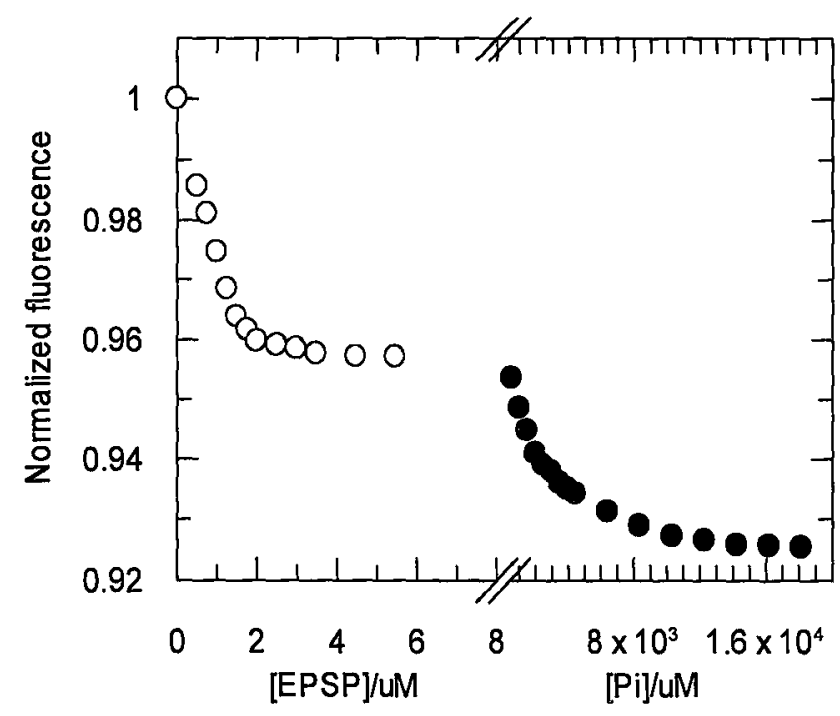

Figure 31. Fluorescence titration with D313A. D313A was first titrated with EPSP (o) and then with phosphate $(\bullet)$.

\subsection{Phosphate analogue charge calculation}

The charge on each deprotonated oxygen and the $\mathrm{X}-\mathrm{O}$ bond length ( $X$ for central atom, $\mathrm{O}$ for deprotonated oxygen) after optimization were reported in Table 5. $\mathrm{pK}_{\mathrm{a}}$ 's are all from the reference. 
Table 5. Charge, bond length and $\mathrm{pK}_{\mathrm{a}}$ of phosphate analogues.

\begin{tabular}{lllllll} 
& $\mathrm{HPO}_{4}{ }^{2-}$ & $\mathrm{HAsO}_{4}{ }^{2-}$ & $\mathrm{HVO}_{4}{ }^{2-}$ & $\mathrm{WO}_{4}{ }^{2-}$ & $\mathrm{FPO}_{3}{ }^{2-}$ & $\mathrm{SO}_{4}{ }^{2-}$ \\
\hline $\begin{array}{l}\text { charge on } \\
\text { oxygen }\end{array}$ & -1.3 & -1.29 & -0.92 & & -1.27 & -1.14 \\
$\begin{array}{l}\text { bond length } \\
\text { ( }\end{array}$ & 1.5 & 1.66 & 1.68 & 1.77 & 1.49 & 1.48 \\
$\mathrm{pK}_{\mathrm{a}}{ }^{\mathrm{a}}$ & 2.23 & 2.19 & & & 0.55 & -3 \\
$\mathrm{pK}_{\mathrm{a}} 2$ & 7.21 & 6.94 & 8.95 & 4.7 & 4.8 & 1.99 \\
$\mathrm{pK}_{\mathrm{a}} 3$ & 12.32 & 11.5 & 14.4 & & & \\
& & & & & & \\
\hline
\end{tabular}

\begin{tabular}{lllllll} 
& $\mathrm{MePO}_{3}{ }^{2-}$ & $\mathrm{MeOPO}_{3}{ }^{2-}$ & $\mathrm{HPSO}_{3}{ }^{2-}$ & $\mathrm{MnO}_{4}^{-}$ & $\mathrm{AlF}_{4}^{-}$ & $\mathrm{HCO}_{3}^{-}$ \\
\hline $\begin{array}{l}\text { charge on } \\
\text { oxygen }\end{array}$ & -1.28 & -1.27 & -1.21 & & \\
bond length & & & \\
$\mathrm{pK}_{\mathrm{a}} 1$ & 1.5 & 1.52 & 1.51 & & 1.25 \\
$\mathrm{pK}_{\mathrm{a}} 2$ & 2.35 & 1.54 & $<2$ & -2.25 & \\
$\mathrm{pK}_{\mathrm{a}} 3$ & & 6.31 & 5.75 & & \\
\hline
\end{tabular}

a $\mathrm{pK}_{\mathrm{a}}$ 's from references (65-67) 


\section{Discussion}

\subsection{MurA THI enzymatic breakdown}

Compared with AroA-catalyzed THI breakdown, MurA THI reacted $3 \times 10^{4}$-fold slower, with $k_{\text {cat }} / K_{\mathrm{m}}$ of $4 \times 10^{3} \mathrm{M}^{-1} \mathrm{~s}^{-1}$. Presumably this was due to slower binding because the overall catalytic efficiency of the two enzymes are similar, with MurA $k_{\text {cat }}=5 \mathrm{~s}^{-1}$ being only 12 times smaller than AroA $k_{\text {cat }}=60 \mathrm{~s}^{-1}$. The slower binding of MurA-THI may due to lower conformational flexibility in MurA. AroA is known to undergo large-scale movements of the two domains relative to each other, while MurA only has two loops that close over the active site, but no large scale domain motions as revealed by $x$-ray crystallography (7).

The THI breakdown rate was so slow compared with overall reaction that chemical equilibrium would be established between the THI breakdown products, [UDP-GIcNAc + PEP] and [EP-UDP-GIcNAc + Pi], making partitioning measurement impossible without adding enzymes to consume the breakdown products before they could react again with MurA. The partitioning ratio for MurA THI breakdown was $0.22 \pm 0.01$.

This coupled enzymatic reaction method was also used in other measurements. The LDH-catalyzed reaction was used to drive pyruvate to 
lactate in the tritium experiment to prevent tritium release from pyruvate ketone-enol tautomerization. It was reported that the enolization reaction of pyruvate had $k=2.8 \times 10^{-5} \mathrm{~s}^{-1}$ in $50 \mathrm{mM}$ Tris $\cdot \mathrm{HCl}$ at $\mathrm{pH} 8.1$ (62). This reaction is greatly accelerated at basic conditions with $k=0.8 \mathrm{~s}^{-1}$ at $1 \mathrm{M} \mathrm{OH}^{-}$, but it slowed in acidic conditions, so $150 \mathrm{mM} \mathrm{HCl}$ was used to quench the tritium experiments.

\subsection{Mechanism of arsenate-promoted EP-OR breakdown}

As arsenate was the most effective analogue at promoting EP-OR breakdown, the mechanism of the arsenate-promoted reaction was examined in detail.

AroA/arsenate catalyzed EPSP hydron exchange at $\mathrm{C} 3$ in ${ }^{2} \mathrm{H}_{2} \mathrm{O}$. This implied either the formation of arseno-THI is reversible or the enzyme reversibly stabilized an oxacarbenium ion intermediate before arseno-THI formation (Fig. 32). If the newly formed methyl group rotates during the intermediate's lifetime, the catalytic base could abstract ${ }^{1} \mathrm{H}$ rather than the ${ }^{2} \mathrm{H}$ that was added. ${ }^{3} \mathrm{H}$ released from $\left[3-{ }^{3} \mathrm{H}\right]$ EPSP into solution supported this conclusion. 
(a)<smiles>[R]O/C(=C/C(=O)[O-])C(=O)O[Si]([O-])([O-])O[Na]</smiles><smiles>[R][O+]=C(C(=O)[O-])C([2H])[2H]</smiles><smiles>[R]O/C(C(=O)[O-])=C(\[2H])O[Si]([O-])(O)O[Na]</smiles>

(b)

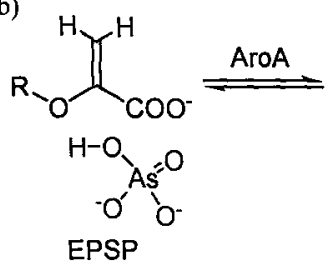

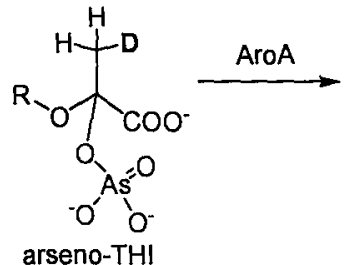<smiles></smiles>

(c)

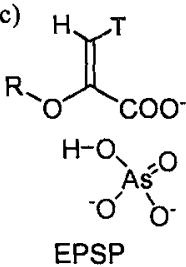<smiles>CCCCCCCCCCCCCC</smiles><smiles>[R]OC(O[As]([O-])([O-])([O-])[O-])(C(=O)[O-])C([2H])[3H]</smiles>

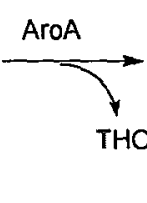
arseno-THI<smiles>O=C([O-])/C=C\OS(=O)(=O)O</smiles>

arsenoenolpyruvate

Figure 32. AroAlarsenate-catalyzed EPSP hydrolysis. (a) Possible reaction pathway for tritium release through oxacarbenium ion, where arsenate acts as a bystander. (b) Possible reaction pathway through for tritium release through reversible formation of arseno-THI. (c) Possible mechanism through formation of arsenoenolpyruvate.

In the reaction of EPSP with AroA plus arsenate in $\mathrm{H}_{2}{ }^{18} \mathrm{O}$, $\mathrm{HAs}^{16} \mathrm{O}_{3}{ }^{18} \mathrm{O}=$ was formed. This did not occur through direct reaction with the enzyme, as there was little ${ }^{18} \mathrm{O}$ exchange in the absence of EPSP. This indicated EPSP helped to activate arsenate for attack, presumably through arsenate ester formation. Arsenate is known to spontaneously and reversibly form arsenate esters with many hydroxyl groups $(70,71)$. Some enzymes such as glucose-6-P isomerase (71), accept arsenate esters as phosphate ester analogues, and catalyze to products. Usually, the products are also arsenate esters but in another form. They are then 
hydrolyzed by water attacking arsenate. In AroA, the only reasonable arsenate ester forming from EPSP and arsenate was arseno-THI. This eliminates the possibility that water attacked EPSP (or the putative oxacarbenium ion intermediate) directly, with arsenate acting as a bystander.

There were two plausible mechanisms for arseno-THI breakdown. It could be released from the enzyme and hydrolyzed by water, or converted to arsenoenolpyruvate by AroA and then hydrolyzed nonenzymatically (Fig. 33). In either case, it would need to be released before pyruvate could be formed. This was consistent with the relatively flexible AroA structure, as shown by rapid THI binding, as discussed above.

(a)

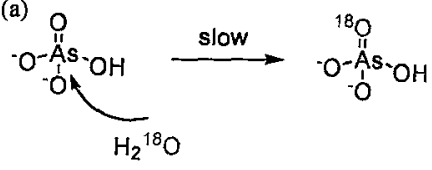

(b)

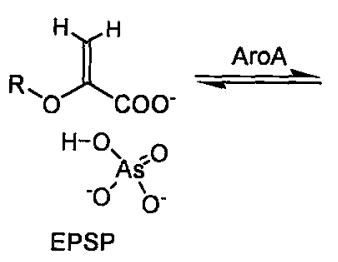

$\mathrm{H}_{2}{ }^{18} \mathrm{O}$
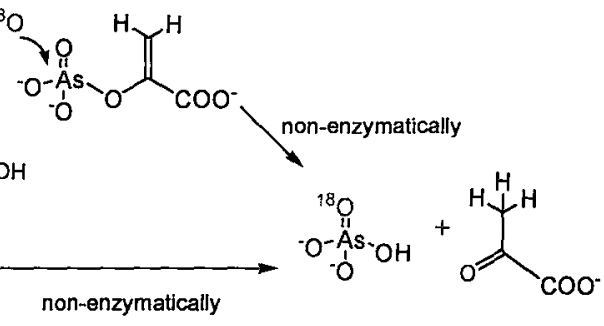

Figure 33. Mechanism of AroA arseno-THI hydrolysis. (a) $\mathrm{H}_{2}{ }^{18} \mathrm{O}$ attack at arsenate was slow under the experiment conditions. (b) The arsenate ${ }^{18} \mathrm{O}$ exchange was accelerated by formation of arseno-THI, which was later hydrolyzed non-enzymatically.

In arsenate/MurA-catalyzed reactions, both ${ }^{2} \mathrm{H}$ incorporation into 
EP-UDP-GIcNAc and release of ${ }^{3} \mathrm{H}$ during $\left[3-{ }^{3} \mathrm{H}\right]$ EP-UDP-GICNAc hydrolysis indicated that C3 was being protonated, then deprotonated. This would be consistent with either arseno-THI formation followed by elimination of $\mathrm{R}-\mathrm{OH}$, or with reversible arseno-THI formation, or an oxacarbenium ion intermediate (Fig 34). When there was no arsenate in presence, MurA catalyzed EP-UDP-GIcNAc hydrolysis incorporated ${ }^{2} \mathrm{H}$ into EP-UDP-GICNAc with $k_{\mathrm{ex}} / k_{\mathrm{cat}}=6.3$ (Fig 24d). This indicated that a cationic intermediate was reversibly formed and then deprotonated (Fig $35 a)$. When there was arsenate in presence, $k_{\mathrm{ex}} / k_{\mathrm{cat}}=6.4$, close to the $k_{\text {ex }} / k_{\text {cat }}$ in MurA catalyzed hydrolysis, implying there was also a reversible formation of cationic intermediate in arsenate/MurA catalyzed hydrolysis. 


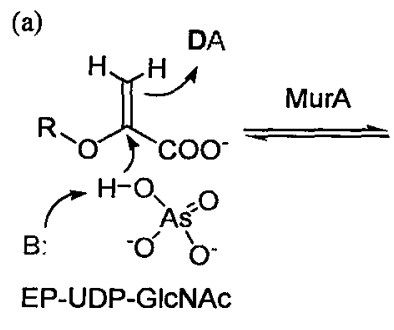

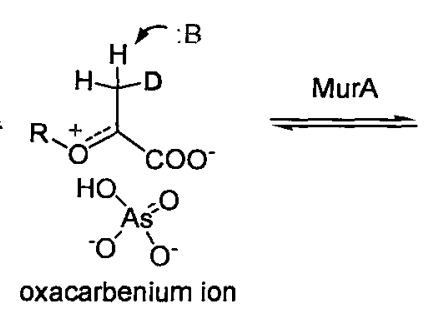<smiles>[R]O/C(C([2H])=O)=C(/O[2H])O[Si]([O-])([O-])O</smiles>

EP-UDP-GICNAC

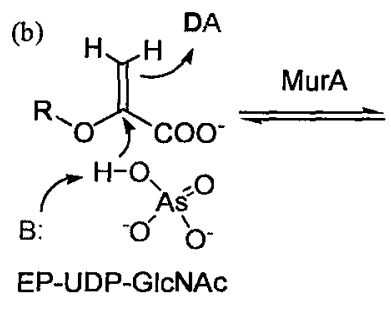<smiles>[R]OC(O[As]([O-])([O-])O)(C(=O)[O-])C([2H])[B]</smiles><smiles>[R]OC(CO[Si](O)(O)O)=C(O[R])O[Na]</smiles><smiles>[R]OC(=C[3H])CO[Ge]([O-])([O-])O</smiles>
EP-UDP-GICNAC

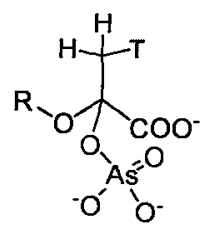

arseno-THI

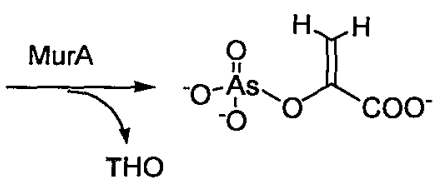

arsenoenolpyruvate

Figure 34. MurA/arsenate-catalyzed EP-UDP-GlcNAc hydrolysis. (a) Possible reaction pathway for tritium release through oxacarbenium ion, where arsenate acts as a bystander. (b) possible reaction pathway through for tritium release through reversible formation of arseno-THI. (c) Possible mechanism for MurAlarsenate-catalyzed EP-UDPGIcNAc hydrolysis through formation of arsenoenolpyruvate.

Incubation of only MurA and arsenate in $\mathrm{H}_{2}{ }^{18} \mathrm{O}$ resulted in complete exchange of the arsenate oxygens, reaching equilibrium with the solvent within 5 min. However, addition of EP-UDP-GICNAc resulted in formation of pyruvate with minimal ${ }^{18} \mathrm{O}$ exchange into arsenate. This indicated that water attacked the $\mathrm{C} 2$ position of arsenoenolpyruvate rather than arsenic. 
There was no direct evidence of arseno-THI formation. It is possible for the arsenate to act as a bystander to induce a cationic intermediate EP-UDP-GICNAc, and then attacked by water directly (Fig 35b). However, based on the similarities to the AroA reaction and the structural similarity of phosphate and arsenate, it is more likely for the arsenate/MurA catalyzed reaction undergoing the similar reaction pathway, through formation of arseno-THI and then arsenoenolpyruvate. The normal pathway of arsenate ester breakdown in water is through As-O bond cleavage $(68,69)$. The lack of ${ }^{18} \mathrm{O}$ incorporation into arsenate in the arsenate/MurA catalyzed reaction was somewhat unexpected and could indicate arsenoenolpyruvate breakdown through either an arsenolactoyl adduct, analogue to the commonly observed phospholactoyl adduct, or by MurA-catalyzed water attack on C2 of arsenoenolpyruvate. (Fig. 35c). 
(a)

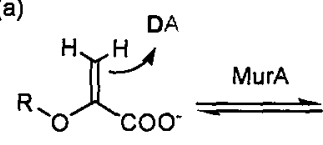
EP-UDP-GICNAC<smiles>[R][O+]=C(C(=O)[O-])C([2H])[CH]C[B]</smiles>

oxacarbenium ion<smiles>[2H]C=C(O[2H])C(=O)[O-]</smiles>

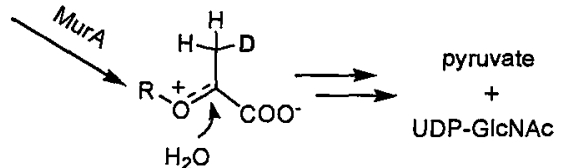

(b)

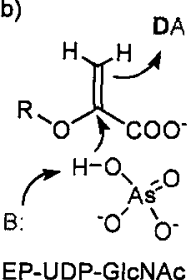<smiles>CCC</smiles>
EP-UDP-GICNAC

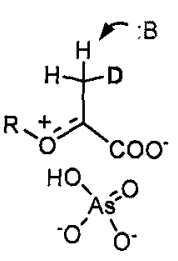
oxacarbenium ion

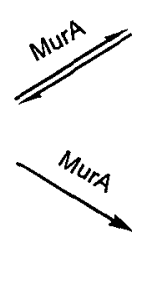<smiles></smiles>

(c)<smiles>[R]O/C=C/C(=O)[O-]</smiles>
EP-UDP-GICNAC<smiles>c1ccccc1</smiles>

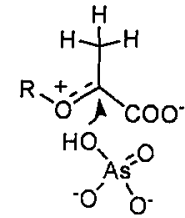
oxacarbenium ion

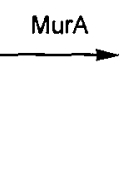

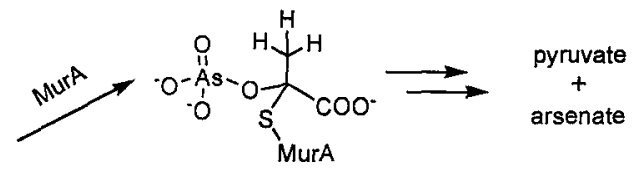

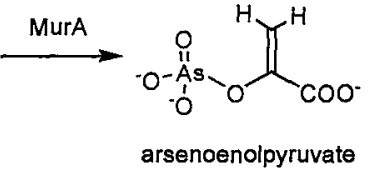

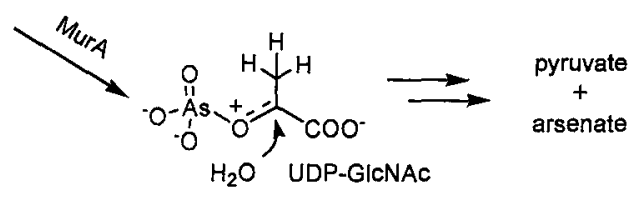

Figure 35. Proposed mechanism of EP-UDP-GlcNAc hydrolysis. (a) Mechanism of MurA catalyzed EP-UDP-GlcNAc hydrolysis. (b) Possible mechanism of arsenate/MurA catalyzed reaction through water directly attack. (c) Possible mechanism of arsenate/MurA catalyzed reaction through arseno-THI formation.

Vanadate/MurA catalyzed EP-UDP-GIcNAc showed very little ${ }^{2} \mathrm{H}$ 
incorporation into C3. It made the first step, formation of cationic intermediate or arseno-THI, almost irreversible. The ${ }^{3} \mathrm{H}$ release experiment and ${ }^{18} \mathrm{O}$ incorporation experiment have not been studied yet. Because of the less ${ }^{2} \mathrm{H}$ incorporation, these experiments could reveal more information about the mechanism.

\subsection{Oxacarbenium ions}

In arsenate/MurA-catalyzed EP-UDP-GlcNAc breakdown, arsenoenolpyruvate was enzymatically hydrolyzed at a less favoured site. This could only happen when the enzyme made nucleophilic attack at C2 carbon more favourable than at arsenic, such as the enzyme distorting arsenoenolpyruvate to have oxacarbenium ion character. It was reported previously that AroA could catalyze hydron exchange in PEP in the presence of dideoxyl-S3P (27) (Fig. 4). This likely arises from transient oxacarbenium ion formation. It is reasonable for MurA to stabilize a similar structure, oxacarbenium ion-like arsenoenolpyruvate (Fig. 36), thus making C2 more electrophilic than arsenic. This work contributed another piece of evidence for oxacarbenium ion mechanism in the first step of MurA-catalyzed natural reaction. 
(a) $\mathrm{R}-\mathrm{OH}$

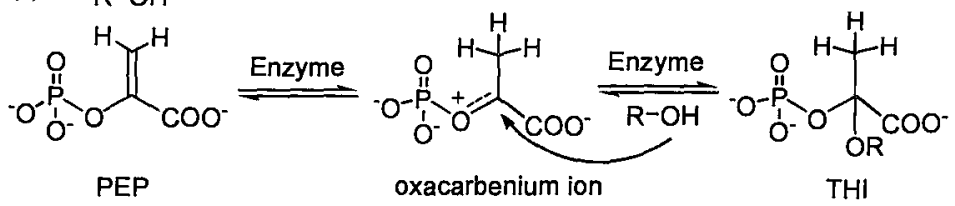

(b)<smiles>[R]OC=C(O[As]1(=O)OO1)C(=O)[O-]</smiles>

arsenoenolpyruvate

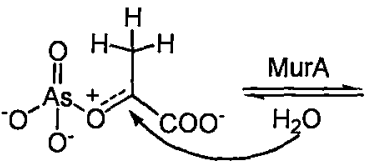

oxacarbenium ion<smiles>[CH]C(=O)C(=O)[O-]</smiles>

pyruvate

Figure 36. (a) Mechanism of the first step of the natural reaction. An oxacarbenium ion of PEP is formed and attacked by an alcohol in each enzyme. (b) The proposed mechanism of arsenoenolpyruvate hydrolysis, through a similar transition state as in (a), an oxacarbenium ion.

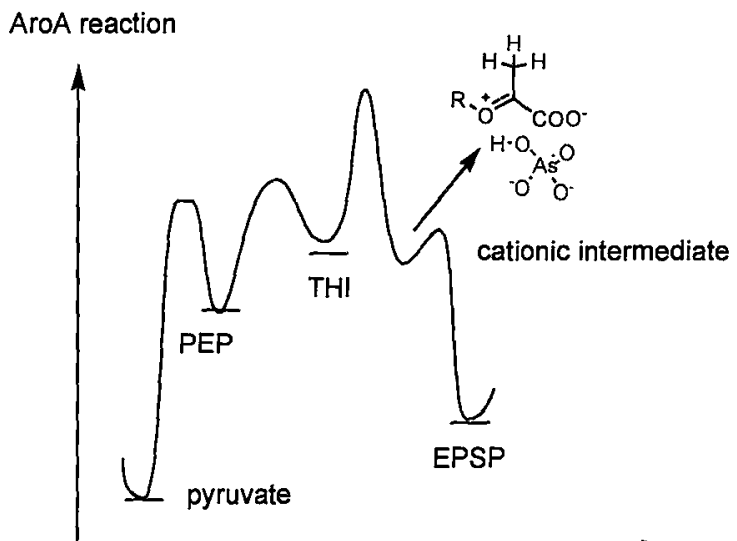

Figure 37. Reaction coordinate in AroAvarsenate-catalyzed EPSP hydrolysis reaction. In arsenate/enzyme catalyzed EP-OR hydrolysis, the observation that the solvent exchange rate was 5 -7-fold faster than hydrolysis implied that arseno-THI formation and/or oxacarbenium ion were reversible. The THI partitioning studies showed EP-OR formation was favoured over PEP + alcohol by only 2.5 and 3 -fold in MurA and AroA reaction respectively. 
This indicated that there is another reversible step between arseno-THI and EP-OR, that is, cationic intermediate (Fig. 37). Another study from our lab demonstrated AroA-catalyzed ketal formation, giving another piece of evidence for this cationic intermediate (72). So the overall reaction pathway for AroA/arsenate-catalyzed EPSP hydrolysis was mapped in Fig. 38.
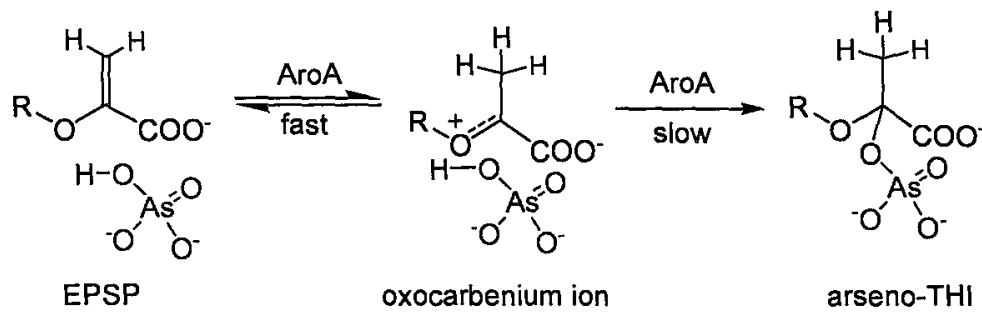

oxocarbenium ion

arseno-THI

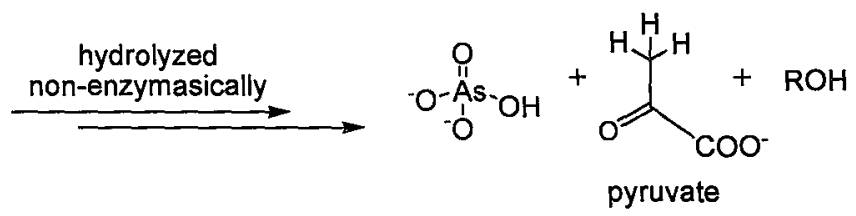

Figure 38. Reaction pathway for AroA/arsenate-catalyzed EPSP hydrolysis

PEP and EP-OR are stable in solution; protonation of carbon bases is difficult both thermodynamically and kinetically. Acid-catalyzed EPSP hydrolysis is through rate-limiting protonation at $\mathrm{C} 3$ to form a transient oxacarbenium ion intermediate. At $25^{\circ} \mathrm{C}, \mathrm{pH} 0, \mathrm{t}_{1 / 2} \approx 12 \mathrm{~h}$ for this reaction (73). In contrast, both AroA and MurA can catalyze their reactions with $t_{1 / 2}$ $<0.15 \mathrm{~s}$ at neutral $\mathrm{pH}$ and $25^{\circ} \mathrm{C}$. This impressive catalytic power is not expressed as soon as EP-OR binds to the enzyme. It is essentially 
unreactive in the absence of the second substrate, phosphate. Phosphate is an intrinsically poor nucleophile. Evidence from arsenate/AroAcatalyzed EPSP hydrolysis indicates the enzyme promotes the reaction by stabilizing an oxacarbenium ion(-like) structure, which is most likely the mechanism in the natural reverse reaction. The mechanism of MurAcatalyzed reaction is under investigation by kinetic isotope effects analysis.

\subsection{Phosphate analogue binding pocket}

Aside from the natural phosphate binding site, phosphate could also bind to AroA in the site equivalent to the phosphate of S3P. The same titration was performed with a non-reactive mutant AroA, D313A, where D313 was located far from both phosphate binding sites. Titration of D313A with phosphate gave similar fluorescence decrease as in $A_{r o} A_{H 6}$ titration, with a slightly smaller $K_{d}$ of $4.2 \mathrm{mM}$. This implied D313A did not destroy the phosphate binding site. This experiment was repeated in the presence of $2 \mu \mathrm{M}$ EPSP $\left(2^{*} K_{d}\right)$, where most of the enzyme were bonded with EPSP. There is no significant difference except for a smaller $K_{d}$ of $2.6 \mathrm{mM}$, which was also consistent with a tighter binding in the second step when EPSP is present (64). This indicated EPSP did not interfere with phosphate binding, supporting the conclusion that phosphate bound that in the normal site when titrated in the absence of EPSP, as did 
arsenate (data not shown).

Titration of $\mathrm{AroA}_{\mathrm{H} 6}$ with monomethyl phosphate was compared to that in the presence of $300 \mu \mathrm{M}$ S3P $\left(K_{d}=143 \mu \mathrm{M}\right)$. The result was 37 $\pm 3 \mathrm{mM}$, close to the monomethyl phosphate binding constant without S3P present $(23 \pm 3 \mathrm{mM})$. This implied that that larger ligand, monomethyl phosphate, also bound to the same site as normal phosphate. This conclusion is also supported by the observation that monomethyl phosphate interfered with EPSP binding (see results in 3.7.2).

\subsection{Two conformational changes upon substrate binding}

The second binding step was also studied by fluorescence titration. It is widely believed that both MurA and AroA-catalyzed reactions involve an induced-fit mechanism in the forward reaction $(8,74)$, where addition of UDP-GlcNAc to free MurA and glyphosate to AroA.S3P complex generate protein conformational changes. However, little attention was paid to the reverse reaction. Fluorescence titration of free AroA with phosphate indicated a conformational change as phosphate bound to AroA. To probe how phosphate and phosphate analogues behaved when there was EPSP in the AroA active centre, phosphate and arsenate were used to titrate the AroA-EPSP complex. The fluorescence change upon EPSP binding was followed by a second fluorescence change upon phosphate or arsenate 
binding, providing evidence for a second conformational change. In the absence of phosphate or an effective analogue, binding of EPSP to AroA could not generate an enough conformational change to efficiently induce cationic intermediate formation. It has to bind with phosphate to induce a second conformational change, by which the enzyme stabilizes the oxacarbenium ion intermediate to active the nucleophilic attack (Fig. 39). Analogues that could not promote the reaction, such as sulphate, also could not induce the second conformational change as shown from fluorescence experiments.

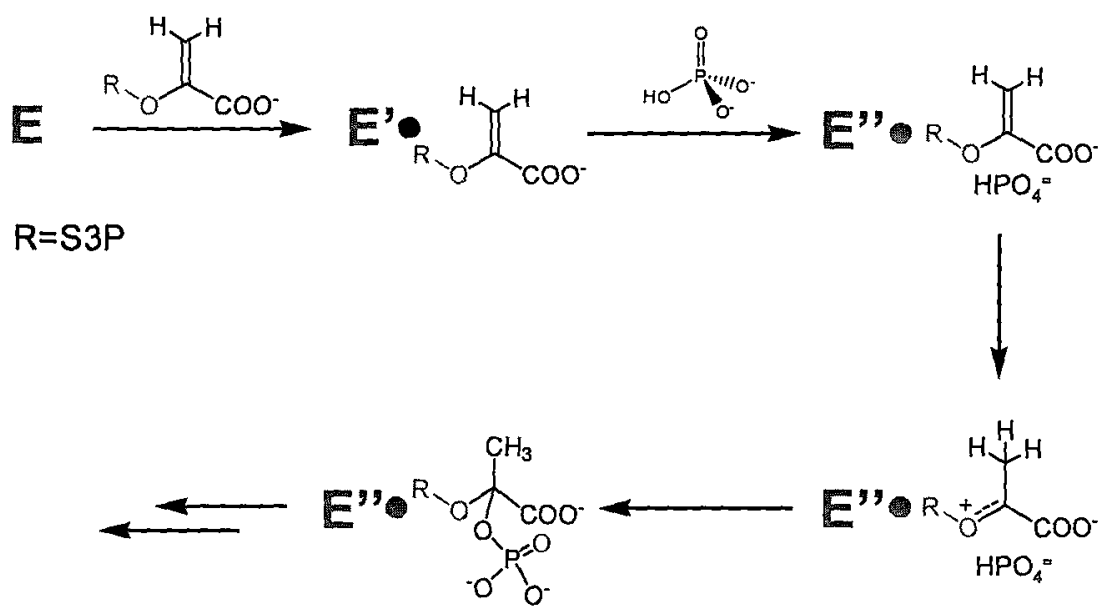

Figure 39. Proposed mechanism for AroA-catalyzed reaction. E represents for enzyme AroA, different color represents for a different conformational state. The second conformation was needed to stabilize an oxacarbenium ion EPSP in the reverse reaction.

\subsection{Phosphate analogues}

Of the four molecules that could promote reaction, all are tetrahedral, and three had a charge of -2 , and are protonated at 
physiological $\mathrm{pH}_{\text {, i.e., }} \mathrm{HPO}_{4}{ }^{=}, \mathrm{HAsO}_{4}{ }^{2}$, and $\mathrm{HVO}_{4}{ }^{2}$. The exception was $\mathrm{FPO}_{4}{ }^{2}$, which is $0.2 \%$ protonated at physiological $\mathrm{pH}$. The lower activity with $\mathrm{FPO}_{4}{ }^{=}$could due to the low concentration of $\mathrm{HFPO}_{4}{ }^{-}$at physiological $\mathrm{pH} . \mathrm{WO}_{4}=$ with $99.8 \%$ deprotonated and -2 charged at physiological $\mathrm{pH}$ was able to compete with phosphate for binding but unable to promote breakdown or solvent exchange. The problem may be size, with $\mathrm{W}-\mathrm{O}$ bond lengths of $1.77 \AA$ compared with $1.50 \AA$ for $\mathrm{HPO}_{4}{ }^{=}$. As implied by the results, tungstate bound at the phosphate site and expelled both phosphate and EPSP out of active centre. Similarly, $\mathrm{HPSO}_{3}=$ with a P-S bond length of $2.13 \AA$ could displace EPSP from catalytic centre (Fig. 40). Monomethyl phosphate $\mathrm{H}_{3} \mathrm{C}-\mathrm{OPO}_{3}{ }$ had one larger functional group, the methoxy, and interfered with EP-OR binding, presumably because the methyl group occupied part of the space occupied by EP-OR.

Displacement of EPSP by $\mathrm{HPSO}_{3}{ }^{=}$and $\mathrm{H}_{3} \mathrm{C}-\mathrm{OPO}_{3}{ }{ }$ was consistent with previous observation in the crystal structures of AroA that its active site was very constrained. 

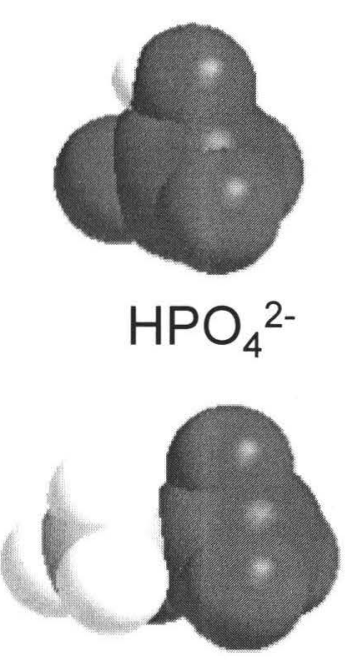

$\mathrm{MeOPO}_{3}{ }^{2-}$

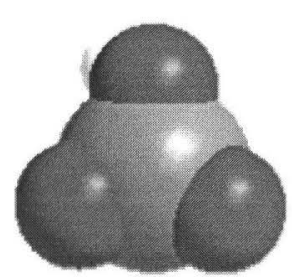

$\mathrm{HWO}_{4}{ }^{2-}$

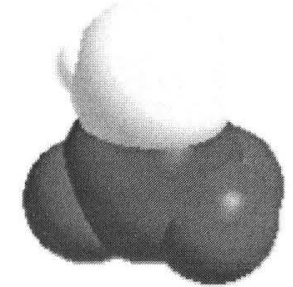

$\mathrm{HSPO}_{3}{ }^{2-}$

Figure 40. Models of phosphate and "big" phosphate analogues. All the models are from computational calculation (see experimental procedure).

In many ways, the closest phosphate analogue was sulphate, in terms of its tetrahedral geometry, size and overall charge. However, as demonstrated by competitive inhibition and several other experiments, including deuterium solvent exchange, sulphate did not bind to AroA. The major difference between $\mathrm{HPO}_{4}{ }^{{ }^{a}}$ and $\mathrm{SO}_{4}{ }{ }$ is the lack of a proton on sulphate at physiological $\mathrm{pH}$. This distinction may be important physiologically. Bacteria actively import sulphate, with intracellular $\mathrm{SO}_{4}{ }^{=}$ concentrations around $100 \mu \mathrm{M}$ (75). It would be expected that enzymes would have a means to distinguish between sulphate and phosphate. It has been proposed that the lack of a proton in $\mathrm{SO}_{4}{ }^{=}$is the main way that proteins distinguish between sulphate and phosphate (76). Now the question is how the enzyme evolved itself to discriminate 
one single proton. An unexpected result from AroA mutation studies was a single mutation D49A decreased ArOA $_{H 6}$ activity by 21000 -fold (30). Based on crystal structures, except for the presumed catalytic base E341 in AroA and C115 in MurA, which was used to deprotonate C3 hydrogen, D49 is the only negatively charged residue around phosphate. This residue is $100 \%$ conserved in both AroA and MurA (30). The enzymes use several hydrogen bond donor resides (K22, R100, R124, Q171 in AroA and K22, R91, R120 in MurA) to stabilize negative charge on phosphate oxygens. The role of a hydrogen bond acceptor residue, D49, and why it was so important to catalysis is not well understood. However, it would not too surprising if the enzymes used this residue to form a strong hydrogen bond in order to differentiate phosphate from sulphate.

Among all the phosphate analogues, only those that could bind to the enzyme together with EPSP could promote the reaction. Analogues that could not bind together with EPSP could not catalyze solvent exchange either. This implied the enzyme needed the second ligand to bind, which helped to stabilize the oxacarbenium ion like form of EPSP, and then make $\mathrm{C} 3$ proton exchangeable and $\mathrm{C} 2$ electrophilic. 


\section{Conclusions}

Thirteen different phosphate analogues were used to study the reverse reactions of AroA and MurA from EP-OR. Among these phosphate analogues, many could bind to the free enzyme, but only three could promote hydrolysis.

The products from EP-OR hydrolysis were pyruvate and the corresponding alcohol (S3P in the AroA/EPSP reaction and UDP-GIcNAc in the MurA/EP-UDP-GICNAc reaction). The most effective analogue was arsenate. The mechanism of the arsenate-promoted reaction was examined in detail. Based on ${ }^{18} \mathrm{O},{ }^{2} \mathrm{H}$ and ${ }^{3} \mathrm{H}$ isotope labeling experiments, hydrolysis proceeded though an arseno-tetrahedral intermediate with AroA, a similar reaction pathway to the natural reaction. This arsenotetrahedral intermediate was converted to arsenoenolpyruvate and degraded spontaneously in water through As $\mathrm{O}$ bond cleavage. MurA also likely catalyzed arseno-tetrahedral intermediate formation, and appeared to catalyze arsenoenolpyruvate breakdown, though it is possible that it was a bystander in the reaction, with the tetrahedral intermediate being formed by water attack on C2 of EP-UDP-GIcNAc.

The catalytic machinery for stabilizing such as unstable oxacarbenium ion like intermediate was investigated. Based on information from all the phosphate analogues, in the AroA-catalyzed 
reverse reaction, there was evidence that AroA undergoes an conformational change upon binding with phosphate, which the protonated form of EPSP was stabilized. This was consistent with the fact that only those who can bind together with EP OR were able to generate an effective second conformational change, thus promoting EP OR breakdown and solvent deuterium incorporation into the $\mathrm{C} 3$ ethylene group. 


\section{References}

1. Bugg, T. D., and Walsh, C. T. (1992) Nat. Prod. Rep. 9, 199-215.

2. Gunetileke, K. G., and Anwar, R. A. (1968) J. Biol. Chem. 243, 57705778.

3. Walsh, C. T., Benson, T. E., Kim, D. H., and Lees, W. J. (1996) Chem. Biol. 3, 83-91.

4. Schmid, J., and Amrhein, N. (1999) The shikimate pathway. In Plant Amino Acids: Biochemistry and Biotechnology, Marcel Dekker: New York, 147-169.

5. Anderson, K. S., and Johnson, K. A. (1990) Chem. Rev. 90, 11311149.

6. Anderson, K. S., Sammons, R. D., Leo, G. C., Sikorski, J. A., Benesi, A. J., and Johnson, K. A. (1990) Biochemistry 29, 1460-1465.

7. Schonbrunn, E., Sack, S., Eschenburg, S., Perrakis, A., Krekel, F., Amrhein, N., and Mandelkow, E. (1996) Structure 4, 1065-1075.

8. Schonbrunn, E., Svergun, D. I., Amrhein, N., and Koch, M. H. (1998) Eur. J. Biochem. 253, 406-412.

9. Brown, E. D. V., E. I.; Walsh, C. T.; Kolter, R. (1995) J.Bacteriol. 177, 4194-4197.

10. Marquardt, J. L., Brown, E. D., Lane, W. S., Haley, T. M., Ichikawa, Y., Wong, C. H., and Walsh, C. T. (1994) Biochemistry 33, 1064610651.

11. Kim, D. H., Lees, W. J., Kempsell, K. E., Lane, W. S., Duncan, K., and Walsh, C. T. (1996) Biochemistry 35, 4923-4928.

12. Steinrucken, H. C., and Amrhein, N. (1984) Eur. J. Biochem. 143, 351-357.

13. Roberts, F., Roberts, C. W., Johnson, J. J., Kyle, D. E., Krell, T., Coggins, J. R., Coombs, G. H., Milhous, W. K., Tzipori, S., Ferguson, D. J., Chakrabarti, D., and McLeod, R. (1998) Nature 393, 801-805. 
14. Anderson, K. S., Sikorski, J. A., and Johnson, K. A. (1988) Biochemistry 27, 7395-7406.

15. Marquardt, J. L., Brown, E. D., Walsh, C. T., and Anderson, K. S. (1993) J. Am. Chem. Soc. 115, 10398-10399.

16. Kim, D. H., Lees, W. J., Haley, T. M., and Walsh, C. T. (1995) J. Am. Chem. Soc. 117, 1494-1502.

17. Kim, D. H., Lees, W. J., and Walsh, C. T. (1994) J. Am. Chem. Soc. $116,6478-6479$.

18. Walker, M. C., and Jones, C. R. (1992) J. Am. Chem. Soc. 114, 7601-7603.

19. Skarzynski, T., Kim, D. H., Lees, W. J., Walsh, C. T., and Duncan, K. (1998) Biochemistry 37, 2572-2577.

20. Sack, S., Dauter, Z., Wanke, C., Amrhein, N., Mandelkow, E., and Schonbrunn, E. (1996) J. Struct. Biol. 117, 73-76.

21. Anderson, K. S., Sikorski, J. A., and Johnson, K. A. (1988) Biochemistry 27, 1604-1610.

22. Castellino, S., Leo, G. C., Sammons, D., and Sikorski, J. A. (1989) Biochemistry 28, 3856-3868.

23. Bondinell, W. E., Vnek, J., Knowles, P. F., Sprecher, M., and Sprinson, D. B. (1971) J. Biol. Chem. 246, 6191-6196.

24. Brown, E. D., Marquardt, J. L., Lee, J. P., Walsh, C. T., and Anderson, K. S. (1994) Biochemistry 33, 10638-10645.

25. Schonbrunn, E., Eschenburg, S., Luger, K., Kabsch, W., and Amrhein, N. (2000) Proc. Natl. Acad. Sci. U. S. A. 97, 6345-6349.

26. Schonbrunn, E., Eschenburg, S., Krekel, F., Luger, K., and Amrhein, N. (2000) Biochemistry 39, 2164-2173.

27. Anton, D. L. H., L.; Fish, S.M.; Abeles, R.H. (1983) Biochemistry 22, 5903-5908.

28. An, M. M., U.; Neidlen, U.; Bartlett, P.A. (2003) J. Am. Chem. Soc. $125,12759-12767$.

29. Krekel, F. S., A.K.; Macheroux, P.; Amrhein, N.; 
Evans, J.N. (2000) Biochemistry 39, 12671-12677.

30. Mizyed, S., Wright, J. E., Byczynski, B., and Berti, P. J. (2003) Biochemistry 42, 6986-6995.

31. Samland, A. K., Etezady-Esfarjani, T., Amrhein, N., and Macheroux, P. (2001) Biochemistry 40, 1550-1559.

32. Huynb, Q. K. K., G. M.; Bild, G.S. (1988) J. Biol. Chem. 263, 735739.

33. Eschenburg, S. K., W.; Healy, M.L.; Schonbrunn, E. (2003) J. Biol. Chem. 278, 49215-49222.

34. Radzicka, A., and Wolfenden, R. (1995) Science 267, 90-93.

35. Alexander, J. K. (1961) J. Bacteriol. 81, 903-910.

36. Tsumuraya, Y., Brewer, C. F., and Hehre, E. J. (1990) Arch. Biochem. Biophys. 281, 58-65.

37. Mieyal, J. J., Simon, M., and Abeles, R. H. (1972) J. Biol. Chem. 247, 532-542.

38. Voet, J. G., and Abeles, R. H. (1970) J. Biol. Chem. 245, 1020-1031.

39. Silverstein, R., Voet, J., Reed, D., and Abeles, R. H. (1967) J. Biol. Chem. 242, 1338-1346.

40. Metzger, B., Helmireich, E., and Glaser, L. (1967) Proc. Natl. Acad. Sci. U. S. A. 57, 994-1001.

41. Gold, A. M., and Osber, M. P. (1972) Arch. Biochem. Biophys. 153, 784-787.

42. Byczynski, B., Mizyed, S., and Berti, P. J. (2003) J. Am. Chem. Soc. $125,12541-12550$.

43. Lagunas, R. (1980) Arch. Biochem. Biophys. 205, 67-75.

44. Lagunas, R. (1970) Biochim. Biophys. Acta 220, 108-115.

45. Jaffe, K., and Apitz-Castro, R. (1977) FEBS Lett. 80, 115-118.

46. Chasteen, N. D. (1983) Struct. Bond. 53, 105-138. 
47. Nour-Eldeen, A. F., Craig, M. M., and Gresser, M. J. (1985) J. Biol. Chem. 260, 6836-6842.

48. Pannifer, A. D., Flint, A. J., Tonks, N. K., and Barford, D. (1998) J. Biol. Chem. 273, 10454-10462.

49. Schlichting, I., and Reinstein, J. (1999) Nat. Struct. Biol. 6, 721-723.

50. Wittinghofer, A. (1997) Curr. Biol. 7, 682-685.

51. Becke, A. D. (1988) Phys. Rev. A 38, 3098-3100.

52. Perdew, J. P., and Wang, Y. (1992) Phys. Rev. B 45, 13244.

53. Frisch, M. J. T., G. W.; Schlegel, H. B.; Scuseria, G. E.; Robb, M. A.; Cheeseman, J. R.; Zakrzewski, V. G.; Montgomery, J. A.;

Stratmann, R. E.; Burant, J. C.; Dapprich, S.; Millam, J. M.; Daniels, A. D.; Kudin, K. N.; Strain, M. C.; Farkas, O.; Tomasi, J.; Barone, V.; Cossi, M.; Cammi, R.; Mennucci, B.; Pomelli, C.; Adamo, C.; Clifford, S.; Ochterski, J.; Petersson, G. A.; Ayala, P. Y.; Cui, Q.; Morokuma, K.; Malick, D. K.; Rabuck, A. D.; Raghavachari, K.; Foresman, J. B.; Cioslowski, J.; Ortiz, J. V.; Stefanov, B. B.; Liu, G.; Liashenko, A.; Piskorz, P.; Komaromi, I.; Gomperts, R.; Martin, R. L.; Fox, D. J.; Keith, T.; Al-Laham, M. A.; Peng, C. Y.; Nanayakkara, A.; Gonzalez, C.; Challacombe, M.; Gill, P. M. W.; Johnson, B. G.; Chen, W.; Wong, M. W.; Andres, J. L.; HeadGordon, M.; Replogle, E. S.; Pople, J. A. (1998) Gaussian 98(Revision A.6), Gaussian, Inc.: Pittsburgh, PA,.

54. Reed, A. E., Curtiss, L. A., and Weinhold, F. (1988) Chem. Rev. 88, 899-926.

55. Dobson, G. P., Hitchins, S., and Teague, W. E. (2002) J. Biol. Chem. $277,27176-27182$.

56. Lecoq, K., Belloc, K., Desgrangers, C., Konrad, M., and DaignanFronier, B. (2001) J. Bacteriol. 2001, 4910-4913.

57. Kresge, A. J., Leibovitch, M., and Sikorski, J. A. (1992) J. Am. Chem. Soc. $114,2618-2622$.

58. Mizyed, S., Oddone, A., Byczynski, B., Hughes, D. W., and Berti, P. J. (2005) Biochemistry 44, 4011-4017.

59. Okumura, A. S., A.; Saruta, A.; Miki, M. (1996) Bull. Chem. Soc. Jpn. 
$69,3021-3030$.

60. Okumura, A. Y., N.; Okazaki, N. (1973) Bull. Chem. Soc. Jpn. 46, 3633.

61. Okumura, A. W., M.; Sakaue, M.; Okazaki, N. (1979) Bull. Chem. Soc. Jpn. 52, 2783.

62. Damitio, J. S., G.; Meany, J.E.; Pocker, Y. (1992) J. Am. Chem. Soc. 114, 3081-3087.

63. Pocker, Y. M., J.E.; Nist, B.J.; Zadorojny,C. (1969) J. Phys. Chem. 78, 2879-2885.

64. Gruys, K. J. M., M. R.; Pansegrau, P. D.; Sikorski, J. A. (1993) Biochem. Biophys. 304, 345-351.

65. Kumler, W. D., and Eiler, J. J. (1943) J. Am. Chem. Soc. 65, 23552361.

66. Bailey, N., Carrington, A., Lott, K. A. K., and Symons, M. C. R. (1960) J. Chem. Soc., 290-297.

67. Bjerrum, J., Schwarzenbach, G., and Sillen, L. G. (1958) Stability constants of metal-ion complexes, with solubility products of inorganic substances, International Union of Pure and Applied Chemistry.

68. Kline, P. C., and Schramm, V. L. (1993) Biochemistry 1993, 1321213219.

69. Schoevaart, R. R., F.; Sheldon, R.A. (2001) J. Org. Chem. 66, 45594562.

70. Long, J. W., and Ray, W. J. (1973) Biochemistry 12, 3932-3937.

71. Lagunas, R. (1970) Biochem. Biophys. Acta. 220, 108-115.

72. M. E. Clark, personal communication

73. O'Neal, C. C., Bild, G. S., and Smith, L. T. (1983) Biochemistry 83, 611-618.

74. Macheroux, P. (1998) Biochem. J. 335, 319. 
75. Dreyfuss, J. (1964) J. Biol. Chem. 239, 2292-2297.

76. O'Brien, P. J., and Herschlag, D. (2002) Biochemistry 41, 3207-3225. 
